\title{
DESENVOLVIMENTO DE UM MEDIDOR DE COMPRIMENTO DE ONDA DE PRECISÃO
}

\author{
Marcelo Souto Urso
}

Dissertação apresentada ao Instituto de Fisica de São Carlos, da Universidade de São Paulo, para a obtenção do título de mestre em Ciências: Física Aplicada, sub-área: Física Computacional

$$
\text { ok }
$$

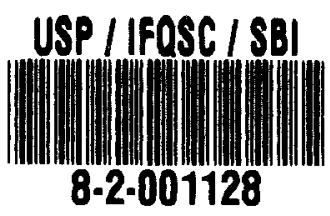

Orientador: Prof. Dr. Sérgio Carlos Zílio 
Urso, Marcelo Souto

Desenvolvimento de um medidor de comprimento de onda de precisão.--São Carlos, 1997.

$80 \mathrm{p}$.

Dissertação (Mestrado) --Instituto de Física de São Carlos, 1997.

Orientador: Prof. Dr. Sérgio Carlos Zilio

1.Óptica. 2.Engenharia.

I. Título. 


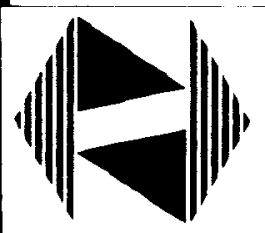

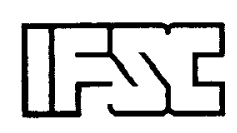

UNIVERSIDADE

Instituto de Física de São Carlos
Av. Dr. Carlos Botelho, 1465

CEP 13560-250 - São Carlos - SP

Brasil

Fone (016) 272-6222

Fax (016) 272-2218

MEMBROS DA COMISSÃo JULGADORA DA DISSERTAÇÃO DE MESTRADO DE MARCELO SOUTO URSO APRESENTADA AO INSTITUTO DE FÍSICA DE SÃO CARLOS, DA UNIVERSIDADE DE SÃO PAULO, EM 11 DE MARÇO DE 1997.

COMISSÃO JULGADORA:

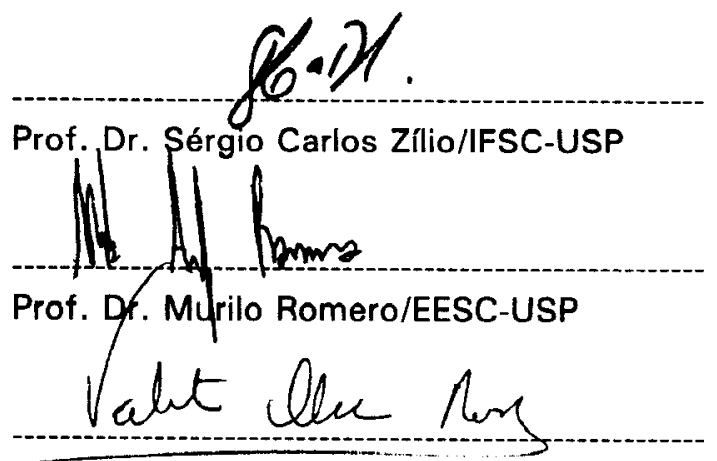

Prof. Dr. Valentin Obac Roda/IFSC-USP

USP - Educação para o Brasil 
A Luís Antonio Souto, pelo primeiro microcomputador; pelo apoio, amizade e confiança dispendidos à minha pessoa. 


\section{AGRADECIMENTOS}

- Ao Prof. Dr. Sérgio Carlos Zílio, meu orientador e amigo, pela incansável e valiosa orientação; principalmente pelo apoio e confiança, sem os quais este trabalho não teria sido realizado.

- Ao Amigo Eng. Sílvio Antonio Tonissi Jr. pelas valiosas sugestões e pelo seu apoio.

- Ao Amigo Evandro Márcio Batistella , que muito auxiliou nos desenhos contidos neste trabalho.

- Aos amigos do laboratório de Eletrônica para Óptica (L.I.E.P.O.), Rui, Paulinho, Tatuí e Carlos.

- A todo o grupo de óptica, especialmente Cleber, Lino e Aparecida, que prontamente me auxiliaram em várias dificuldades no decorrer do projeto.

- Aos técnicos do departamento que direta ou indiretamente auxiliaram de alguma forma o desenvolvimento do projeto.

- À FAPESP pela concessão de uma bolsa de mestrado. 


\section{índice}

Lista de figuras -

Lista de abreviaturas e símbolos - iii

Resumo -

Abstract - - $v$

1- INTRODUÇÃO -- 01

2- MEDIDOR DE ONDA POR ATIVIDADE ÓPTICA

2.1- Atividade óptica - - 04

2.2- Descrição do sistema opto-mecânico - 08

3- COMPONENTES ELETRÔNICOS - 15

3.1- Placa de tratamento dos sinais analógicos - 16

3.2- Placa de tratamento dos sinais digitais - 21

3.2.1- Bloco de mapeamento -

3.2.2- Bloco lógico - 25

3.2.3- Bloco de comando - 27

3.2.4- Bloco dos contadores - 29

3.2.5- Bloco de monitoração - 30

3.2.6- Bloco de comunicação com o PC - 30

3.3- Placa de subsídio e apoio - 32

3.3.1- Controle de temperatura --1-- 32

3.3.2- Controle de velocidade - 34

3.3.3 Medidor de potência - 36

3.4- Fonte de alimentação --.- 37

4- PROGRAMAS - 38

4.1- Módulo de baixo nível (DLL) - 39 
4.1.2- Subrotina Carrega -

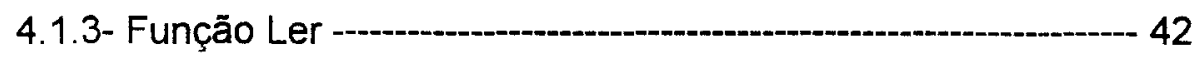

4.2- Programa principal - 46

4.2.1- Resolução de equação --.-- 47

4.2.2- Cálculo das médias --a-- 48

5- RESULTADOS

6- ESTÁGIO ADICIONAL DE ALTA PRECISÃO 54

6.1- Principio de funcionamento - 54

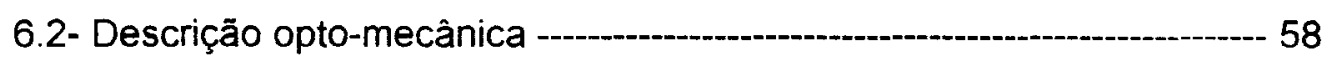

6.3- Componentes eletrônicos - 61

6.3.1- Placa analógica - 61

6.3.2- Tratamento dos sinais digitais - 66

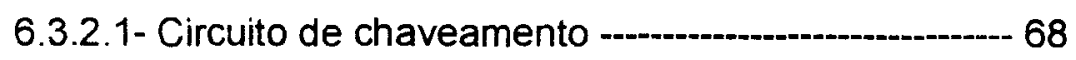

6.3.2.2- Alteração no circuito de controle -..-- 69

6.3.2.3- Alteração no circuito de monitoração ------------ 70

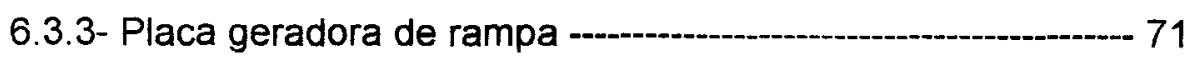

6.3.4- Fonte de alimentação - 73

6.4- Programas - 73

6.4.1 - Função Ler2 - 73

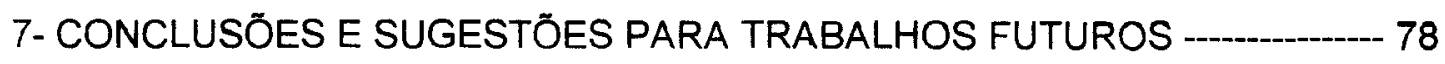


7- APÊNDICE A

8- APÊNDICE B

k

9- APÉNDICE C

10- APÊNDICE D s 


\section{LISTA DE FIGURAS}

Figura 1 - Rotação da polarização da luz no cristal de quartzo ---a- 04

Figura 2 - Diagrama esquemático do meio chiral --a--a- 05

Figura 3 - Poder rotatório do quartzo - 07

Figura 4 - Técnica de conoscopia para o alinhamento do eixo óptico do cristal -- 09

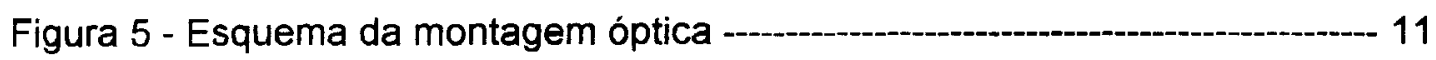

Figura 6 - Sinais luminosos que os fotodiodos recebem -

Figura 7 - Valores experimentais de $\Delta n \times \sigma$ do cristal de quartzo utilizado ------- 13

Figura 8 - Diagrama esquemático do medidor de onda por atividade óptica ------ 15

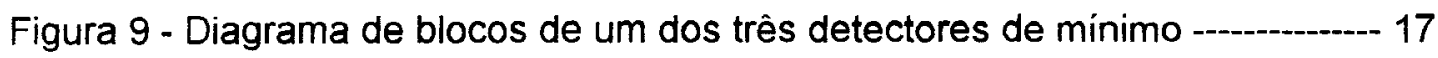

Figura 10 - Carta de tempos do detector de minimos ---o--- 18

Figura 11 - Esquema elétrico do detector de mínimo - 19

Figura 12 - Circuito dos monoestáveis -- 20

Figura 13 - Exemplo de sinais elétricos que saem dos monoestáveis ------------ 21

Figura 14 - Diagrama de blocos da placa interna ao PC -

Figura 15 - Esquema elétrico do circuito de mapeamento --.---o- 24

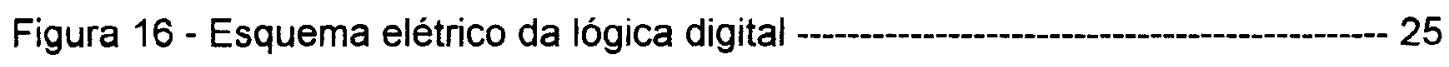

Figura 17 - Carta de tempos da lógica digital --a--a- 26

Figura 18 - Esquema elétrico do circuito de controle -- 28

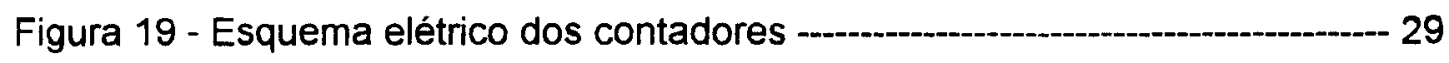

Figura 20 - Esquema elétrico do circuito de monitoração --- 30

Figura 21 - Esquema elétrico da interface com o barramento do PC -----a-------- 31

Figura 22 - Esquema elétrico do controlador térmico -

Figura 23 - Esquema elétrico do controlador de velocidade - 
Figura 24 - Esquema elétrico do medidor de potência -a- 36

Figura 25 - Tela principal do programa do medidor de onda - 46

Figura 26 - Exemplo do cálculo da média das medidas -- 49

Figura 27 - Comparação entre o medidor desenvolvido e um comercial ---------- 51

Figura 28 - Histograma das medidas para $6328 \AA$

Figura 29 - Posicionamento da lâmina de vidro no Vernier Fabry-Pérot ----------- 55

Figura 30 - Sinais captados nos dois fotodiodos do Vernier Fabry-Pérot ---_-_-_- 57

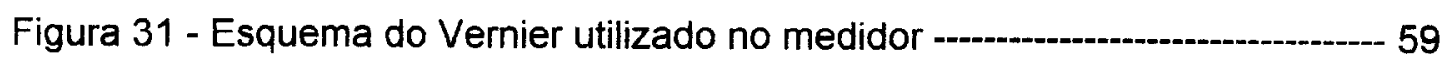

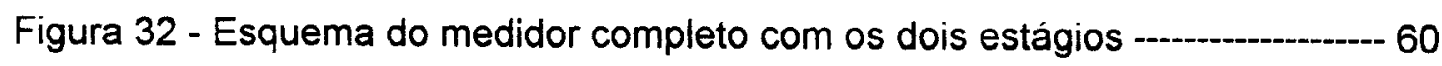

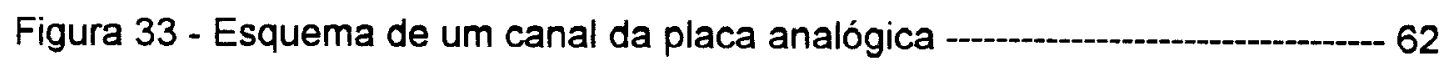

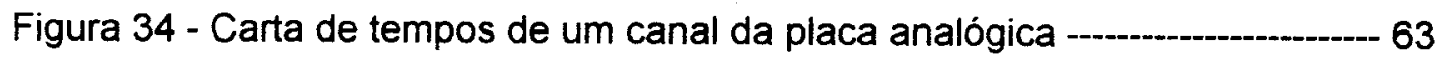

Figura 35 - Sinais do medidor Fabry-Pérot que vão ao computador ----.-.-.-.-.-.-.- 64

Figura 36 - Diagrama esquemático do gerador de gatilhos -

Figura 37 - Carta de tempos do gerador de gatilho - 65

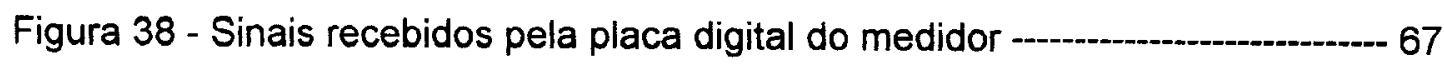

Figura 39 - Esquema elétrico do muliplexador de entrada -

Figura 40 - Esquema elétrico do circuito de controle modificado --_-_-_-_-_- 69

Figura 41 - Esquema elétrico do circuito de monitoração modificado --------------- 71

Figura 42 - Sinal obtido pelo gerador de rampa - 72

Figura 43 - Esquema elétrico do gerador de rampa para o galvo-motor -.--1---- 72 


\section{LISTA DE ABREVIATURAS E SÍMBOLOS}

$\sigma$ - Número de onda $\left(\mathrm{cm}^{-1}\right)$

$\lambda$ - Comprimento de onda (Ângstrons ou nm )

$d \theta / d \lambda$ - Sensibilidade da medida

P - Polarizador

m - Número de semi voltas redundantes dentro do cristal

I - Distância percorrida pela luz dentro do cristal

$\Delta n$ - Diferença de índices de refração para polarizações circulares ortogonais

MOAO - Medidor de onda por atividade óptica

E - Espelho

1 - Íris

DF - Divisor de feixe

$T T L$ - Lógica transistor-transistor; $(+5 \mathrm{~V}=1$ e $\quad O V=0)$

M - Ordem do Vernier Fabry-Pérot 


\section{RESUMO}

Este trabalho original descreve o desenvolvimento e construção de um medidor comprimento de onda de precisão para feixes de laser. O primeiro estágio do dispositivo baseia-se na atividade óptica de um cristal de quartzo natural e fornece uma precisão de uma parte em $10^{4}$. O segundo estágio, o qual não foi concluído, envolve o uso de um Vernier Fabry-Pérot, montado com espaçadores de zerodur, que pode aumentar a precisão da medida para algumas partes em $10^{7}$. 


\begin{abstract}
This original work reports on the development and construction of a precision laser beams wavemeter. The first part of the instrument is based on the optical activity of a natural quartz cristal and provides an accuracy of one part in $10^{4}$. The second part, that was not concluded, employs a Fabry-Pérot Vernier, assembled with zerodur spacers, which increases the accuracy to a few parts in $10^{7}$
\end{abstract}




\section{1- INTRODUÇÃO}

O uso de laser em diversos tipos de aplicações tem se expandido rapidamente nos últimos anos. Sua utilização em usinagem de peças, oftalmologia, artes e telecomunicações são apenas alguns poucos exemplos da importância de tais dispositivos nos dias de hoje.

O sucesso das várias técnicas que utilizam lasers depende da caracterização e monitoramento de parâmetros tais como o comprimento da onda, a potência, duração de pulso, estabilidade de direcionamento, qualidade do perfil Gaussiano, etc. Em particular, lasers contínuos sintonizáveis tem aplicações importantes nas áreas de metrologia e espectroscopia óptica. ${ }^{1}$ São em geral equipamentos caros que necessitam algum tipo de dispositivo para monitorar sua frequência de operação. Dentre as abordagens empregadas para tal fim, uma das mais populares é o uso de celas de referência gasosas, principalmente a de $\mathrm{I}_{2}{ }^{2}$ Neste caso, quando a frequência do laser coincidir com alguma linha de absorção do gás, de valor conhecido e catalogado, ${ }^{3}$ aquela será a frequência de operação do laser. Entretanto, em regiöes espectrais onde as linhas de absorção do gás de referência são poucas, torna-se necessário o uso de um monocromador ou de um medidor de comprimento de onda. ${ }^{1}$ O monocromador com rede de difração é um instrumento bastante conhecido e não será abordado aqui. Já o medidor de comprimento de onda, que denominaremos apenas de medidor de onda por simplicidade, tem seu uso cada vez mais difundido devido a sua facilidade de uso e precisão, e vem gradativamente substituindo os monocromadores em aplicações que envolvem a determinação de comprimentos de onda de lasers mono-modos.

O medidor de onda convencional baseia-se no conhecido interferômetro de Michelson, onde franjas de interferência geradas pela luz do laser sob estudo são 
contadas quando o espelho móvel do interferômetro desloca-se de uma dada distância L. ${ }^{1} O$ comprimento de onda da luz do vácuo, $\lambda$, é dado por $\lambda=2 n L N$, onde $n$ é o índice de refração do ar e $N$ é o número de franjas contadas. $O$ custo deste tipo de instrumento está diretamente ligado ao movimento do espelho móvel, em particular à sua estabilidade mecânica e à maneira pela qual $L$ é medido. Nos modelos mais baratos, com precisão de 1 parte em $10^{4}$, a distância que o espelho se desloca é da ordem de $5 \mathrm{~mm}$ e o deslocamento é medido com um sistema de franjas de Moiré. Já nos modelos mais caros, com precisão de 1 parte em $10^{6}, 0$ espelho se move cerca de $30 \mathrm{~cm}$ e seu deslocamento é monitorado por um laser de He-Ne estabilizado em frequência. Neste caso, conta-se o número de franjas geradas pelo laser de frequência desconhecida e pelo laser padrão, e através da comparação dos dois números de franjas é possivel a obtenção do comprimento de onda desconhecido.

Neste trabalho descrevemos a construção de um medidor de onda baseado na atividade óptica de um cristal de quartzo natural, que possibilita uma precisão de 1 parte em $10^{4}$. Ao contrário dos medidores convencionais baseados no interferômetro de Michelson, o instrumento desenvolvido dispensa o uso de estágio de translação de precisão, barateando assim seu custo. Como resultado obteve-se um dispositivo inédito com as características de alta confiabilidade, portatibilidade, baixo custo e fácil manuseio. O uso de uma linguagem simples e compacta possibilita seu uso por pessoas não especializadas. Além destas vantagens, o medidor por atividade óptica funciona como primeiro estágio de um Vernier Fabry-Pérot, também desenvolvido neste trabalho, que produz uma resolução de algumas partes em $10^{7}$.

O trabalho está apresentado da seguinte forma: no capítulo 2 discutimos os princípios físicos do funcionamento do medidor de onda baseado na atividade 
óptica de um cristal de quartzo natural, detalhes da construção do sistema optomecânico, da eletrônica utilizada para aquisição dos dados, e do programa para gerenciamento e tratamento dos dados. No capitulo 3 são apresentados os resultados e análise estatística da medida de comprimento de onda, demonstrando a precisão pretendida de 1 parte em $10^{4}$. O capítulo 4 trata da construção do segundo estágio do medidor de alta precisão tendo como plataforma um Vernier Fabry-Pérot com espaçadores de zerodur. Finalmente, no capitulo 5 são apresentadas as conclusões e sugestões para trabalhos futuros. 


\section{2- MEDIDOR DE ONDA POR ATIVIDADE ÓPTICA}

\section{1- Atividade óptica}

Atividade óptica è a propriedade que certos materiais possuem de introduzir uma rotação no plano de polarização de um feixe de luz linearmente polarizada, conforme a luz se propaga em uma dada direção no referido material; tal fenômeno pode ser visto na figura 1.
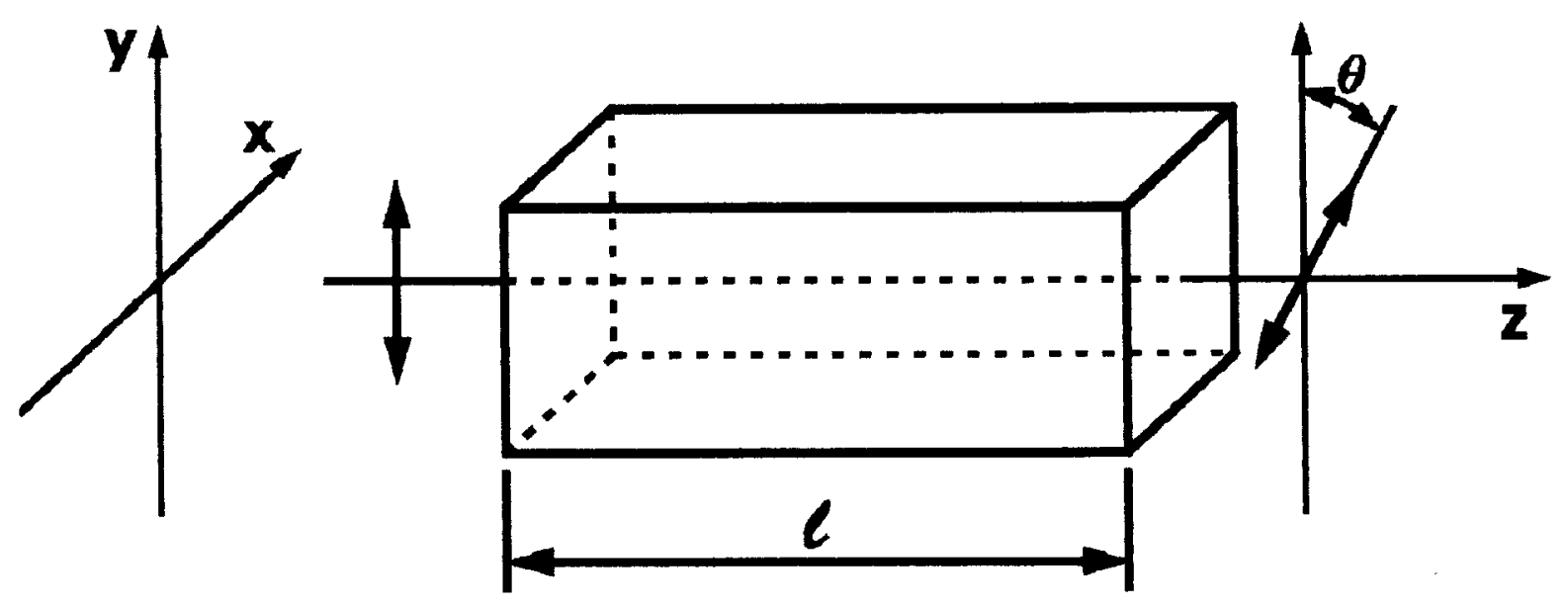

Figura 1 - Rotação da polarização da luz no cristal de quartzo.

O ângulo de rotação do plano de polarização, $\theta$, depende da distância $l$ percorrida pela luz dentro do meio e de uma caracteristica intrinseca do material, chamada de poder rotatório. ${ }^{4} \mathrm{Na}$ prática, costuma-se definir o poder rotatório específico como sendo o ângulo rodado por unidade de comprimento. Olhando na direção $z>0$, se o plano de polarização da luz rodar à direita o material é chamado destro-rotatório (destrógiro) e se rodar para a esquerda, levo-rotatório (levógiro). Alguns exemplos de meios que exibem atividade óptica são: quartzo 
cristalino (com a luz propagando-se na direção do eixo óptico), clorato de sódio e alguns tipos de açucares.

A atividade óptica pode ser explicada levando-se em conta a simetria do material. De acordo com a figura 2, se luz linearmente polarizada incidir sobre 0 cristal, as componentes $x$ e y estarão sujeitas à mesma simetria e portanto possuem a mesma velocidade de propagação (mesmo índice de refração). Isto indica a inexistência de birrefringência. Já no caso de luz circularmente polarizada, as componentes polarizadas à direita $\left(\sigma^{+}\right)$e à esquerda $\left(\sigma^{-}\right)$encontram os triângulos de formas diferentes e portanto estão sujeitas a diferentes simetrias. Isto faz com que os indices de refração $n_{+}$e n. para estas duas polarizações sejam diferentes e como consequência, estas polarizações adquirem fases diferentes durante sua propagação pelo cristal.

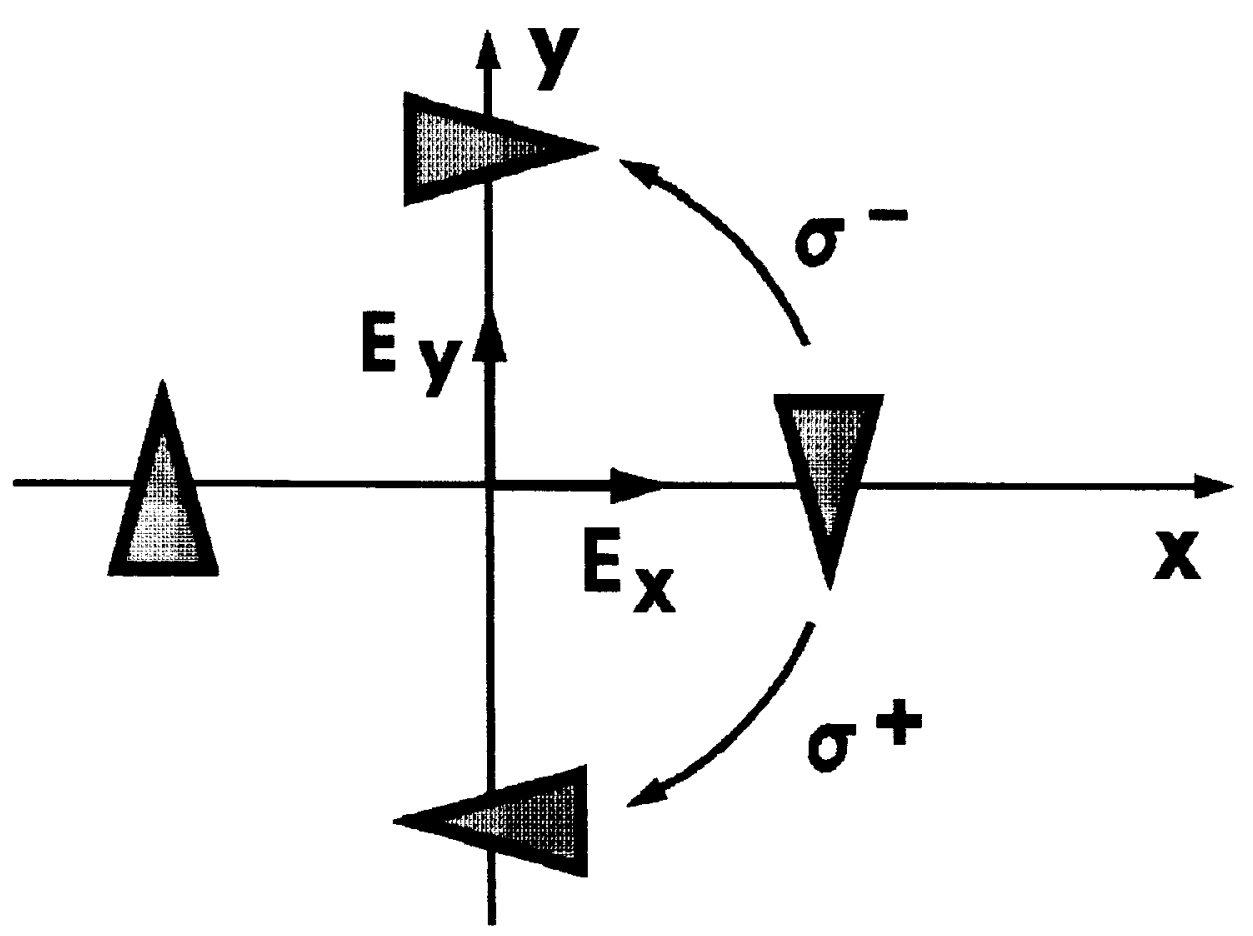

Figura 2 - Diagrama esquemático do meio chiral. 
Este fato acarreta uma rotação do plano de polarização da luz linearmente polarizada, que pode ser expressa pelo uso do formalismo de Jones, ${ }^{5}$ como descrito a seguir.

Consideremos um feixe de luz linearmente polarizada na direção $x$, propagando-se ao longo do eixo z. Podemos decompor esta luz em duas componentes ortogonais circularmente polarizadas e no formalismo de Jones este fato se expressa como:

$$
|E\rangle=E_{0}\left(\begin{array}{l}
1 \\
0
\end{array}\right)=\frac{E_{0}}{2}\left(\begin{array}{c}
1 \\
-i
\end{array}\right)+\frac{E_{0}}{2}\left(\begin{array}{l}
1 \\
i
\end{array}\right)
$$

Após percorrer uma distância $l$ dentro do meio, as componentes $\sigma^{+}$e $\sigma^{*}$ adquirem fases diferentes e o campo elétrico na saida da amostra pode ser escrito da forma:

$$
\begin{aligned}
\left|\mathrm{E}^{\prime}\right\rangle & =\frac{\mathrm{E}_{0}}{2}\left(\begin{array}{c}
1 \\
-\mathrm{i}
\end{array}\right) \exp \left\{\mathrm{ik}_{+} l\right\}+\frac{\mathrm{E}_{0}}{2}\left(\begin{array}{l}
1 \\
\mathrm{i}
\end{array}\right) \exp \left\{\mathrm{ik}_{-} l\right\} \\
& =\frac{E_{0}}{2} e^{i \psi}\left[\left(\begin{array}{c}
1 \\
-i
\end{array}\right) e^{i \theta}+\left(\begin{array}{l}
1 \\
i
\end{array}\right) e^{-i \theta}\right]
\end{aligned}
$$

onde $k_{ \pm}=\frac{2 \pi}{\lambda} n_{ \pm}$e as fases $\psi=\left(k_{+}+k_{-}\right) \frac{l}{2}$ e $\theta=\left(k_{+}-k_{-}\right) \frac{l}{2}$ foram introduzidas. Somando as matrizes da eq. (2) obtemos:

$$
\left|E^{\prime}\right\rangle=E_{0} e^{i \psi}\left(\begin{array}{c}
\cos \theta \\
\operatorname{sen} \theta
\end{array}\right)
$$


que representa uma onda linearmente polarizada cujo plano de polarização encontra-se rodado de um ângulo $\theta$ relativo à direção inicial que a polarização da luz tinha antes de penetrar no meio. De acordo com a definição de $\theta$ temos:

$$
\theta=\frac{\pi}{\lambda}\left(\mathrm{n}_{+}-\mathrm{n}_{-}\right) l
$$

de forma que o poder rotatório especifico $(\delta=\theta / l)$ é dado por:

$$
\delta=\frac{\pi}{\lambda} \Delta \mathrm{n}(\lambda)
$$

onde a dispersão de $\Delta n(\lambda)=n_{+}-n_{-}$com o comprimento de onda foi considerada. A figura 3 nos mostra o poder rotatório específico do quartzo como função do comprimento de onda.

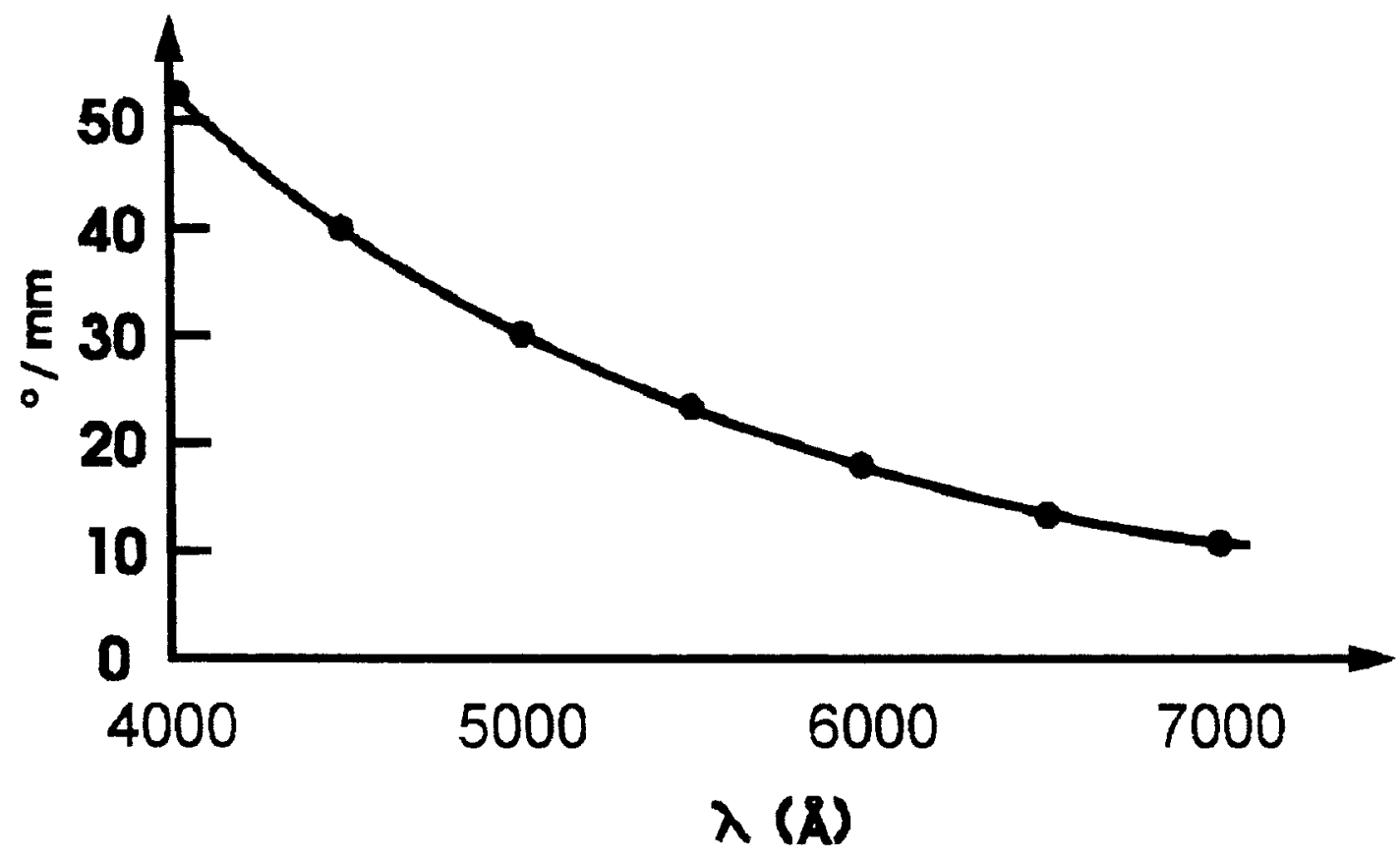

Figura 3 - Poder rotatório do quartzo. 
Nota-se que esta grandeza varia com $\lambda$ e esta variação, chamada de dispersão rotatória, pode ser usada na determinação do comprimento de onda da luz monocromática.

\section{2- Descrição do sistema opto-mecânico}

Para a construção do medidor de onda foi utilizado um cristal de quartzo natural com luz propagando-se ao longo de seu eixo óptico, de maneira a não haver birrefringência da luz no material. Medindo-se o ângulo que a polarização da luz é rodada pelo cristal determina-se o comprimento de onda desconhecido, ou alternativamente, o número de onda $\sigma$, definido como o inverso de $\lambda$. Da eq. 4 tem-se que a dispersão rotatória é proporcional ao comprimento do cristal, ou em outras palavras, a sensibilidade da medida, $d \theta / d \lambda$, será maior quanto mais longo for o cristal. Porém, por limitações práticas relacionadas com o tamanho do material que se dispunha, foi utilizado um cristal com $10 \mathrm{~cm}$ de comprimento.

O corte, lapidação e polimento do cristal foram feitos através de técnicas convencionais. ${ }^{6}$ Para o alinhamento do eixo óptico do cristal foi utilizada a técnica de conoscopia, que consiste em colocar o cristal entre polarizadores cruzados e fazer luz monocromática divergente passar por este sistema. ${ }^{7}$ Para facilitar 0 alinhamento, utilizou-se um pedaço de papel para limpeza de lentes para divergir o feixe, como mostra a figura 4. 


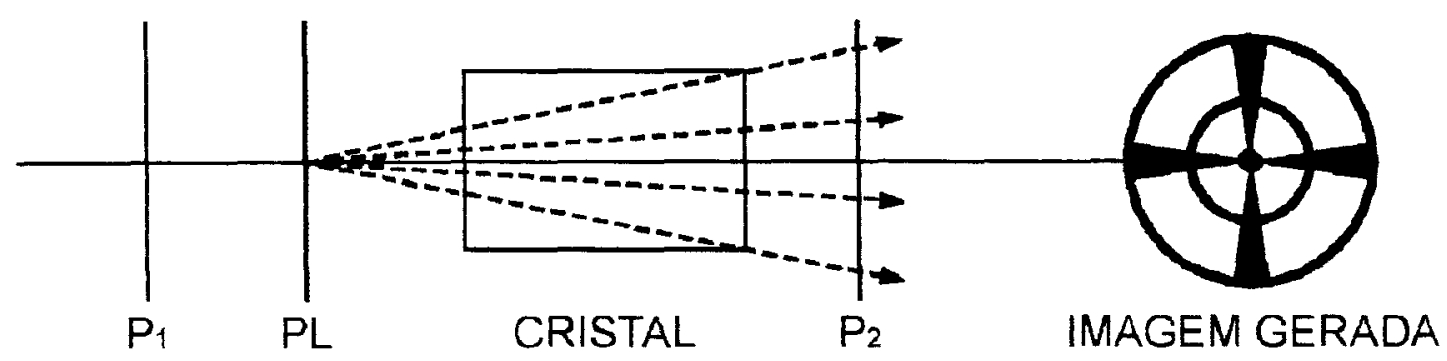

P1 e P2 - Polarizadores

PL - Papel para limpeza de lentes

Figura 4 - Técnica de conoscopia para o alinhamento do eixo óptico do cristal.

O espalhamento provocado pelo papel (PL), além de divergir parcialmente o feixe, despolariza um pouco a luz de forma que uma pequena fração colimada passando pelo segundo polarizador serve para definir o eixo óptico do sistema. Observa-se num anteparo, após o polarizador $P_{2}$, uma formação geométrica do tipo cruz de malta. O cristal estará alinhado quando o centro da cruz coincidir com o eixo óptico do sistema. A técnica descrita acima é utilizada durante o processo de polimento e também por ocasião da colocação do cristal na montagem óptica do medidor de onda.

De acordo com a figura 3 , um cristal de quartzo $\mathrm{com} 10 \mathrm{~cm}$ de comprimento produz uma rotação entre $1500^{\circ}$ e $4500^{\circ}$ para o comprimento de onda na região do visível. Como o aparato somente mede um ângulo $\theta$ entre $0^{\circ}$ e $180^{\circ}$, é necessária a determinação de quantas semirotações redundantes de $180^{\circ} \circ$ plano de polarização da luz realizou dentro do cristal. Para tal fim utiliza-se um divisor de feixes para gerar dois feixes de luz paralelos que percorrem o cristal. Um pedaço extra de quartzo cristalino de $4 \mathrm{~mm}$ de comprimento, orientado da mesma forma que o cristal longo, é adicionado à extremidade deste de maneira a cobrir apenas 
metade de sua área transversal (figura 5). Desta forma, um dos feixes percorrerá uma distância $l_{1}=10 \mathrm{~cm}$ dentro do meio cristalino, enquanto que a distância percorrida pelo outro será de $l_{2}=10.4 \mathrm{~cm}$. Isto provoca uma rotação adicional na polarização do segundo feixe que é sempre menor que $180^{\circ}$ e permite a determinação do número de rotações redundantes, $m$. que $\circ$ primeiro feixe realizou.

Para entender como isto pode ser conseguido, vamos expressar a discussão acima em termos matemáticos, utilizando as equações desenvolvidas anteriormentes. Chamando de $\theta_{1}$ e $\theta_{2}$ os ângulos de rotação medidos (menores que $180^{\circ}$ ) dos feixes que passam respectivamente pelas seções de cristal de comprimentos $l_{1}$ e $l_{2}$, e usando a equação 4 , considerando os ângulos medidos em graus e o comprimento de onda em $\mathrm{cm}$ temos:

$$
\begin{aligned}
& \theta_{1}+180 m=\frac{180}{\lambda} \Delta \mathrm{n} l_{1} \\
& \theta_{2}+180 m=\frac{180}{\lambda} \Delta \mathrm{n} l_{2}
\end{aligned}
$$

Subtraindo (6.a) de (6.b) temos:

$$
\frac{\Delta \mathrm{n}}{\lambda}=\frac{\Delta \theta}{180 \Delta l}
$$

onde $\Delta l=l_{2}-l_{1}$ e $\Delta \theta=\theta=-\theta_{1}$. Substituindo (7) em (6.a) obtemos 


$$
180 m=\left(\Delta \theta \frac{l_{1}}{\Delta l}-\theta_{1}\right)
$$

que nos fornece $o$ valor de $m$ independente do conhecimento de $\Delta \mathrm{n}$ e $\lambda$. Na dedução da equação (3) foi suposto explicitamente que os dois feixes sofrem o mesmo número de rotações redundantes $e$ isto nem sempre é verdade. Pode acontecer que 0 feixe 2 sofra $m+1$ rotações redundantes, 0 que experimentalmente resulta em $\theta_{2}<\theta_{1}$, fato que não deveria ocorrer para um mesmo $m$ pois $l_{2}>l_{1}$ e $\Delta n(\lambda)>0$. Para contornar este problema e trabalhar com o mesmo valor de $m$ nas equações, soma-se $180^{\circ}$ a $\theta_{2}$ sempre que este for menor que $\theta_{1}$.

A montagem óptica do medidor de onda está esquematizada na figura 5.

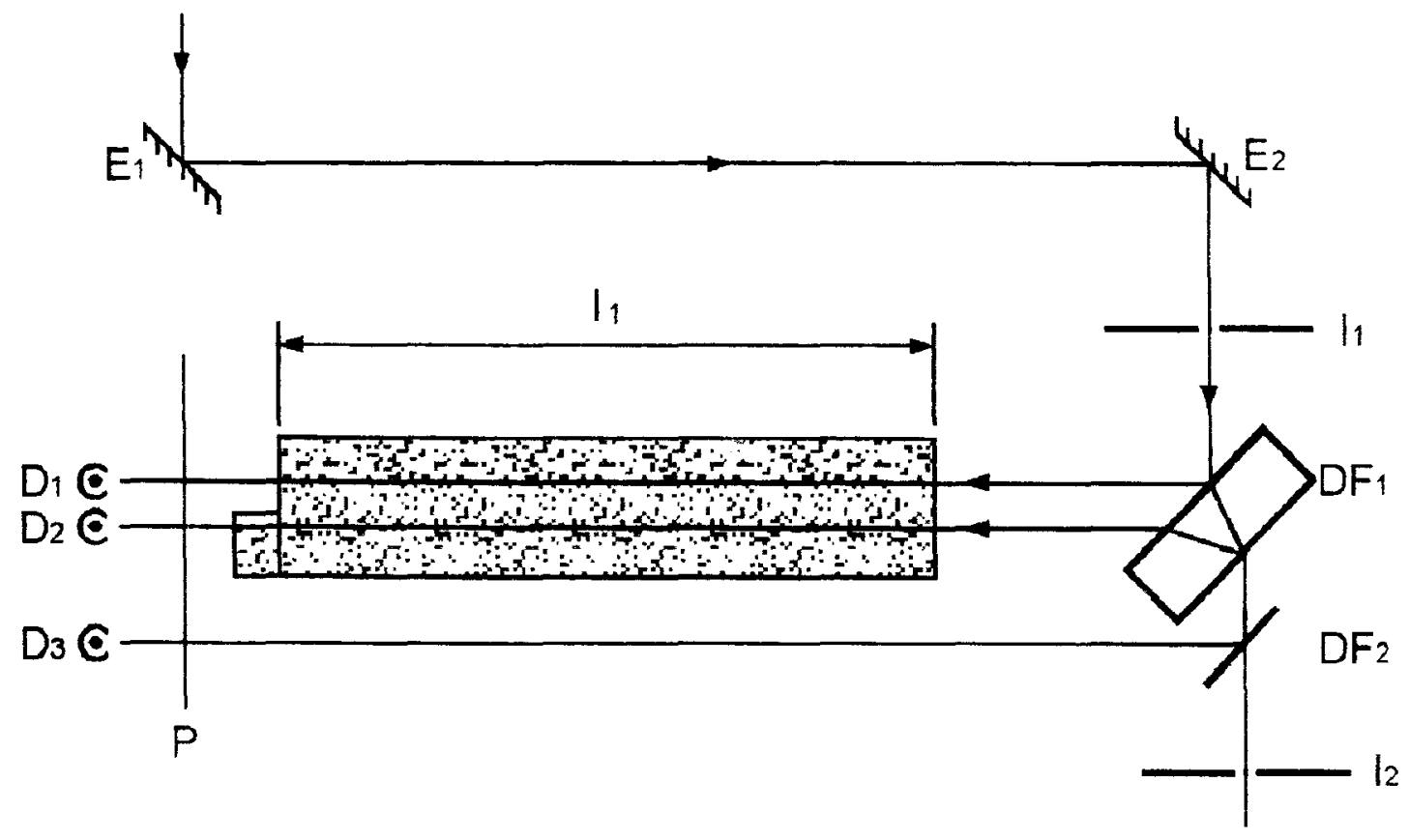

Figura 5 - Esquema da montagem óptica. 
Os espelhos de entrada, $E_{1}$ e $E_{2}$, servem para centrar o feixe nas íris $I_{1}$ e $I_{2}$ e consequentemente alinhar o sistema. No caso de feixe de laser não ser polarizado deve-se colocar um polarizador antes do espelho $E_{1}$. O divisor de feixes $D F_{1}$, que nada mais é que uma placa de vidro espessa, gera os dois feixes que passam pelo cristal. Um segundo divisor de feixes, $\mathrm{DF}_{2}$, feito com uma lâmina de microscópio, gera um terceiro feixe que passa fora do cristal e serve como referência para o ângulo $0^{\circ}$. Os três feixes são interceptados por um polarizador plástico rotativo, do tipo Polaroid, e incidem sobre fotodiodos não polarizados (MRD 300). O polarizador é cortado na forma de um disco de $7 \mathrm{~cm}$ de raio cujo centro é conectado a um motor D.C. que roda com velocidade angular da ordem de $1000 \mathrm{rpm}$. A figura 6 mostra a evolução temporal das intensidades de luz que chegam aos detectores. É preferivel trabalhar com os detetores saturados para se obter uma boa definição dos mínimos de transmissão, que correspondem à situação na qual o eixo de transmissão do polarizador $P$ está perpendicular ao plano de polarização da luz.

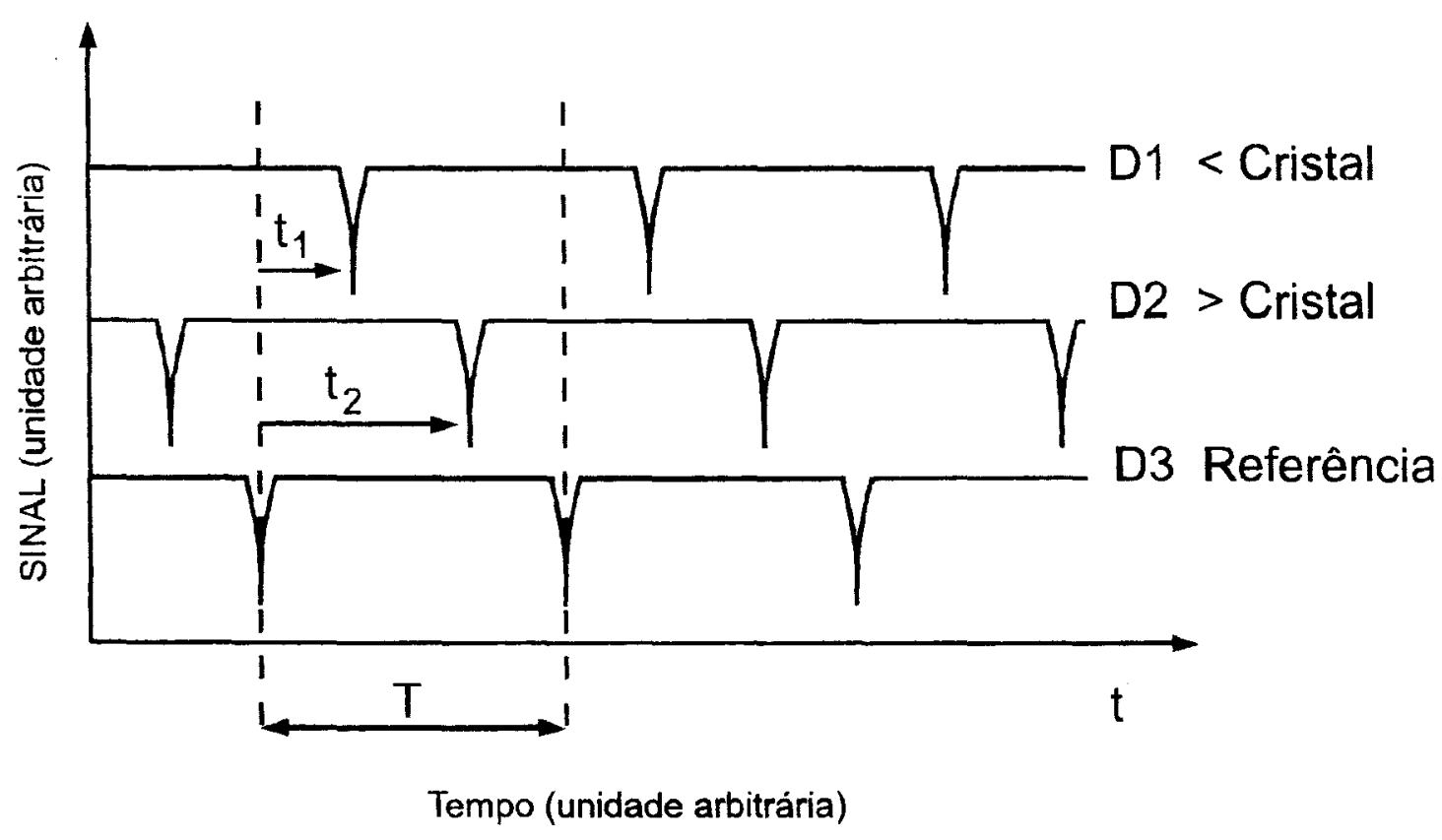

Figura 6 - Sinais luminosos que os fotodiodos recebem. 
O sinal de referência do detetor $D_{3}$ fornece um disparo para a medida de $t_{1}$ e $t_{2}$ e define o tempo $T$ que corresponde a uma rotação de $180^{\circ}$. Em linhas gerais, a medida dos ângulos $\theta_{1}$ e $\theta_{2}$, ocorre da seguinte forma: quando um mínimo do sinal de referência $\left(D_{3}\right)$ é detectado, são disparados três contadores, sendo um para cada detector. Estes contarão números proporcionais a t $t_{1}, t_{2}$ e $T$ da figura 6 . Sabendo que $T$ corresponde a uma rotação de $180^{\circ}$, determina-se $\theta_{1}$ e $\theta_{2}$ através das medidas de $t_{1}$ e $t_{2}$ (regra de três).

Para se calcular o comprimento de onda é necessário o conhecimento da dispersão de $\Delta n$ em função do número de onda.

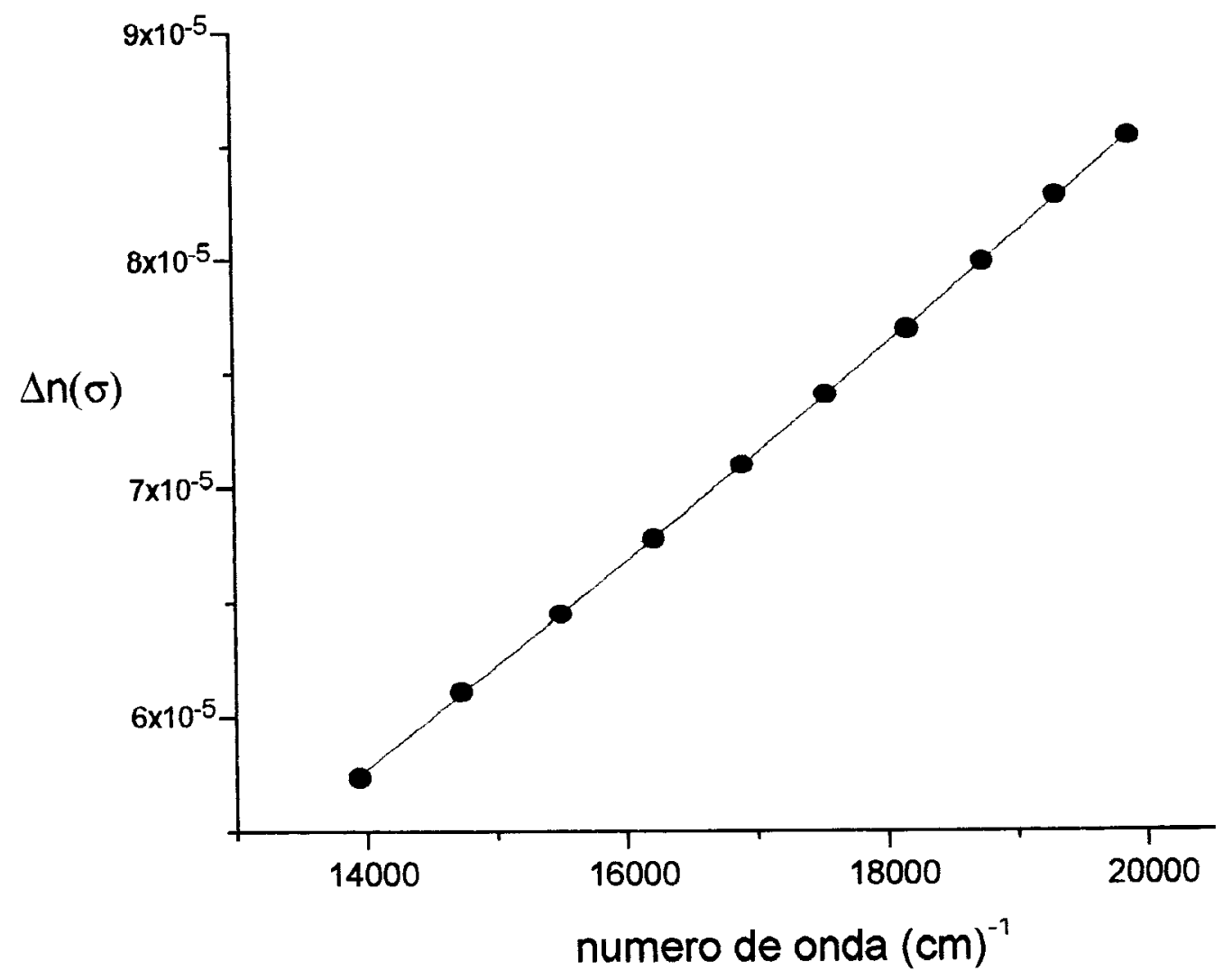

Figura 7 - Valores experimentais de $\Delta n \times \sigma$ do cristal de quartzo utilizado. 
Para estudar este comportamento utilizamos um espectrofotômetro para o visivel, com o cristal colocado no compartimento de amostra entre dois polarizadores com eixos de transmissão paralelos. Isto nos permitiu determinar para quais comprimentos de onda o plano de polarização da luz sofre rotações múltiplas de $180^{\circ}$ e a partir dai foi possível encontrar o valor de $\Delta n(\sigma)$ através da eq. (6.a). O resultado está mostrado na figura7, que mostra o valor da dispersão de $\Delta$ n como função do número de onda. Estes pontos podem ser ajustados por uma função polinomial do tipo:

$$
\Delta \mathrm{n}(\sigma)=\mathrm{a}_{0}+\mathrm{a}_{1} \sigma+\mathrm{a}_{2} \sigma^{2}+\mathrm{a}_{3} \sigma^{3}
$$

com $a_{0}=-1766,43358352, a_{1}=0,325180901437 \mathrm{~cm}, a_{2}=-1,98990930216 \times 10^{-5}$ $\mathrm{cm}^{2}$ e a3 $=4,06354656602 \times 10^{-10} \mathrm{~cm}^{3}$. Inserindo a equação. (9) em (6.a) obtemos:

$$
\theta_{1}+180 m=\frac{180}{\lambda} \ell_{1}\left(a_{0}+a_{1} \sigma+a_{2} \sigma^{2}+a_{3} \sigma^{3}\right)
$$

Como $\sigma=1 / \lambda$, a equação se torna:

$$
\mathrm{a}_{3} \sigma^{4}+\mathrm{a}_{2} \sigma^{3}+\mathrm{a}_{1} \sigma^{2}+\mathrm{a}_{0} \sigma+D=0
$$

com $D=-\left(\frac{m}{l}+\frac{\theta_{1}}{180 l}\right) 10^{5}$

Como $m$ já foi determinado através da equação (8), para um dado $\theta_{1}$ medido, calcula-se numericamente as raízes do polinômio, que fornecem o valor de $\sigma$ que se deseja determinar. 


\section{3- Componentes eletrônicos}

A aquisição e processamento dos dados são realizados por um sistema eletrônico do qual faz parte um microcomputador padrão IBM-PC e duas placas eletrônicas, que em conjunto medem a rotação da polarização linear da luz ao atravessar toda a extensão de uma amostra de cristal de quartzo. A figura 8 apresenta um diagrama esquemático com as diversas partes deste sistema.

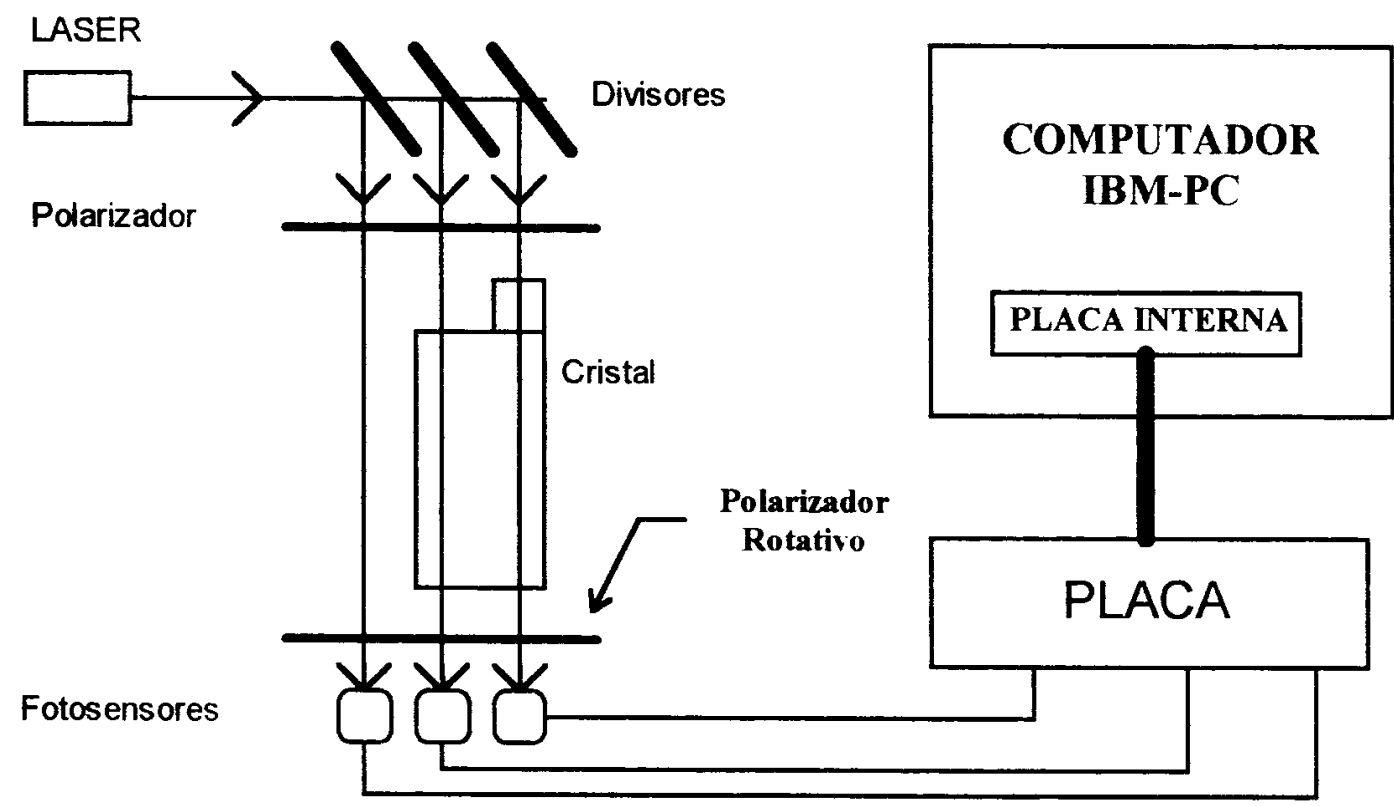

Figura 8 - Diagrama esquemático do medidor de onda por atividade óptica.

Uma placa de circuito impresso que opera externamente ao microcomputador possui a função de captar os sinais provenientes dos três fotodiodos e transformá-los em sinais digitais (nivel $T T L$ ) equivalentes aos sinais originais no que diz respeito à frequência de cada um e as defasagens temporais entre eles.

Uma segunda placa de circuito impresso conectada diretamente ao barramento do microcomputador, mede as defasagens temporais entre estes 
sinais já tratados pela placa anterior. Um programa em linguagem de máquina controla todas as funções desta placa interna ao microcomputador, bem como, transfere os valores das defasagens lidas a um outro programa escrito em Visual Basic, da Microsoft, que calcula o comprimento de onda da luz, através das equações apresentadas na seção precedente e mostra o resultado na tela do computador.

Além destas duas placas anteriormente citadas, temos outras duas que fornecem subsidios para que o sistema opere corretamente. A primeira delas é a fonte de alimentação regulada que fornece as tensões necessárias para todos os circuitos. A segunda é um conjunto de circuitos que realizam várias funções, tais como: estabilizar a temperatura do sistema, manter a velocidade do polarizador rotativo constante; medir e indicar em um galvanômetro a potência do feixe de luz incidente (muito útil na hora de se alinhar o sistema para o uso).

Do ponto de vista funcional, a parte eletrônica deste medidor de onda pode ser dividida em quatro partes principais: (1) tratamento dos sinais analógicos, (2) tratamento dos sinais digitais, (3) subsídio e apoio e (4) fonte de alimentação.

\section{1- Placa de tratamento dos sinais analógicos}

Os sinais analógicos devem ser tratados de maneira conveniente para que possam ser medidos. Para este fim, um circuito eletrônico foi desenvolvido especialmente para converter os sinais vindos dos detectores ópticos em sinais compativeis com os outros estágios do medidor. O circuito responsável por esta função fica localizado numa placa externa ao microcomputador; placa esta, que chamaremos por motivos práticos de "placa analógica". 
A placa analógica contém três canais que convertem os sinais analógicos captados pelos fotodiodos (figura 6) em sinais digitais que reproduzem fielmente os sinais originais no que concerne à frequência e defasagem temporal entre si. Cada canal gera um estreito pulso digital (T.T.L.) toda vez que o sinal luminoso que incide no fotodetector (figura 6) atingir um ponto de mínima potência. Doravante, por simplificação, estes circuitos de cada canal serão chamados de detectores de mínimo. A figura 9 mostra um diagrama de blocos de um dos detectores de minimo.

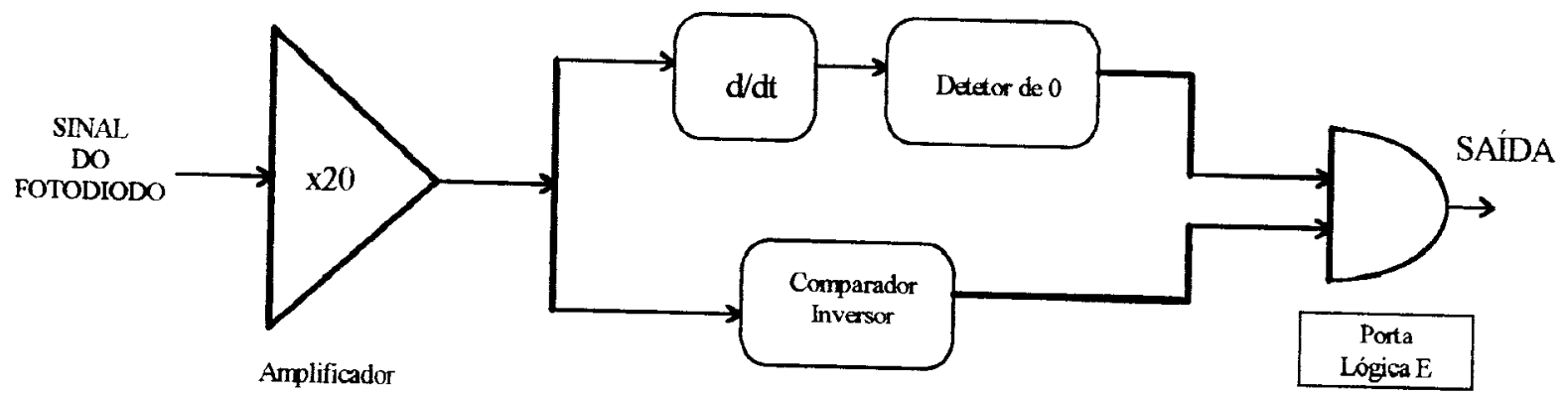

Figura 9 - Diagrama de blocos de um dos três detectores de mínimo.

O funcionamento deste bloco começa com a amplificação do sinal elétrico fornecido pelo fotodiodo. As intensidades máximas destes sinais passam de $0,5 \mathrm{~V}$ para 10V. Em seguida, o sinal amplificado é dividido e injetado simultâneamente em dois pequenos estágios que operam paralelamente. O primeiro destes estágios é composto de um diferenciador em cascata com um detector de zero; portanto, a sua saída fica no estado lógico alto $(+5 \mathrm{~V})$ sempre que a derivada do sinal de entrada for nula. A saida do segundo estágio assume o estado lógico alto (+5V) 
sempre que o sinal já amplificado do seu respectivo foto-sensor for menor que $5 \mathrm{~V}$. Trata-se portanto de um comparador inversor.

O detector de mínimo é conseguido através de uma operação lógica " $E$ " entre as saidas destes dois estágios. Um pequeno pulso surge na saída do detetor de mínimo toda vez que o sinal do seu correspondente foto-sensor atinge um valor de mínimo. A carta de tempos deste circuito pode ser vista na figura 10.

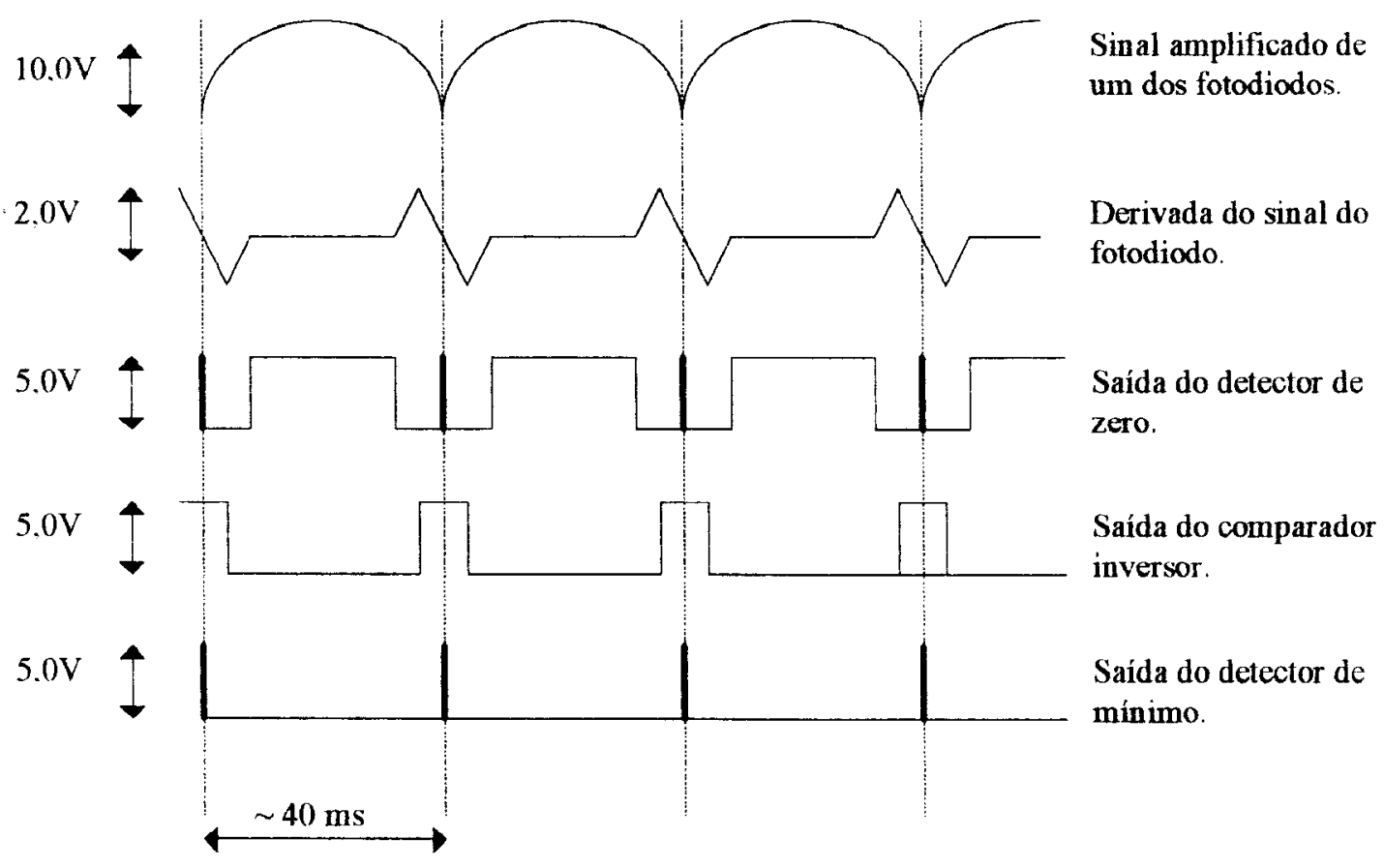

Figura 10 - Carta de tempos do detector de mínimos. 
A figura 11 é o esquema elétrico de um dos detectores de minimo utilizados no protótipo. Os circuitos dos outros dois canais são idênticos a este.

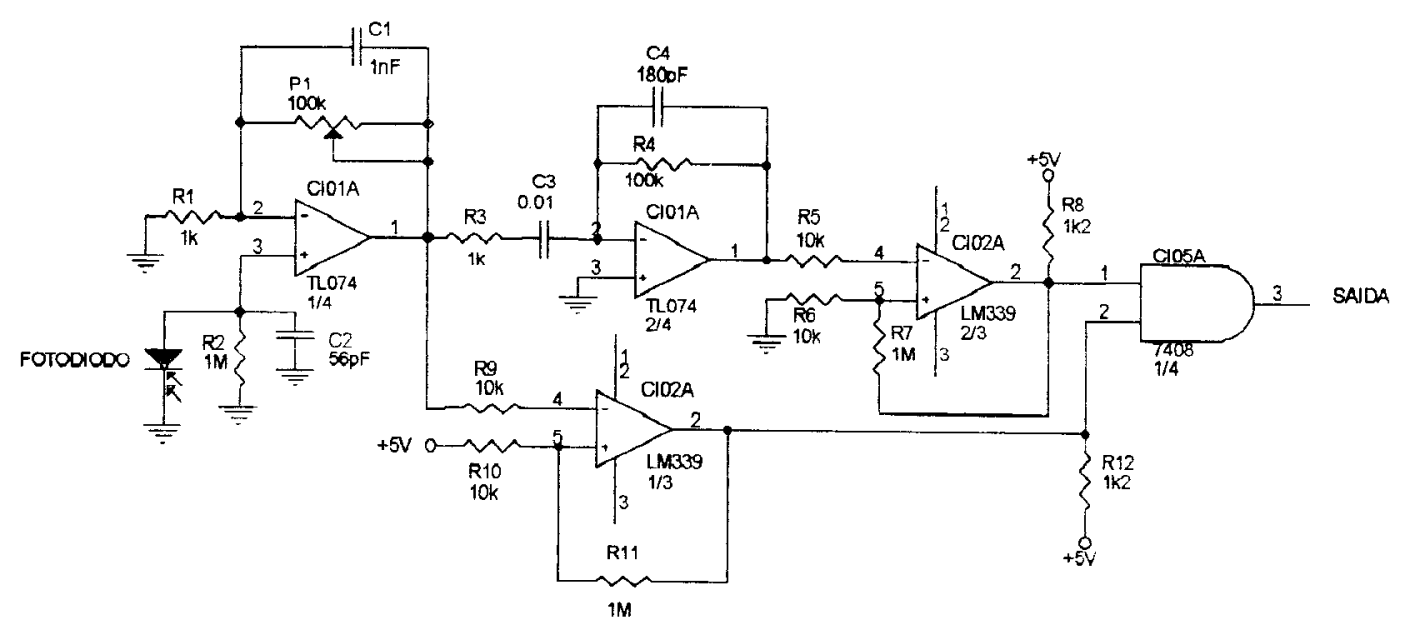

Figura 11 - Esquema elètrico do detector de mínimo.

As saidas dos detetores de minimo não são convenientes para a conexão com o microcomputador via cabos, pois são ruidosas com pulsos muito estreitos. O tempo em que permanecem em nível alto $(+5 \mathrm{~V})$ pode chegar a ser de apenas algumas dezenas de microsegundos variando com o alinhamento do feixe laser e conforme a qualidade e a velocidade de rotação do polarizador. As saidas dos detectores de mínimo são utilizadas para disparar três respectivos monoestáveis sensiveis à subida, programados para ficarem com nivel alto por quatro milessegundos. Com isto, consegue-se contornar problemas de ruídos que a histerese dos comparadores nos detectores de mínimo não conseguiram evitar. Os sinais ficam mais fáceis de se acompanhar no osciloscópio, mantendo um período relativamente estável. A figura 12 mostra, o diagrama elétrico de um dos três monoestáveis utilizados na montagem do protótipo. 


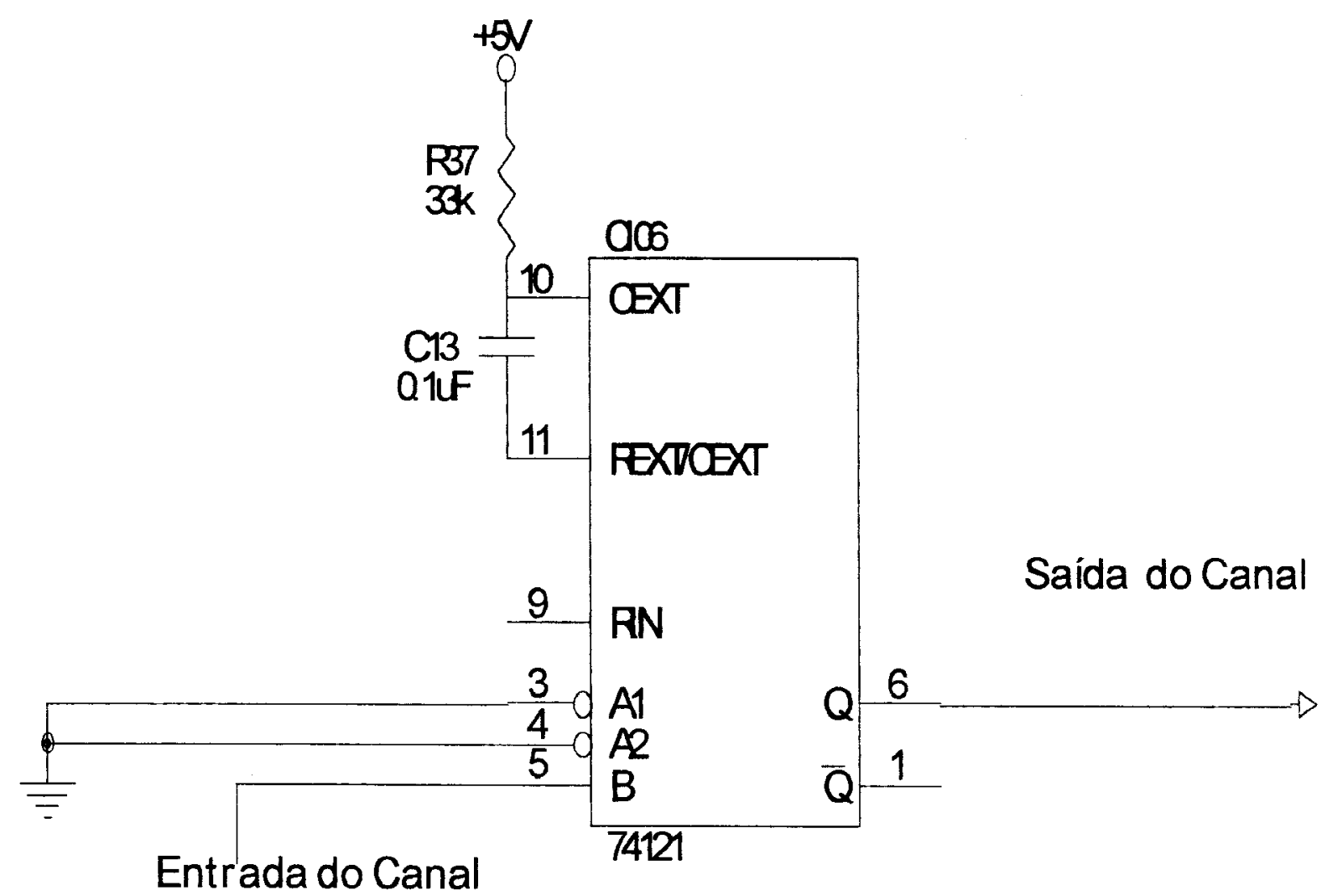

Figura 12 - Circuito dos Monoestáveis.

Após serem injetados em três monoestáveis idênticos ao apresentado na figura 12 , os três canais podem ser finaimente conectados à placa digital que realizará as medidas das defasagens temporais entre os três sinais que agora são digitais. A figura 13 mostra o perfil dos sinais que são enviados ao microcomputador. 


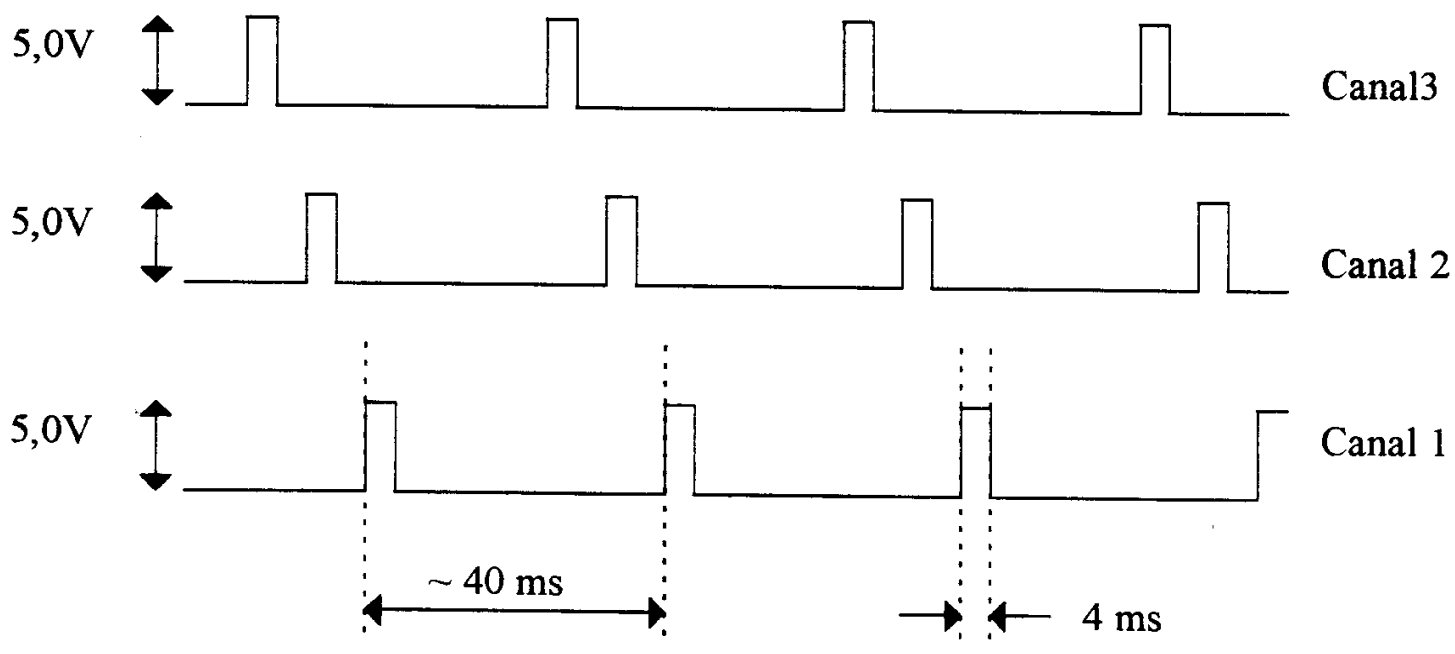

Figura 13. Exemplo de sinais elétricos que saem dos monoestáveis.

As defasagens entre os três canais variam em função da frequência da luz e a placa que será apresentada a seguir se encarrega de medir estas defasagens.

\section{2- Placa de tratamento de sinais digitais}

Trata-se de uma placa que vai diretamente conectada ao barramento do microcomputador. A grosso modo pode-se dizer que ela mede a defasagem temporal de até dois sinais digitais pulsados e iguais com relação a um terceiro que serve como referência. As principais funções desta placa são: medir as defasagens temporais dos sinais digitais que recebe da placa analógica (externa) e transferir os valores medidos para o programa que controla o seu funcionamento. 
Para efeitos didáticos e considerando apenas o medidor por atividade óptica, podemos subdividí-la em 6 blocos: 1) Bloco de mapeamento, 2) Bloco Lógico, 3) Bloco de comando, 4) Bloco dos contadores, 5) Bloco de monitoração, 6) Bloco de comunicação.

A figura 14 mostra todos estes blocos e a maneira como eles estão interligados.

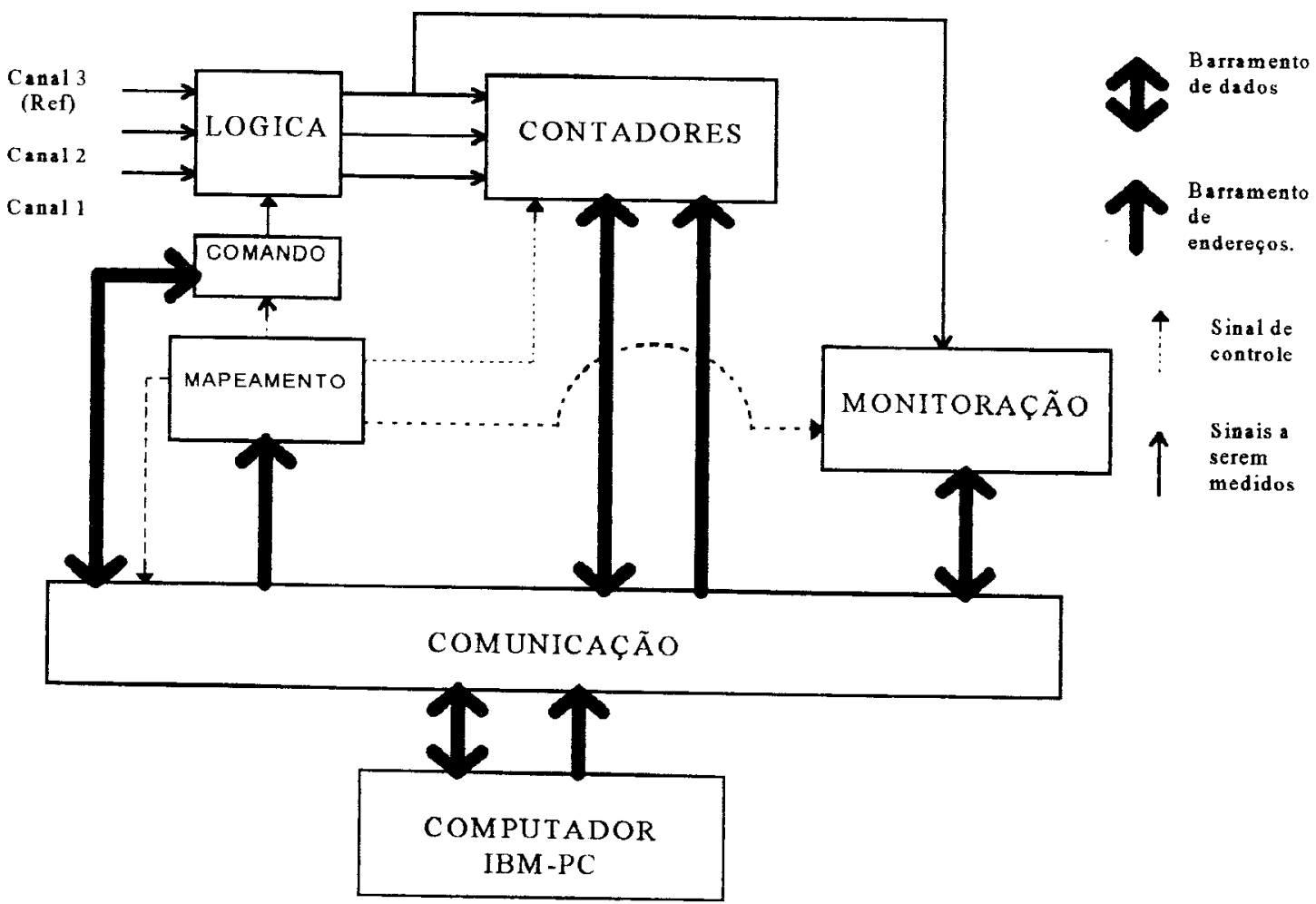

Figura 14 - Diagrama de blocos da placa interna ao PC.

O bloco de mapeamento se encarrega de gerenciar qual bloco está acessando o barramento do computador em determinado instante. O bloco lógico converte os três sinais vindos da placa analógica em sinais cujos pulsos têm as durações que devem ser contadas pelos contadores. O bloco de comando possibilita que o programa consiga atuar no circuito da lógica digital que é aqui 
chamado de bloco lógico. O bloco dos contadores é que quantificam as defasagens dos sinais. $O$ bloco de monitoração possibilita que o programa de controle possa "saber" o que está ocorrendo no canal 1 (sinal de referência) em determinados instantes. O bloco de comunicação funciona como uma válvula, permitindo que a placa digital somente transfira dados ao computador em momentos propicios. Existem alguns componentes nesta placa que não estão neste diagrama, pois não fazem porte do medidor de onda por atividade óptica; serão mostrados em um outro capítulo que trata do módulo de altissima precisão que pode ser acoplado neste projeto. Cada bloco será explicado separadamente logo a seguir.

\subsection{1- Bloco de mapeamento}

Este bloco é responsável pelo gerenciamento da placa toda no que diz respeito à utilização dos barramentos de dados e de endereços do microcomputador. Determinados comandos no programa de controle da placa fazem este circuito habilitar ou não os demais blocos para que operem de maneira harmoniosa e ordenada, impedindo que os demais blocos da placa conflitem ao acessar os barramentos. Este bloco também evita que a placa conflite com as outras partes do próprio computador. Através deste circuito, os demais foram mapeados em entrada e saida, podendo ser acessados convenientemente através de uma rotina em linguagem de máquina. Basta se referenciar uma especifica posição de memória que um respectivo bloco será habilitado. Temos na figura 15 o esquema elétrico do circuito que realiza esta tarefa. 


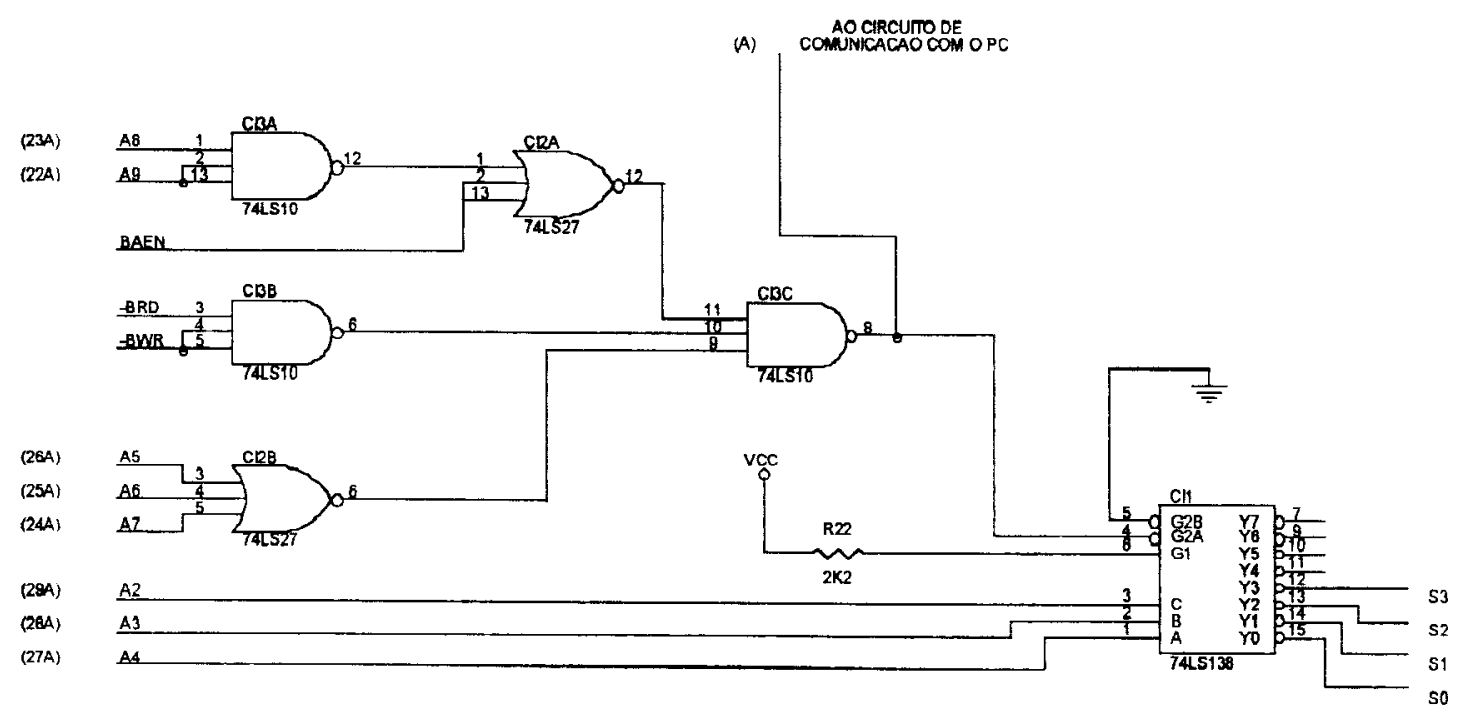

Figura 15 - Esquema elétrico do circuito de mapeamento.

Toda vez que o barramento de endereços contiver um valor maior ou igual a $300 \mathrm{~h}$ e menor e igual a $303 \mathrm{~h}$ a saída SO do circuito da figura 15 passa para o estado lógico alto $(+5 \mathrm{~V})$, zerando as outras saidas. Analogamente, os intervalos de endereços $304 \mathrm{~h}$ a $307 \mathrm{~h} ; 308 \mathrm{~h}$ a $30 \mathrm{Bh}$ e $30 \mathrm{Ch}$ a $30 \mathrm{Fh}$, afetam as saidas $\mathrm{S} 1$, S2 e S3, respectivamente. Estas saidas é que controlam qual bloco da figura 14 está autorizado a escrever ou ler no barramento de dados do microcomputador; podese então controlar o acesso, proporcionando então um funcionamento sincronizado entre as partes. 


\subsection{2- Bloco lógico}

Este bloco altera convenientemente os sinais elétricos provenientes da placa externa, para que possam ser utilizados pelo bloco dos contadores. Os três sinais semelhantes e defasados no tempo, são transformados em três pulsos com durações variáveis. A figura 16 mostra este circuito.

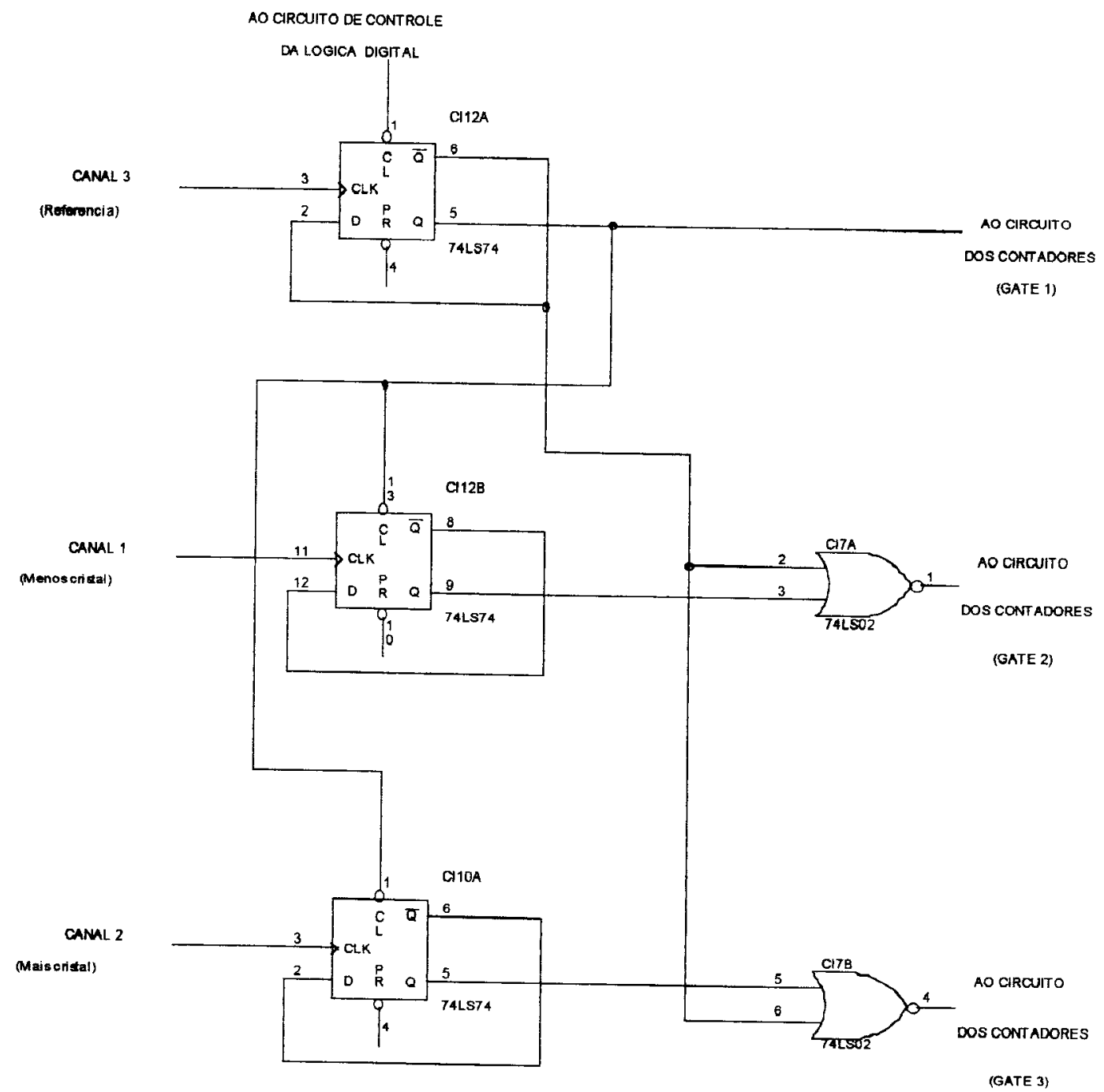

Figura16 - Esquema elétrico da lógica digital. 
O circuito é composto de três "flip-flops" mais duas portas "ou-inversoras". Inicialmente todas as três saídas devem estar em zero. Quando o canal 1 recebe um pulso positivo todas as três saídas sobem para o nivel lógico alto $(+5 \mathrm{~V})$, a saída de cada canal só torna a descer o nivel lógico quando o respectivo canal receber um pulso positivo. Com isto, obtêm-se três pulsos com durações temporais diferentes $T, t 1$ e $t 2$. Todos serão injetados independentemente nas portas de três contadores, que contam enquanto as respectivas portas estiverem com nivel lógico alto. A figura 17 nos mostra uma carta de tempos do referido circuito.

\section{Sinais provenientes da placa externa.}

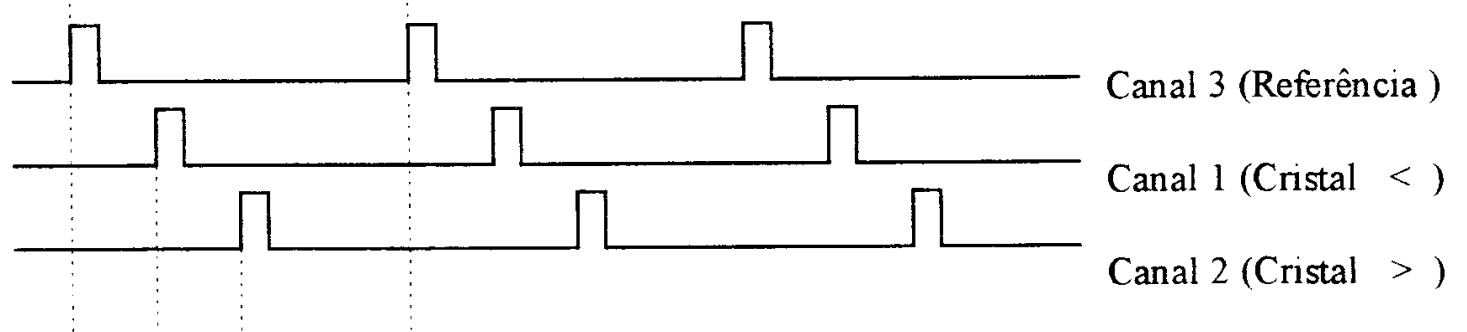

Saídas da lógica digital

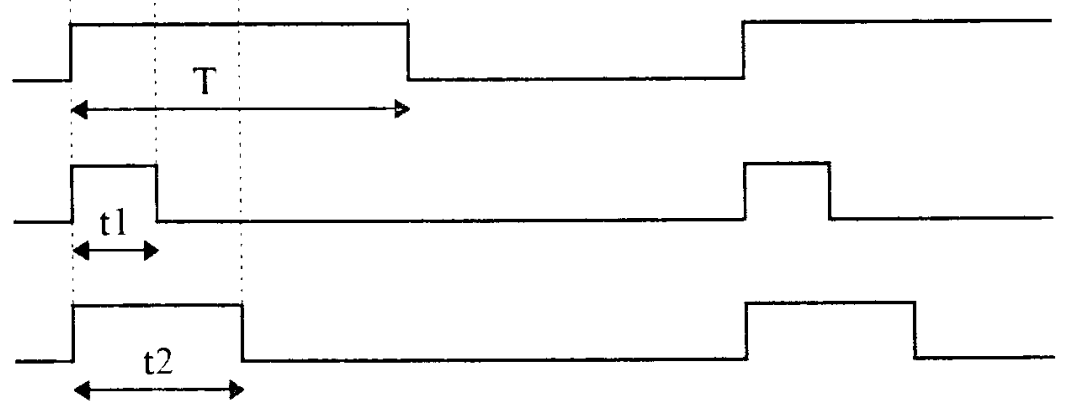

Ao contador 0

Ao contador 1

Ao contador 2

Figura 17 - Carta de tempos da lógica digital 
Analisando as três saídas da lógica digital na figura 17 , nota-se que a largura de pulso $\mathrm{T}$ é igual ao período do sinal elétrico do canal 3 (referência). A duração do pulso t1 está ligado ao tempo de atraso do sinal no canal 1 relativo ao canal 3 (referência). Analogamente, o comprimento do terceiro pulso (t2) fornece o atraso temporal do sinal no canal 2 relativo ao canal 3 . Portanto, se contarmos o tempo de duração destes três pulsos teremos: quanto tempo correspondem $180^{\circ}$ de defasagem (pulso do canal 3), quanto tempo o canal 1 está defasado com relação à referência (pulso do canal 1) e analogamente, quanto tempo o canal 2 está defasado com relação ao canal 3 (pulso do canal 2). Uma simples regra de três nos fornece quantos graus cada um dos dois canais estão defasados da referência, de acordo com:

$$
\begin{aligned}
& \theta_{1}=\frac{180^{\circ}}{T} * t_{1} \\
& \theta_{2}=\frac{180^{\circ}}{T} * t_{2}
\end{aligned}
$$

\subsection{3- Bloco de comando}

Este bloco permite que o programa de controle do sistema zere e trave as saídas da lógica digital (bloco lógico). Isto é muito útil para que se consiga sincronizar o funcionamento dos blocos com os programas. Toda vez que se armazena, mesmo que temporariamente, no endereço $030 \mathrm{Ch}$, um valor que em base binária possua o digito menos significativo igual a zero, todas as saidas da lógica digital permanecem indefinidamente fixas em zero. Para que o circuito seja 
liberado novamente, deve-se obrigatoriamente armazenar neste mesmo endereço um valor que possua o digito binário menos significativo igual a um. Interessante notar que quando este circuito assume um estado ele fica desta forma indefinidamente, até que receba um comando especifico para que mude de estado lógico. O circuito é formado por um "latch" e por duas portas lógicas que estão sendo utilizadas apenas como inversoras para compatibilizar os sinais que vêm dos outros blocos. A figura 18 mostra o diagrama esquemático deste bloco.

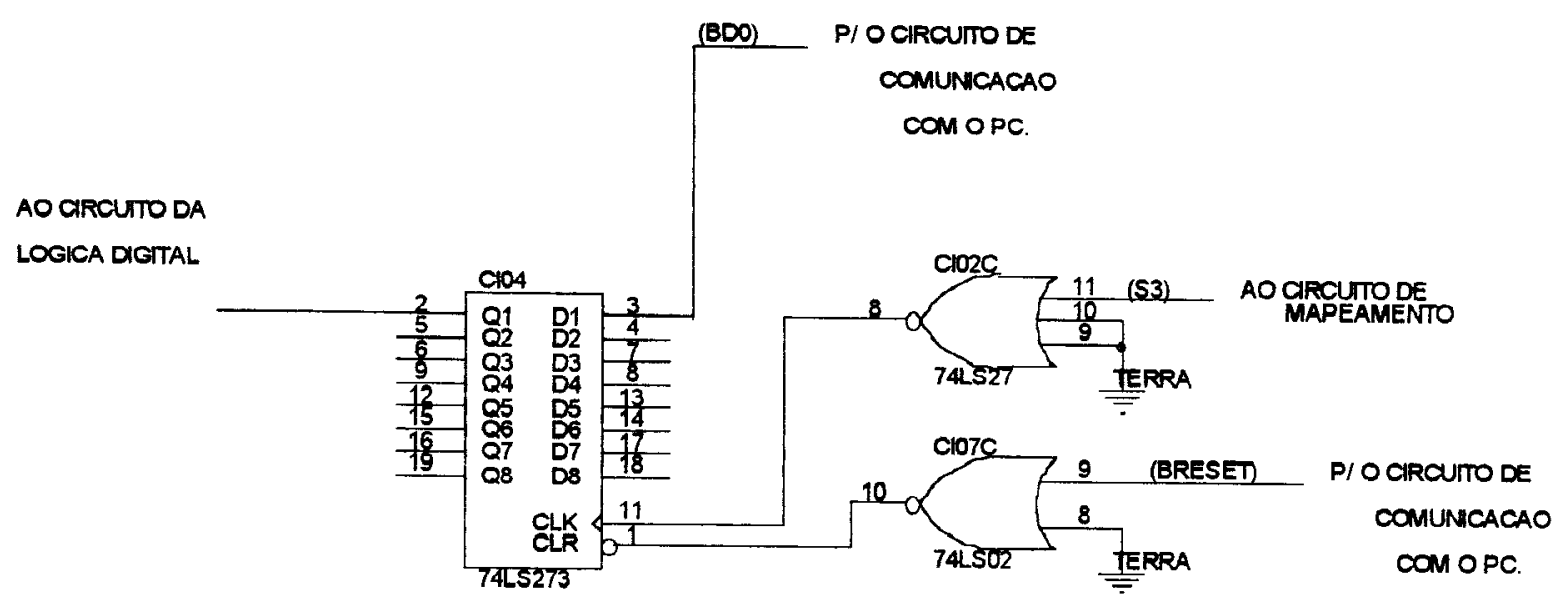

Figura 18 - Esquema elétrico do circuito de controle.

Este bloco foi projetado para controlar mais funções além da lógica digital. O projeto inicial prevê uma segunda etapa do medidor de onda o qual será melhor explicado em um capitulo subsequente. 


\subsection{4- Bloco dos contadores}

Este bloco é que efetivamente mede quantos graus rotacionaram cada uma das polarizações dos dois feixes de luz que atravessam comprimentos diferentes do cristal de quartzo. Ele é formado por três contadores digitais que calculam as durações dos pulsos gerados (figura 7) pela lógica digital. A base de tempo dos contadores é obtida da divisão por doze do relógio de vídeo (14.31Mhz) que está disponível no soquete de expansão do microcomputador. Como a base de tempo é a mesma para os três contadores e os seus portos estão ligados respectivamente nas saídas três, um e dois da lógica digital, as contagens obtidas serão proporcionais a $T, t_{1}$ e $t_{2}$ da figura 17 , que por sua vez, são respectivamente proporcionais aos ângulos de $180^{\circ}, \theta_{1}$ e $\theta_{2}$. A figura 19 mostra o diagrama esquemático deste bloco.

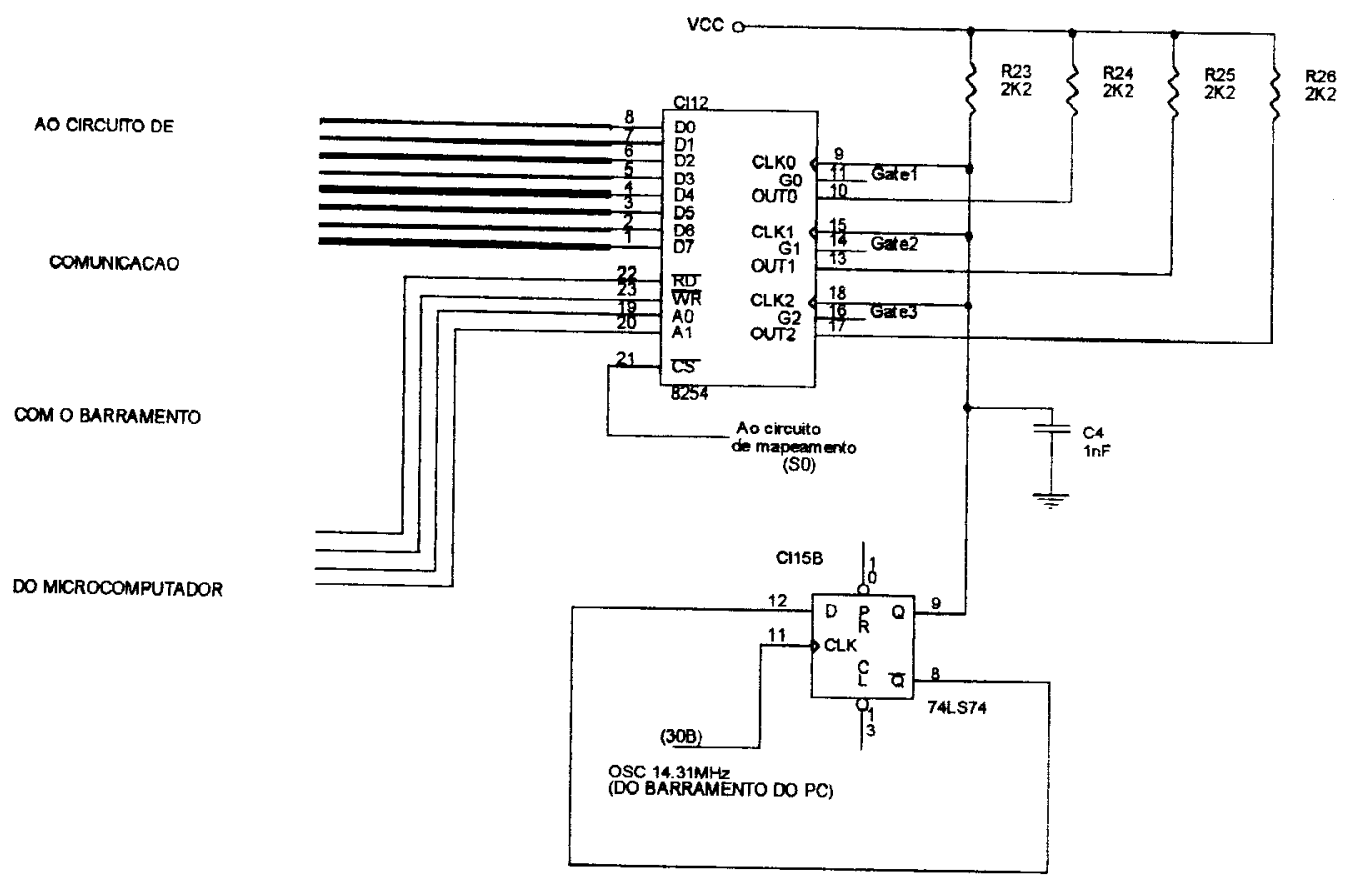

Figura 19 - Esquema elétrico dos contadores. 
As contagens obtidas são enviadas ao microcomputador pelo bloco de comunicação, que será explicado dentre em breve, podendo então serem utilizadas para calcular o comprimento de onda desejado.

\subsection{5- Bloco de monitoração}

Este circuito é necessário para que o programa de controle do sistema possa monitorar o pulso que vai ao porto do contador do canal 3 (referência). 0 programa espera este pulso atingir um nível lógico baixo (e consequentemente todos os outros dois também estarão baixos) para "zerar" os contadores.

P/ a saida do canal 1

da logica digital

Ao circuito de

mapeamento (S2)

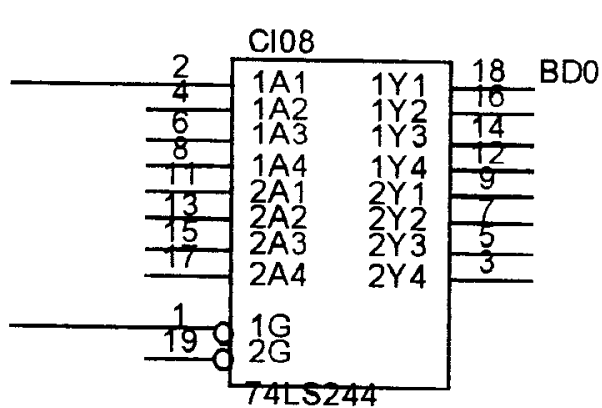

Ao circuito de comunicacao com o pc

Figura 20 - Esquema elétrico do circuito de monitoração.

\subsection{6- Bloco de comunicação com o PC}

Para que qualquer placa se comunique com 0 barramento de um microcomputador do tipo PC, torna-se necessário a utilização um circuito isolador 
e de reforço de corrente elétrica dos sinais. Dois circuitos integrados 74LS245 fazem este papel, conectando a placa do medidor de onda num slot de 8 bits do $P C$, permitindo que os dados fluam bilateramente entre o computador e a placa do medidor de onda.

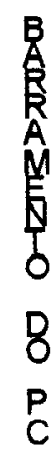

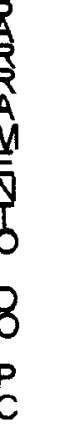
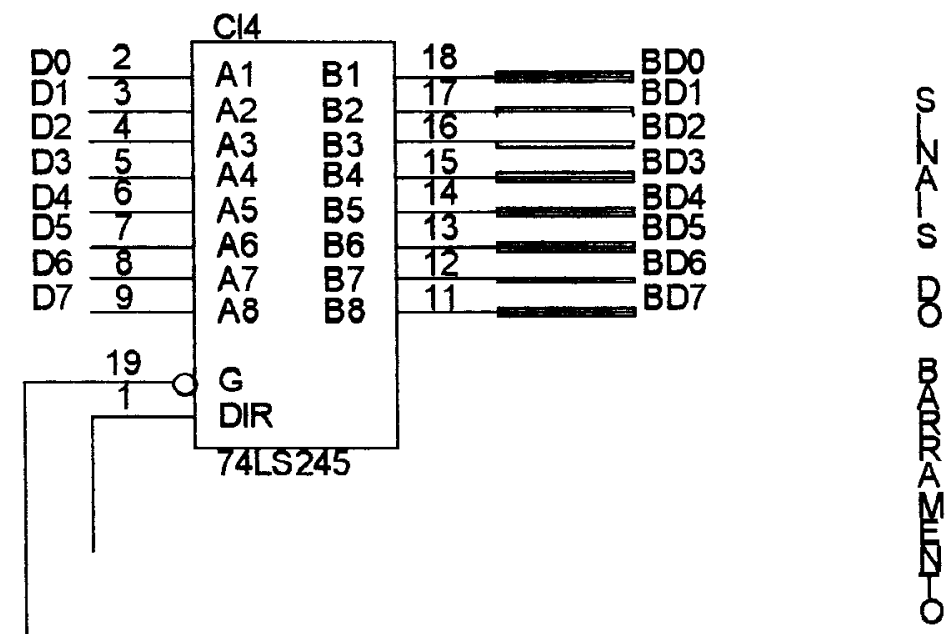

(A) Ao circuito de mapeamento.

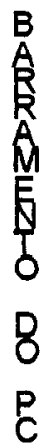

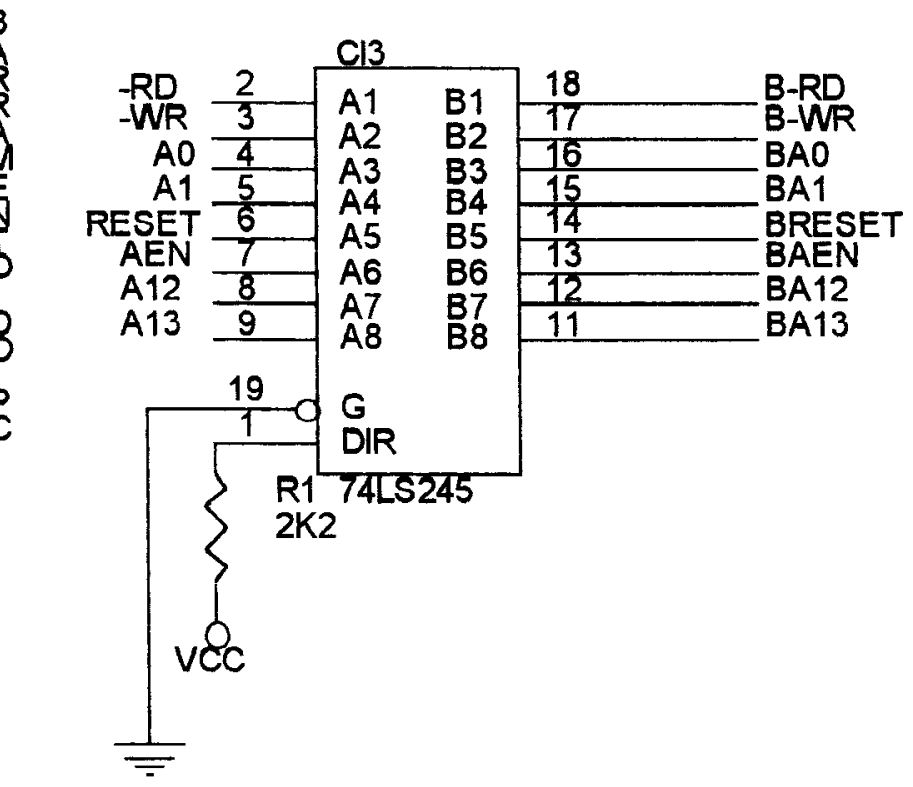

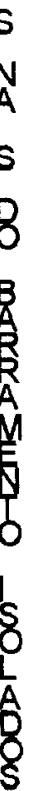

Figura 21 - Esquema elétrico da interface com o barramento do PC. 
Um dos circuitos integrados está sempre habilitado pois realiza apenas leituras. Já o outro pode escrever ou ler no barramento de dados. Toda vez que uma operação de leitura ou escrita é feita no intervalo de endereços de 300 hexadecimal até o 3FF hexadecimal, o circuito de mapeamento habilita este componente para que ele acesse o barramento de dados. Portanto o acesso somente é realizado em situações bem determinadas.

3.3- Placa de subsidio e apoio

Esta é uma segunda placa externa ao microcomputador, que fornece subsídios mínimos para que o medidor de onda funcione corretamente.

Ela pode ser dividida em três circuitos básicos: 1) Controle de temperatura, 2) Controle de velocidade, 3) Medidor de potência

\subsection{1- Controle de temperatura}

Utilizou-se um sistema de controle de temperatura de malha fechada proporcional e integral. Este controle mostrou-se crucial para que todas as etapas do medidor de onda alcançassem a precisão desejada. As dimensões das peças que compõem o aparelho variam e portanto o alinhamento da luz e o comprimento do cristal são funções da temperatura. Observou-se uma variação de quase $1 \AA{ }^{\circ} \mathrm{C}$ na medida do comprimento de onda da luz. 
O circuito começa com o sensor de temperatura, que é um resistor variável (N.T.C.) de dois mil ohms (à $\left.25^{\circ} \mathrm{C}\right)$. Quanto maior for a temperatura, menor o valor de sua resistência. Portanto, no circuito, a tensão sobre o sensor é inversamente proporcional à temperatura. Este sinal do sensor é então injetado em um amplificador diferencial inversor. Temos então um sinal de erro que após ser integrado fecha a malha através dos quatro transistores de potência que estão mecanicamente fixados no corpo do medidor. A dissipação de potência elétrica que os transistores realizam se encarrega de aquecer o sistema. A figura 22 mostra o circuito utilizado para estabilizar a temperatura do sistema.

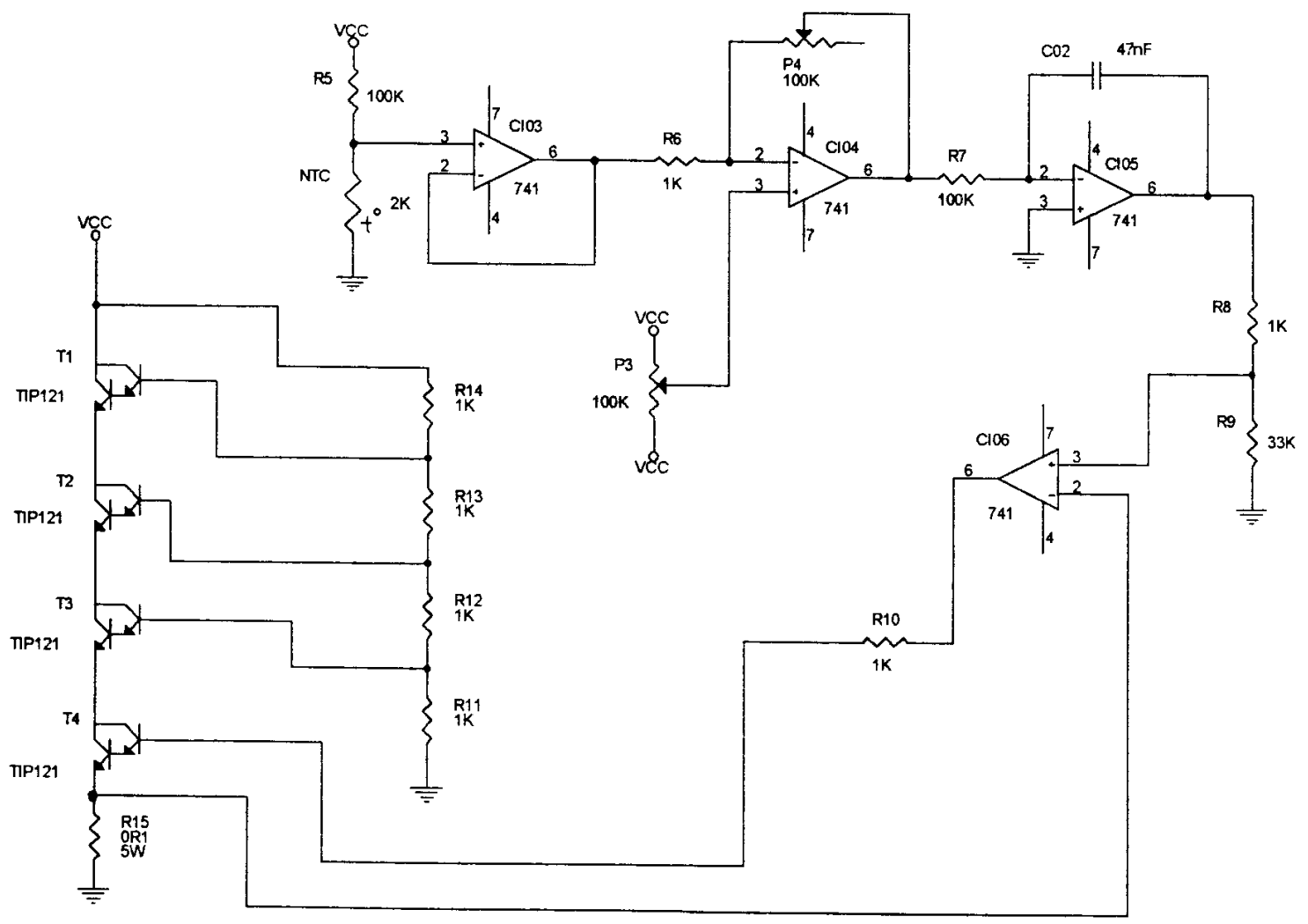

Figura 22 - Esquema elétrico do controlador térmico. 
Trabalha-se a uma temperatura um pouco acima da temperatura ambiente pois o controle não tem a capacidade de refrigerar. Quando a temperatura atinge $40^{\circ} \mathrm{C}$ os transistores apresentam pouco aquecimento, mantendo apenas uma pequena intensidade de corrente elétrica para manter a temperatura constante. Quando a temperatura está abaixo deste valor, os transistores começam a aquecer para compensar e manter a temperatura do sistema estável.

\subsection{2- Controle de velocidade}

Para avaliar o ângulo que a polarização linear de dois feixes de luz possuem entre si, pode-se utilizar um polarizador de luz rotativo. Fazendo ambos os feixes atravessarem juntos o polarizador e observando as suas intensidades logo após, pode-se determinar o ângulo entre as duas polarizações. Se houver um ângulo maior que $0^{\circ}$ e menor que $180^{\circ}$, os minimos de intensidade de luz conseguidos nos dois feixes estarão defasados no tempo. Medindo-se esta defasagem temporal pode-se calcular o ângulo entre as duas polarizações, utilizando-se para isto as equações $12 \mathrm{a}$ ou $12 \mathrm{~b}$.

O polarizador rotativo deve possuir uma rotação estável e constante para que os ângulos de defasagens entre os planos de polarização dos três feixes de luz possam ser lidos convenientemente. Para isto, a velocidade do motor foi ajustada para algo em torno de $1000 \mathrm{rpm}$, pois nesta rotação o pequeno motor Singer apresentou um funcionamento mais uniforme e os períodos obtidos nos sinais luminosos ficam em torno de $30 \mathrm{~ms}$ que é um valor satisfatório para que as outras partes do medidor de onda operem bem. O motor possui um sensor de velocidade, que nada mais é que uma pequena bobina colocada dentro de sua 
carcaça. Esta bobina capta os campos magnéticos do rotor, portanto gera um pequeno sinal senoidal de mesmo periodo que o eixo do motor.

Para estabilizar a velocidade do motor o circuito transforma a pequena senóide que vem do sensor de velocidade do motor em um trem de pulsos digitais. Estes pulsos são injetados no gatilho de um monoestável; a saida do monoestável é então retificada e com isto temos uma tensão proporcional à velocidade do motor. Invertendo este sinal teremos uma tensão inversamente proporcional à velocidade, que ajustada convenientemente, fecha a malha. Quando o motor tende a diminuir sua rotação, recebe uma maior tensão e vice-versa, ficando então estabilizada sua velocidade. A figura 23 mostra o esquema elétrico do circuito utilizado no protótipo para manter a rotação do polarizador constante.

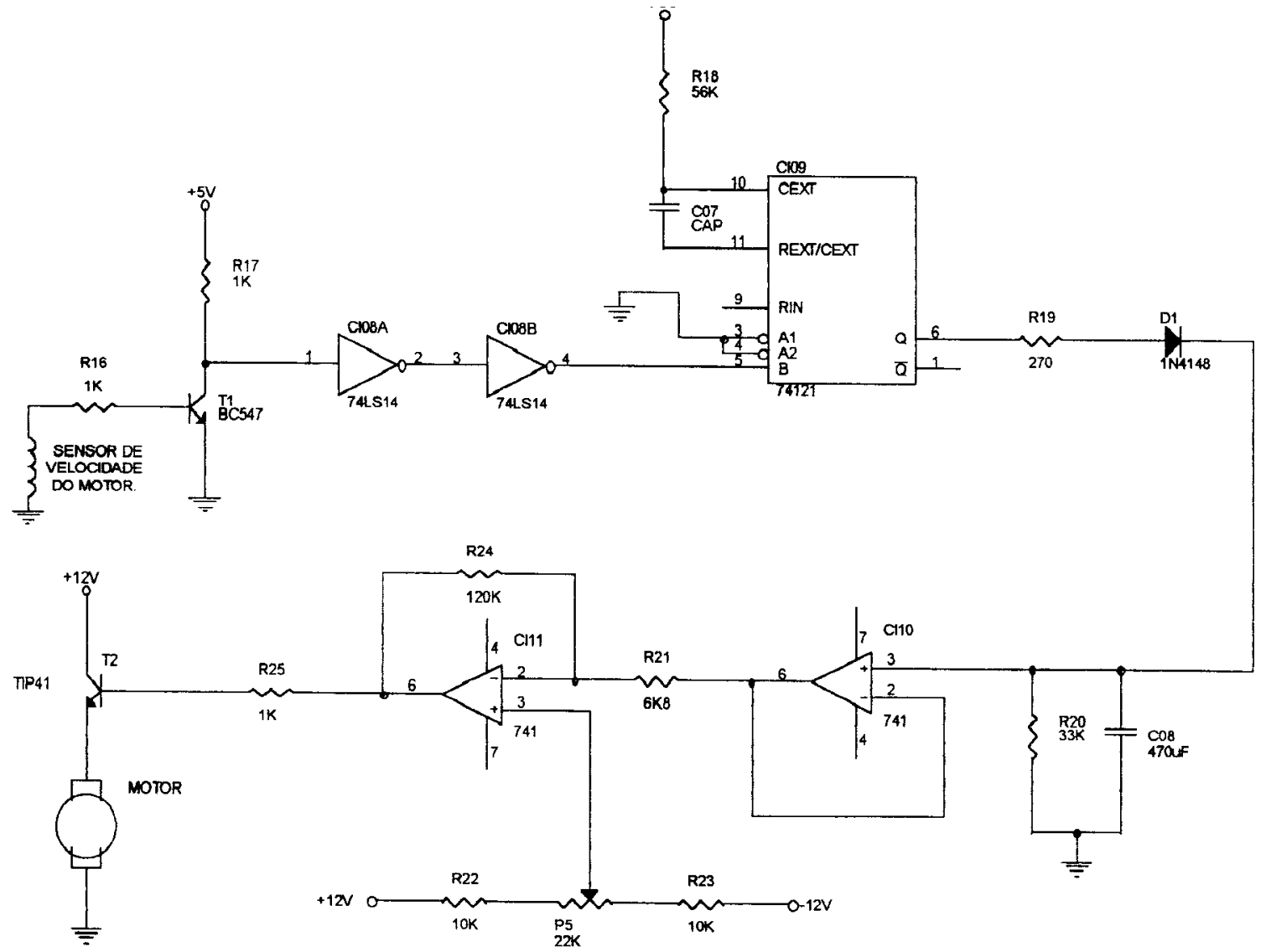

Figura 23 - Esquema elétrico do controlador de velocidade. 


\subsection{3- Medidor de potência}

Foi construído um pequeno medidor de potência, o qual mostra em um galvanômetro a intensidade de luz que chega a um detector alinhado com 0 sistema óptico do medidor de onda. Este dispositivo, embora muito simples, pois trata-se apenas de um amplificador com ajuste de ganho e de zero, mostrou-se imprescindível no alinhamento do sistema. Quando o galvanômetro acusa uma intensidade luminosa dentro de um intervalo pré-determinado, garante-se que o feixe está alinhado e com boa intensidade. Após sua instalação, o medidor se tornou muito mais prático. Isto veio de encontro à intenção de construir um dispositivo prático e de simples manuseio. A figura 24 mostra o diagrama elétrico do circuito utilizado no protótipo.

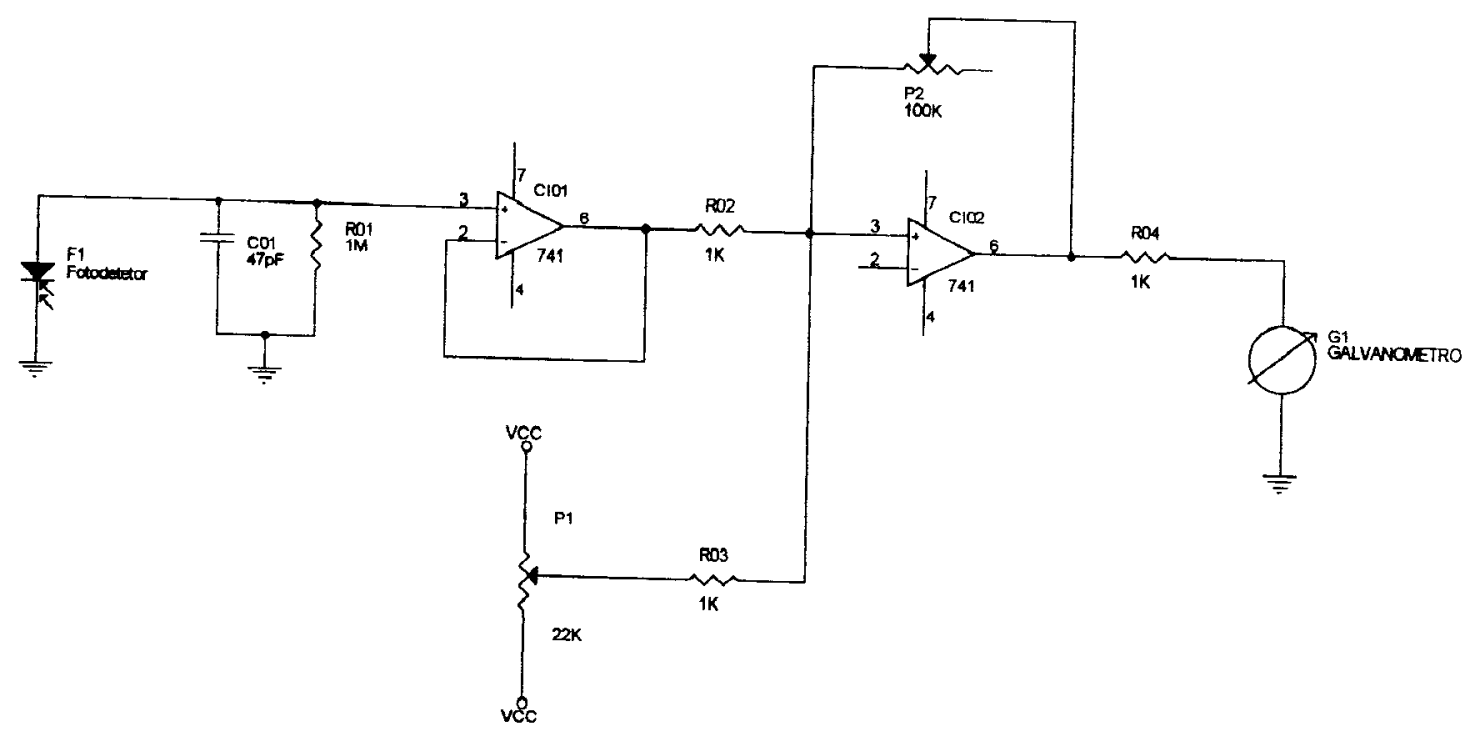

Figura 24 - Esquema elétrico do medidor de potência. 


\section{4- Fonte de alimentação}

Utilizou-se uma fonte simétrica estabilizada em $12 \mathrm{~V}$ que alimenta os circuitos de baixa intensidade de corrente (inclusive as partes digitais de $5 \mathrm{~V}$, através de uma regulagem adicional que existe na própria placa ) e uma fonte DC de alta intensidade de corrente de $24 \mathrm{~V}$ que alimenta o circuito de estabilização térmica. A fonte de alta potência não precisa ser estabilizada. $\mathrm{Na}$ de baixa potência foram utilizados dois integrados da conhecida familia LM78XX e LM79XX, os quais são responsáveis pela regulagem, estabilização, proteção contra curtos e sobreaquecimentos. 


\section{4- Programas}

O programa completo, que serve como uma ponte ligando o usuário ao medidor de onda, realiza as seguintes funções principais: controla todo o sistema, faz a leitura dos dados, calcula o comprimento de onda, mostra na tela o valor calculado e armazena os valores em arquivo. Ele é composto de duas partes distintas que são: 1) módulo de baixo nível (Subrotinas em linguagem de máquina) e 2) módulo principal (alto nivel). Ambas operam conjuntamente intercambiando informações e realizando suas funções especificas.

A primeira delas é um programa de baixo nivel, mais especificamente uma D.L.L. ( "Dynamic Language Linking") para o sistema operacional Windows $3.1 \mathrm{da}$ Microsoft. Em todo o seu desenvolvimento foi utilizada a linguagem de máquina do processador 8086 da Intel. Esta D.L.L controla diretamente a placa que vai conectada ao barramento do microcomputador, transferindo informações bilateralmente entre as partes envolvidas, servindo de elo de ligação entre os circuitos eletrônicos e o programa que realiza os cálculos dos comprimentos de onda.

O segundo programa foi escrito em uma linguagem de alto nivel, o Visual Basic 3.0 da Microsoft. Este programa recebe os valores da D.L.L. por referência, realiza os cálculos necessários e mostra o resultado ao usuário, podendo também automatizar alguns experimentos, tirando médias dos comprimentos de onda e gravando as medidas em um arquivo. Ambos serão detalhados nos tópicos a seguir. 


\section{1- Módulo de baixo nível (D.L.L.)}

Este módulo nada mais é que um conjunto de três subrotinas que são chamadas pelo programa principal do medidor de onda. Estas subrotinas controlam e acessam todas as funçōes necessárias da placa digital do medidor para se avaliar o comprimento de onda da luz. As subrotinas contidas nesta D.L.L são: INIC55, CARREGA e LER. Logo a seguir cada uma destas subrotinas serão apresentadas e explicadas.

\subsection{1- Subrotina Inic55}

Esta subrotina deve ser obrigatoriamente a primeira função a ser executada antes de se utilizar o medidor de onda, pois ela inicializa os três contadores existentes na placa digital.

Cada um dos contadores possui vários modos de operação, podendo trabalhar de maneiras distintas, independentemente. Todos os três precisam ser programados para que funcionem da maneira adequada. Neste caso particular os contadores são programados para operar no modo 4 (para maiores informações consultar a referência 10). Esta subrotina é chamada apenas uma vez no inicio do programa principal que será abordado dentro em breve. Segue abaixo o segmento do código que contém a rotina INIC55.

INIC55 PROC FAR

WINPROLOG

MOV DX,TIMEC ; Endereça o 82C54 


$\begin{array}{lll}\text { MOV } & A X, 38 \mathrm{H} & \\ \text { OUT } D X, A L & \text {; Prog. o contador } 0 \\ \text { MOV } & A X, 78 H & \\ \text { OUT DX,AL } & \text {; Prog. o contador } 1 \\ \text { MOV AX,OB8H } & \\ \text { OUT DX,AL } & \text {; Prog. o contador } 2 \\ \text { WINEPILOG } & \\ \text { RET } & \\ \text { INIC55 ENDP }\end{array}$

Para programar os contadores, basta escrever um valor conveniente no endereço que o contador 82C54 está mapeado. Este valor contém as informações de qual contador está sendo programado e qual modo de operação se deseja.

\subsection{2- Subrotina Carrega}

Esta subrotina zera e trava as saídas da lógica digital da figura 16 , e em seguida inicializa os contadores da figura 19. As saidas do circuito da lógica digital são zeradas e travadas toda vez que se armazena o número 1 no endereço de memória $030 \mathrm{C}$ hexadecimal. Isto é feito para que o circuito da lógica digital da figura 16 pare de acompanhar os sinais vindos do medidor, e assim os contadores também ficam inoperantes.

Os contadores são inicializados com 65535 pois tratam-se de contadores descendentes; a cada pulso contado eles decrementam o valor. Portanto sempre 
começam a contagem com 65535 e vão diminuindo até zero. A listagem desta subrotina comentada segue logo abaixo.

\title{
CARREGA PROC FAR
}

WINPROLOG
MOV DX,POR273
MOV AL, 0
OUT DX,AL

;Trava Lógica Digital

\author{
MOV DX, TIMEO \\ MOV AL,OFFH \\ OUT DX,AL \\ OUT DX,AL
}

; Seta byte menos sig. do contador 0

; Seta byte mais sig. do contador 0

MOV DX,TIME1

MOV AL,OFFH

OUT DX,AL

; Seta byte menos sig. do contador 1

OUT DX,AL

; Seta byte mais sig. do contador 1

MOV DX,TIME2

MOV AL,OFFH

OUT DX,AL

; Seta byte menos sig. do contador 2

OUT DX,AL

; Seta byte mais sig. do contador 2 


\section{WINEPILOG}

RET

CARREGA ENDP

\subsection{3- FUNÇÃO LER}

Esta função é que controla o processo de medida das defasagens dos sinais e transfere os valores ao programa principal, sendo acessada periodicamente. Todo o procedimento de leitura e transferência de dados realizados pela função LER pode ser chamado de ciclo de aquisição.

No início do ciclo de aquisição, a função LER libera a lógica digital e fica monitorando, através do circuito de monitoração que está mapeado no endereço 308 hexadecimal, o pulso de porto do canal 1 (que é o canal de referência). No instante que este pulso se torna zero o sistema começa a se preparar para medir as defasagens entre os sinais que vêm do medidor; os contadores são inicializados e o sistema fica esperando o nivel lógico do porto 1 subir novamente. Quando o porto 1 subir, o circuito da lógica digital passa a controlar o processo, pois é ele quem determina a largura dos pulsos de porto dos três canais. Os contadores contam o tempo que seus respectivos portos ficam em nivel lógico alto O programa retoma o controle, travando a lógica digital, assim que o porto do canal 1 descer para zero. Os valores das contagens são passados por referência ao programa principal e o ciclo está concluido podendo começar novamente. Segue abaixo o segmento do código que contém a subrotina ler. 
LER PROC FAR

WINPROLOG

MOV DX,POR273

MOV AL, 1

OUT DX,AL

; Destrava a lógica digital

MOV DX,POR244

; Seleciona o 74LS244

LOOP5:

IN AL,DX

; Espera porto 1 ser alto

TEST AL, 1

JZ LOOP5

LOOP6:

IN AL,DX

; Espera porto 1 ser baixo

TEST AL, 1

JNZ LOOP6

MOV DX,TIMEO

MOV AL,OFFH

OUT DX,AL

; Seta byte menos sig. contador 0

OUT DX,AL

; Seta byte mais sig. contador 0

MOV DX,TIME1

OUT DX,AL

; Seta byte menos sig. contador 1

OUT DX,AL

; Seta byte mais sig. contador 1

MOV DX,TIME2 
OUT DX,AL

OUT DX,AL

MOV DX,POR244
; Seta byte menos sig. contador 2

; Seta byte mais sig. contador 2

; Seleciona o circuito de monitoração

KING:

IN AL,DX

TEST AL, 1

JZ KING

KONG:
; Espera porto 1 ser alto

; Espera porto 1 ser baixo

$\begin{array}{ll}\text { TEST } & A L, 1 \\ \text { JNZ } & \text { KONG }\end{array}$

MOV DX,POR273

MOV AL,O

OUT DX,AL

; Trava a lógica digital

MOV DX, TIMEO

; Seleciona contador 0

IN AL,DX

MOV CL,AL

IN $\quad A L, D X$

MOV AH,AL

MOV AL,CL

LES BX,DWORD PTR [BP+6]

MOV ES:[BX],AX

; Transfere a contagem 


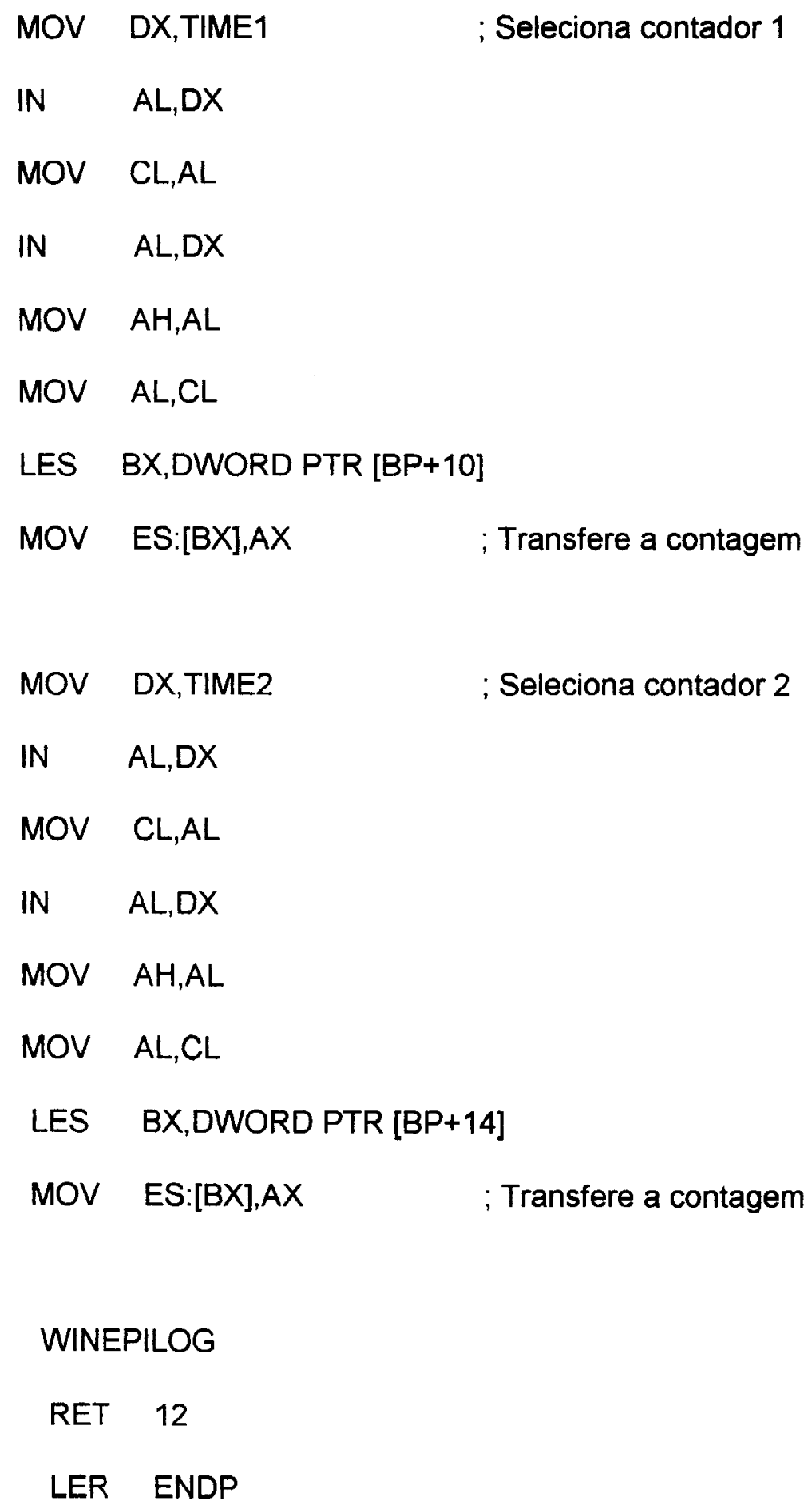




\section{2- Programa Principal}

Este programa, que roda sobre a plataforma Windows, foi escrito em Visual Basic 3.0 da Microsoft. Suas principais funções são receber os valores das contagens e calcular o valor instantâneo do comprimento de onda da luz.

Um algoritimo simplificado deste programa, para uma leitura apenas poderia ser: programar a placa digital (chamar a subrotina Inic55), Inicializar os contadores (chamar a subrotina Carregar), ler as contagens (chamar a função Ler), transformar as contagens em ângulos de defasagens, calcular "m" (número de semivoltas redundantes que a luz gira sua polarização dentro do cristal), calcular o comprimento de onda. (resolução de um polinômio pelo método da inversão de sinal e de aproximações sucessivas) e mostrar o resultado no monitor. A figura 25 mostra a tela principal do programa utilizado no medidor.

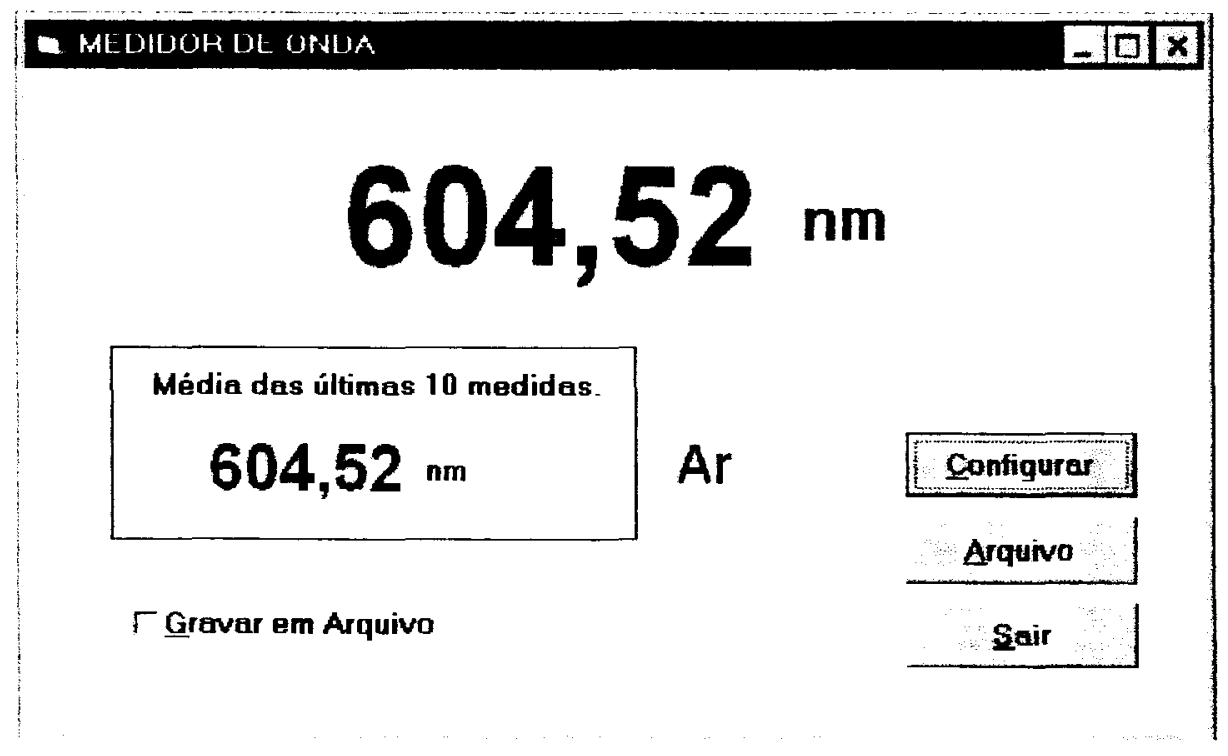

Figura 25 - Tela principal do programa do medidor de onda. 
O programa principal não traz nenhuma grande inovação, como já foi dito anteriormente; ele age basicamente como uma ponte de ligação do usuário com as rotinas de baixo nível que controlam e acessam o sistema. O programa foi escrito utilizando-se apenas os conceitos e comandos básicos da programação visual.

Podemos destacar duas importantes operações que são realizadas, sem as quais o sistema não seria viável: Resolução numérica de uma equação e cálculo da média dos valores. Ambas operações serão detalhadas nos tópicos a seguir.

\subsection{1- Resolução de equação}

O cálculo do comprimento de onda consiste na resolução numérica de uma equação de ordem três. O método utilizado para o cálculo da raiz foi o da pesquisa de sinal com aproximações sucessivas, que se baseia no fato de que num intervalo numérico existe um número impar de raízes de uma função, se esta mudar de sinal neste intervalo. Este método é muito eficiente quando a raiz desejada de uma equação está num intervalo numérico bem conhecido. Este è justamente o nosso caso, pois a raiz de nossa equação sempre está no intervalo de 5000 a $20000 \mathrm{~cm}^{-1}$.

Grosseiramente falando, o processo todo consiste em se calcular o valor do polinômio para alguns pontos relativamente bem espaçados dentro do intervalo de busca e ir diminuindo este espaçamento nas proximidades do ponto em que a função muda de sinal. O programa calcula o valor do polinômio para vários números de onda no intervalo, iniciando em 5000 com incrementos de 500 até que o resultado do polinômio mude de sinal. Quando esta mudança de sinal ocorre, 
retorna-se ao último número de onda antes da mudança de sinal e diminui-se pela metade o passo do incremento. O processo continua até que o resultado do polinômio esteja tão próximo de zero quanto se deseje. Segue abaixo o segmento do código do programa principal que realiza esta tarefa.

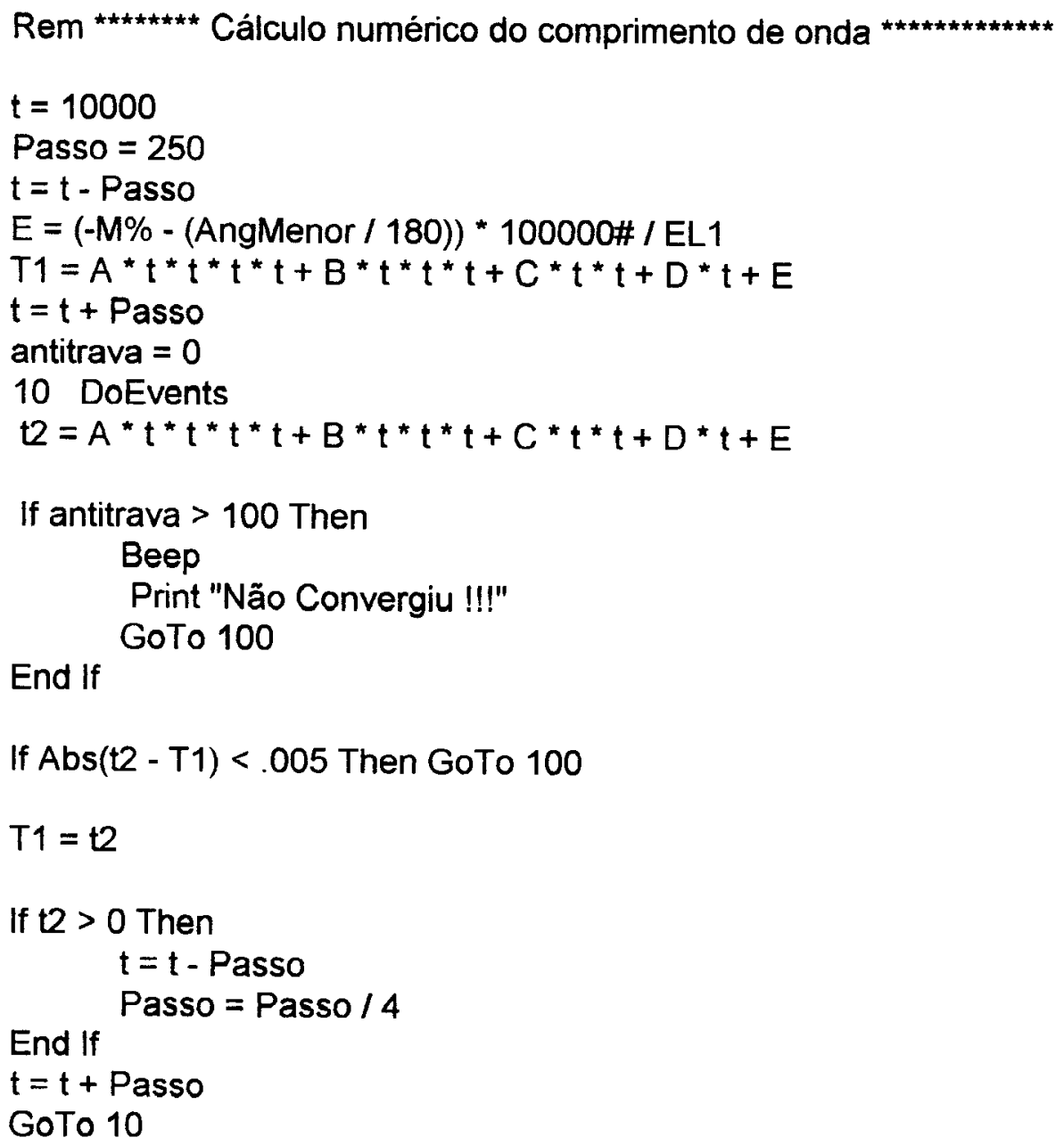

\subsection{2- Cálculo das médias}

Dois valores são apresentados em dois campos de exibição na tela do programa principal (figura 25). O valor que aparece no campo mais acima no vídeo é o comprimento de onda instantâneo e o que está logo abaixo é a média 
dos dez últimos valores exibidos no campo anterior. Cada campo de exibição utiliza um tipo de média diferente antes de apresentar os resultados no monitor. A primeiro deles utiliza um tipo de média muito peculiar. Um número de aquisições especificadas pelo usuário são armazenadas e ordenadas em uma fileira de valores ascendentes e somente o valor central é considerado, os outros são desprezados.
6328,00
5400,00
6328,25
6327,99
6328,01
6328,00
6327,99
6328,03
6328,00
5400,00
6328,01
6328,00
6328,03
6328,00
Resultado
Medidas
6328,25

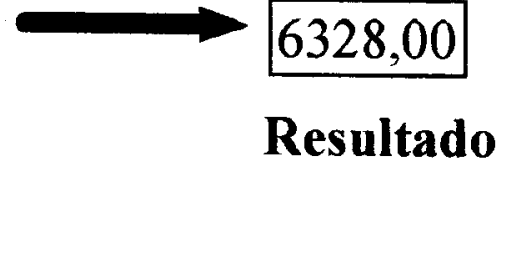

\section{Valores}

\section{Ordenados}

Figura 26 - Exemplo do cálculo da média das medidas

Este tipo de média foi adotado pela forma que as aquisições são feitas. Qualquer ruído nos circuitos da lógica da figura 16 gera uma leitura muito discrepante que contamina o resultado do comprimento de onda com um erro de alguns angstrons caso uma média ponderada comum seja utilizada. O tipo de média apresentada na figura 26 mostrou-se extremamente eficiente e rápido, para dez pontos, consegue-se uma atualização no valor do comprimento de onda na tela do micro, aproximadamente a cada segundo.

O segundo campo utiliza média ponderada dos dez últimos comprimentos de onda mostrados no campo anterior. Este tipo de média é útil para se minimizar 
- "ruido branco" das medidas. A favor do desempenho, o programa não fica armazenando dez leituras para somente depois mostrar a média; ele continuamente mostra a média das dez últimas medidas exibidas. Isto se justifica, pois normalmente o medidor será utilizado para monitorar uma fonte de luz, que na maior parte do tempo mantém a frequência da luz constante; portanto na maioria das vezes pode-se utilizar os valores antigos para se calcular uma média. Obviamente esta média somente é exibida quando pelo menos dez medidas já tiverem sido exibidas na tela. 


\section{5- RESULTADOS}

Até este ponto, foi descrito o princípio de funcionamento e a construção de um medidor de onda por atividade óptica. Quando comparado a instrumentos comerciais de mesmo porte notamos a existência de algumas vantagens, dentre as quais destacamos: (i) custo inferior pelo fato de não possuir partes móveis de alta precisão mecânica, (ii) facilidade de uso pois nos aparelhos baseados no interferômetro de Michelson a luz precisa ter um bom modo transversal (o feixe deve ser gaussiano) enquanto que para o presente instrumento só é importante a polarização da luz, definida pelo polarizador de entrada.

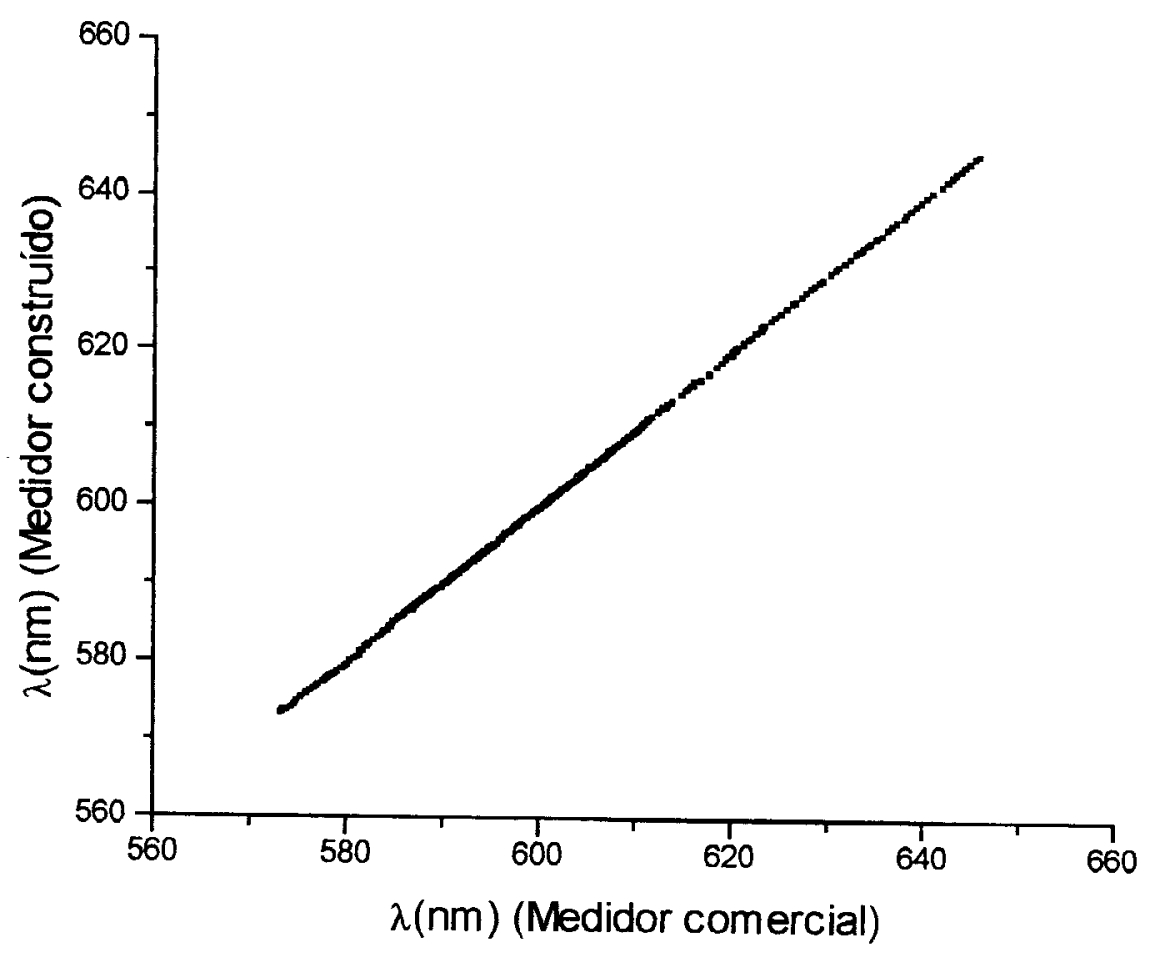

Figura 27 - Comparação entre o medidor desenvolvido e um comercial. 
Os resultados conseguidos, foram muito encorajadores e presentemente estamos utilizando o medidor de onda construído para monitorar a frequência de operação de lasers de corante sintonizáveis utilizados em medidas de aprisionamento magneto-óptico. O medidor de onda pode ser caracterizado pela sua precisão absoluta e pela estabilidade. Verificamos que a precisão absoluta está limitada em 1 parte em $10^{4}$, principalmente pela imprecisão na determinação de $\Delta n(\lambda)$. Este fato foi verificado através da medida das várias linhas de um laser de He-Ne sintonizável (PMS, modelo LSTP-1010) e comparação com seus valores conhecidos. Foram feitos também testes comparativos entre o nosso medidor $\mathrm{e}$ um medidor comercial da Burleigh (modelo "WaveMeter Junior") que possui uma precisão equivalente. Os resultados comparativos estão apresentados na figura 27.

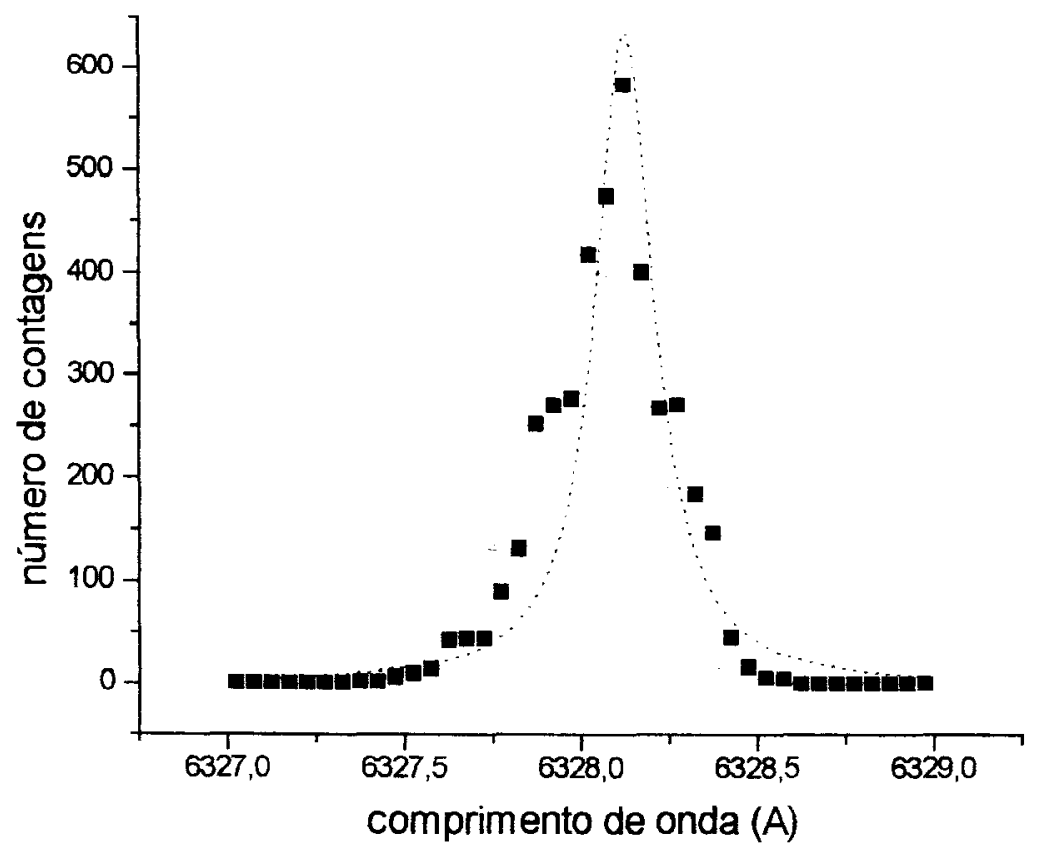

Figura 28 - Histograma das medidas para $6328 \AA$. 
Para demonstrar a estabilidade das medidas foram determinados uma série de valores de comprimentos de onda com o laser operando em $6328 \AA \mathrm{com}$ os quais construimos um histograma, como mostra a figura 28 . Através de um ajuste com uma função gaussiana obtivemos uma variância de $0.4 \AA$, que corresponde a uma variação fracional melhor que 1 parte em $10^{4}$, demonstrando uma estabilidade adequada para as medidas realizadas. 


\section{6- ESTÁGIO ADICIONAL DE ALTA PRECISÃO}

O vernier Fabry-Pérot (VFP) é o responsável pela parte de alta precisão do medidor de onda. Esta etapa já está concluida, porém os testes definitivos ainda não foram realizados por problemas técnicos. Para o teste e calibração de tal dispositivo, precisariamos de fontes de luz monocromáticas de comprimentos de onda muito bem definidos, ou de um medidor com precisão superior ao que pretendemos montar. A não disponibilidade de um medidor de onda tão preciso nos deixou somente a opção de se utilizar as linhas do sódio, fazendo espectroscopia de saturação numa cela de vidro. Isto não foi realizado pois surgiram alguns entraves que serão esclarecidos no decorrer do trabalho.

\section{1- Princípio de funcionamento}

Este estágio do medidor de onda, utiliza principios de interferometria pois o principal elemento desta etapa é um vernier Fabry-Pérot (VFP), que consiste de dois étalons Fabry-Pérot de baixa finesse e intervalos espectrais levemente diferentes. Subdividindo-se em dois o feixe que se deseja medir e injetando um em cada étalon, obtém-se um padrão de franjas semelhantes, diferindo apenas na posição relativa entre as franjas. Para se medir o comprimento de onda, é necessário fazer os dois padrões de franjas "correrem" e então medir a defasagem existente.

Os intervalos espectrais livres dos dois étalons são da ordem de 6.5 e 6.8 $\mathrm{GHz}$. Conforme as franjas são varridas, os picos dos dois étalons coicidem em 
alguma posição. Continuando a varredura, a diferença entre os picos dos dois étalons aumenta por múltiplos inteiros da diferença dos dois intervalos espectrais livres $(0.3 \mathrm{GHz})$, até que num certo ponto eles coincidem novamente. A separação entre duas coincidências consecutivas (da ordem de $150 \mathrm{GHz}$ ) é o intervalo espectral livre do vernier. Esta diferença define a ordem do Vernier Fabry-Perot, que chamaremos de $M$. Dentro de uma dada ordem, a frequência é estabelecida unicamente pela separação entre dois picos adjacentes (ressonâncias), um do étalon mais curto e outro do mais longo.

Para que as franjas de interferências variem em posição espectral, basta alterar o caminho óptico dentro dos étalons. Isto foi conseguido através de uma pequena lâmina de vidro móvel colocada estrategicamente dentro do Vernier. A figura 29 mostra esquematicamente como a lâmina de vidro está posicionada no Vernier.

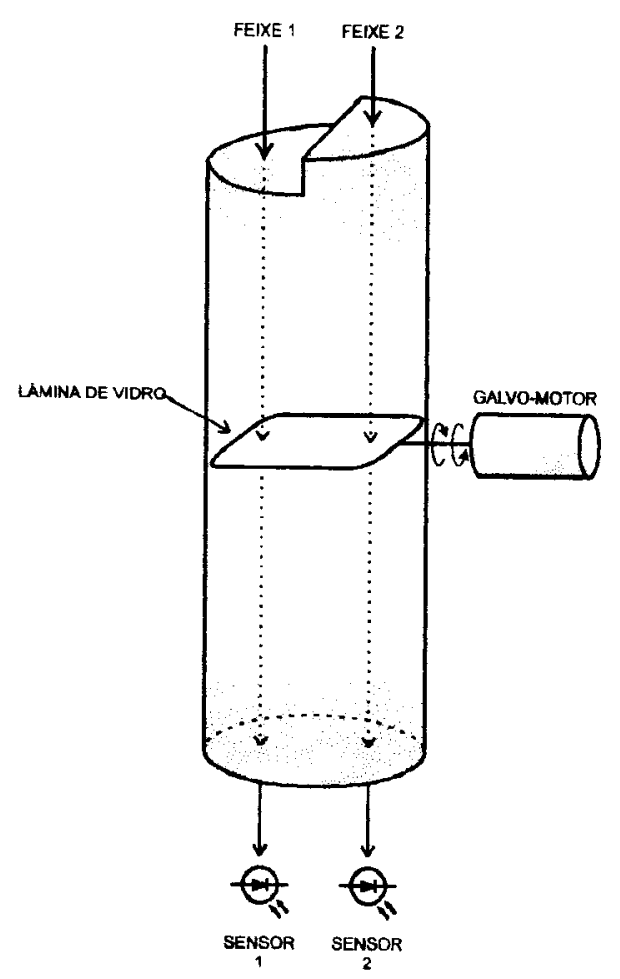

Figura 29 - Posicionamento da lâmina de vidro no Vernier Fabry-Pérot. 
O ângulo formado pela lâmina de vidro e pelos feixes de laser varia periodicamente. Consequentemente, o comprimento de vidro que a luz tem que atravessar também varia desta forma. Quanto menor o valor do ângulo, menor o caminho percorrido pela luz dentro da lâmina de vidro. Como a velocidade da luz no vidro e no ar são diferentes, a luz demora mais ou menos tempo para percorrer a mesma distância, dependendo do comprimento de vidro que tem que atravessar. O resultado disto é que os pontos de interferências construtivas e destrutivas (franjas de interferências geradas pelos étalons) da luz mudam de lugar constantemente; o padrão de franjas fica se movendo (tecnicamente falando, as franjas correm).

Os picos são monitorados por dois fotodectores. Da mesma forma que no estágio anterior de menor precisão (Medidor de Onda por Atividade Óptica), existe uma placa dedicada a transformar convenientemente estes sinais analógicos em sinais digitais equivalentes. Estes sinais digitais são então enviados para a mesma placa digital (conectada ao barramento do microcomputador) que foi utilizada pelo estágio anterior. Esta placa se encarrega de medir a separação entre dois picos e deixar disponivel ao computador os resultados das medidas. $O$ computador então recebe as informações pertinentes, faz os cálculos e mostra no visor o comprimento de onda calculado. A figura 30 mostra um exemplo de padrão de sinais que são captados pelos dois fotodetectores e que serão injetados num circuito eletrônico que os transformará em sinais digitais de mesma frequência e com a mesma defasagem temporal entre si. Este procedimento é semelhante à utilizada no primeiro estágio do medidor (capítulo 3). 


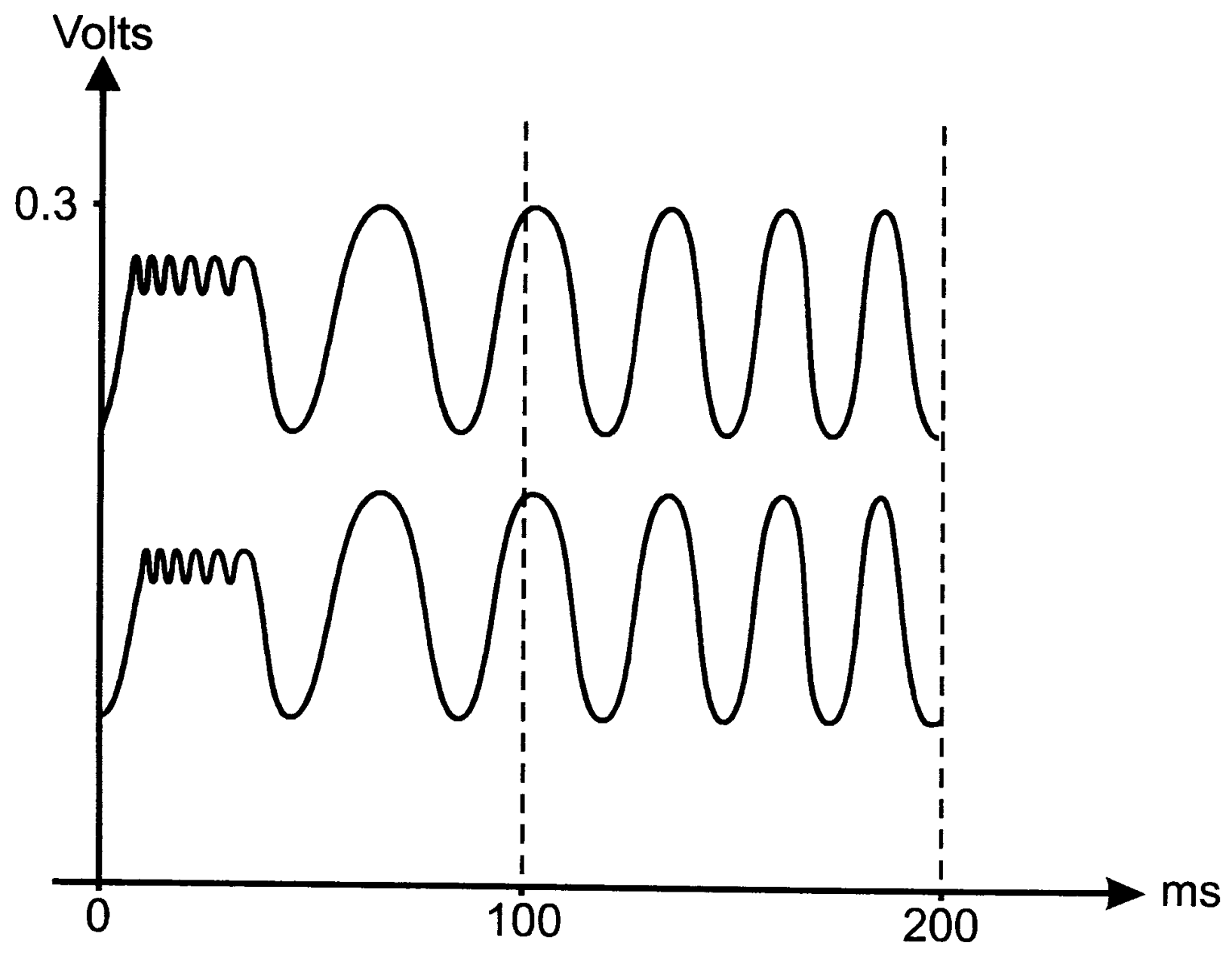

Figura 30 - Sinais captados nos dois fotodetectores do Vernier Fabry-Pérot.

Com este procedimento é possivel conseguir-se uma precisão na frequência do laser da ordem de $100 \mathrm{MHz}$. Para determinarmos a ordem M do vernier é preciso conhecer o comprimento de onda grosseiramente, com precisão em torno de $60 \mathrm{GHz}$ e isto é conseguido pelo medidor de onda por atividade óptica. Uma vez conhecido $\mathrm{M}$, basta medir a separação entre franjas adjacentes dos dois étalons e com estes valores calcular o comprimento de onda desejado. 


\section{2- Descrição opto-mecânica}

As componentes opto-mecânicas deste estágio adicional de alta precisão consistem basicamente em um Vernier Fabry-Pérot, uma lâmina de vidro preparada com superficies anti-refletoras, um galvo-motor e dois fotodiodos MRD300 (utilizados em controles remotos de televisores comerciais). O Vernier é composto de dois étalons. Os étalons que utilizamos na montagem nada mais são que interferômetros onde a luz entra e é refletida internamente várias vezes. A cada reflexão, uma fração de luz escapa do interferômetro e, como estas reflexões são todas paralelas e sobrepostas, surgem franjas de interferências de luz na saída de cada étalon. As franjas de interferências são geradas pela sobreposição de vários feixes de luz de mesma frequência defasados entre si. Estas defasagens entre os feixes de luz são consequência direta das diferenças de caminhos ópticos percorridos por cada um dos feixes dentro do interferômetro. O feixe de luz para o qual se deseja determinar o comprimento de onda deve ser subdividido em dois. Cada feixe resultante deve atravessar um dos étalons e as suas franjas de interferência devem atingir o respectivo fotodiodo, para que possam ser captadas e processadas. Como os espaçadores dos étalons funcionam como um padrão de comprimento secundário, eles foram construídos com um material de baixo coeficiente de dilatação térmica, o zerodur. A figura 31 mostra esquematicamente como é o Vernier que foi utilizado em nosso medidor. 


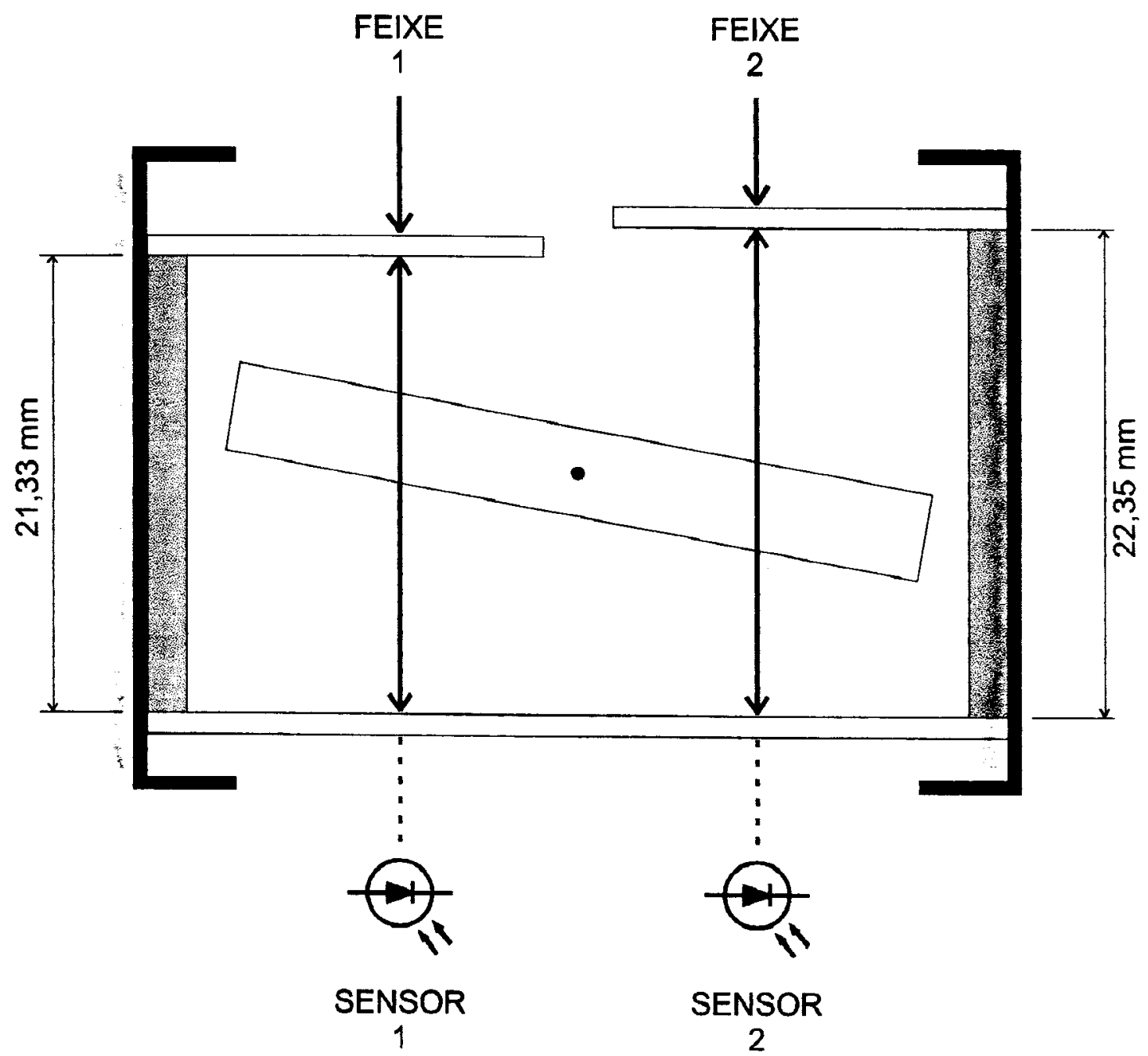

Figura 31 - Esquema do Vernier utilizado no medidor.

Além de os étalons terem sido confeccionados com material de baixa dilatação, todo o medidor possui, como já foi visto anteriormente, um sistema que estabiliza a temperatura de forma que os comprimentos dos espaçadores dos étalons apresentem pouca variação. A figura 32 mostra como este novo estágio se acopla ao medidor por atividade óptica da figura 5. 


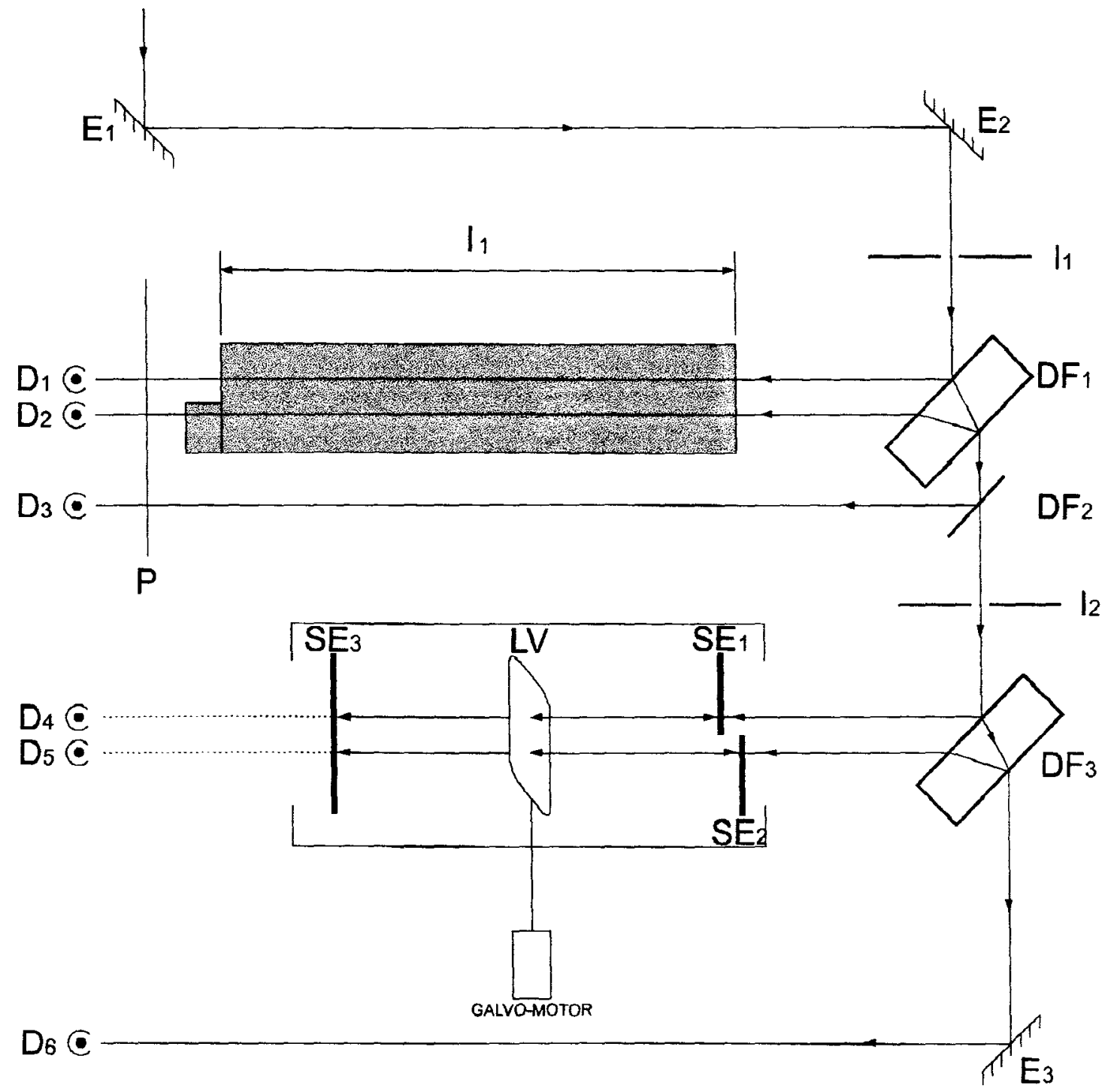

Figura 32 - Esquema do medidor completo com os dois estágios.

O feixe transmitido pela íris $I_{2}$ incide num divisor de feixes $D F_{3}$, idêntico a $\mathrm{DF}_{1}$, e gera dois feixes secundários. Cada um destes feixes passa pelos diferentes étalons e as franjas geradas por cada um incidem em dois fotodiodos que captarão os sinais. A lâmina de vidro que está acoplada ao galvo-motor se move alterando o caminho óptico dentro dos étalons, fazendo as franjas correrem. Esta varredura de franjas é que propicia a medida do comprimento de onda da luz. 
O feixe que atravessa $\mathrm{DF}_{3}$ é desviado pelo espelho $E_{3}$ atingindo o fotodiodo utilizado pelo medidor de intensidade luminosa, que foi explicado na secção 3.3.3, figura 24.

\section{3- Componentes eletrônicos}

Os componentes eletrônicos para este estágio são praticamente iguais aos utilizados no estágio anterior, as diferenças serão descritas a seguir. Este módulo do medidor utiliza quatro placas de circuito para seu funcionamento: 1) placa analógica, 2) placa digital, 3) placa geradora de rampa para o galvo-motor e 4) fonte de alimentação.

\subsection{1- Placa analógica}

Como no estágio anterior, esta placa converte os sinais analógicos vindos dos fotodiodos em sinais digitais que a placa digital possa utilizar. A figura 33 mostra o diagrama esquemático de um dos canais que converte o sinal analógico em digital; o outro é idêntico a este.

Construtivamente falando, este circuito é diferente pois agora, além de serem apenas dois os canais medidos, os perfis dos sinais oriundos dos fotodiodos diferem bastante dos que tínhamos na etapa anterior, como se pode ver comparando as figuras 28 e 6 . 


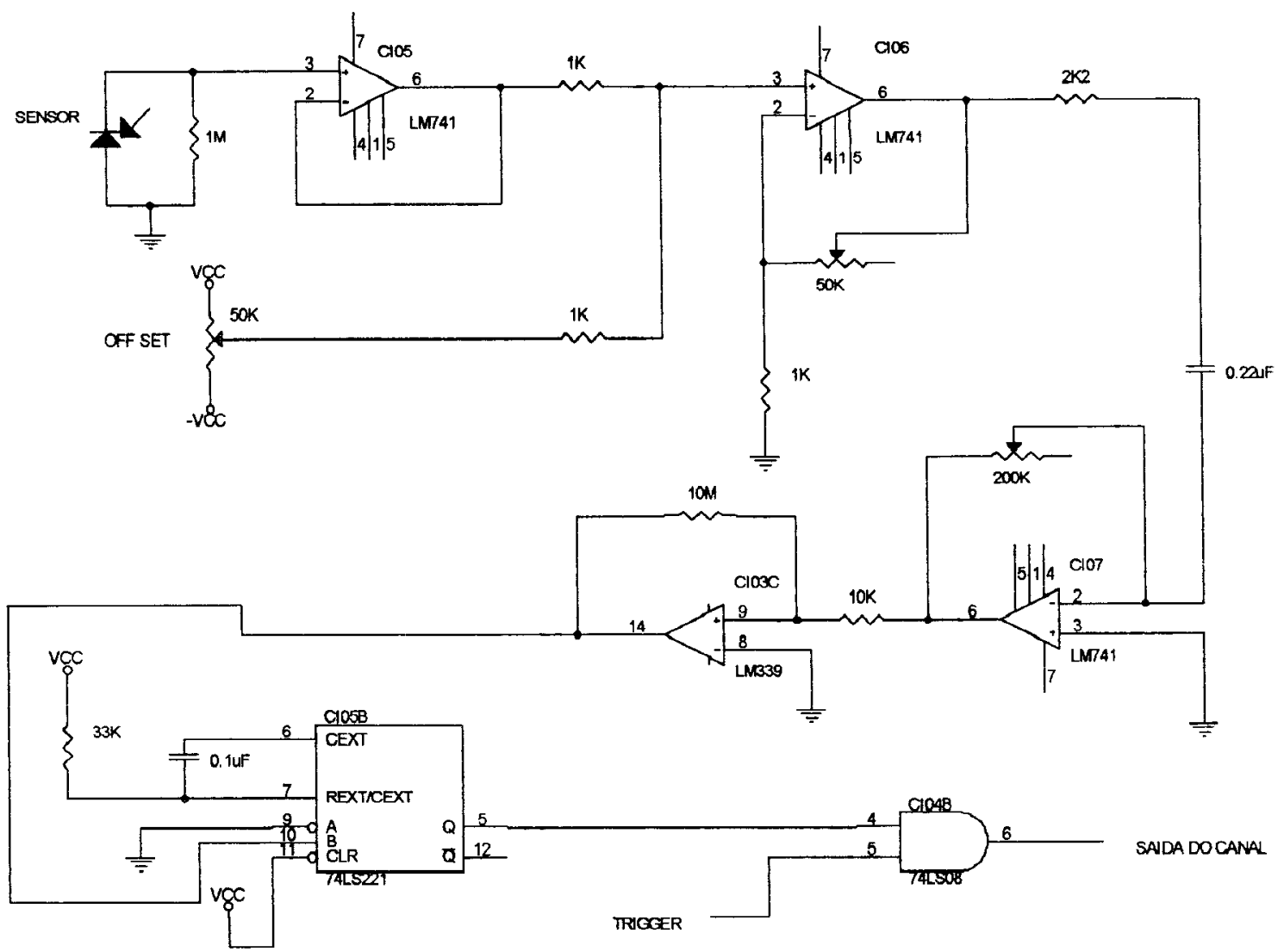

Figura 33 - Esquema de um canal da placa analógica.

O sinal do fotodiodo é amplificado e a derivada deste sinal é transformada em pulsos digitais (com amplitudes entre 0 e $5 \mathrm{~V}$ ) através de um comparador de $0 \mathrm{~V}$ com histerese. Toda vez que a derivada estiver no semi-ciclo positivo temos $5 \mathrm{~V}$; caso contrário OV. O pulso obtido é injetado num monoestável disparado na subida e programado para ficar em nível alto por $4 \mathrm{~ms}$. É feito em seguida um " $E$ " lógico do sinal de saída deste monoestável com o sinal de gatilho (que também é gerado nesta placa). Os pulsos gerados pelo monoestável somente são enviados para a placa digital enquanto o nível lógico do gatilho estiver alto $(+5 \mathrm{~V})$. A figura 34 mostra os principais sinais elétricos do circuito de um canal desta placa analógica. 

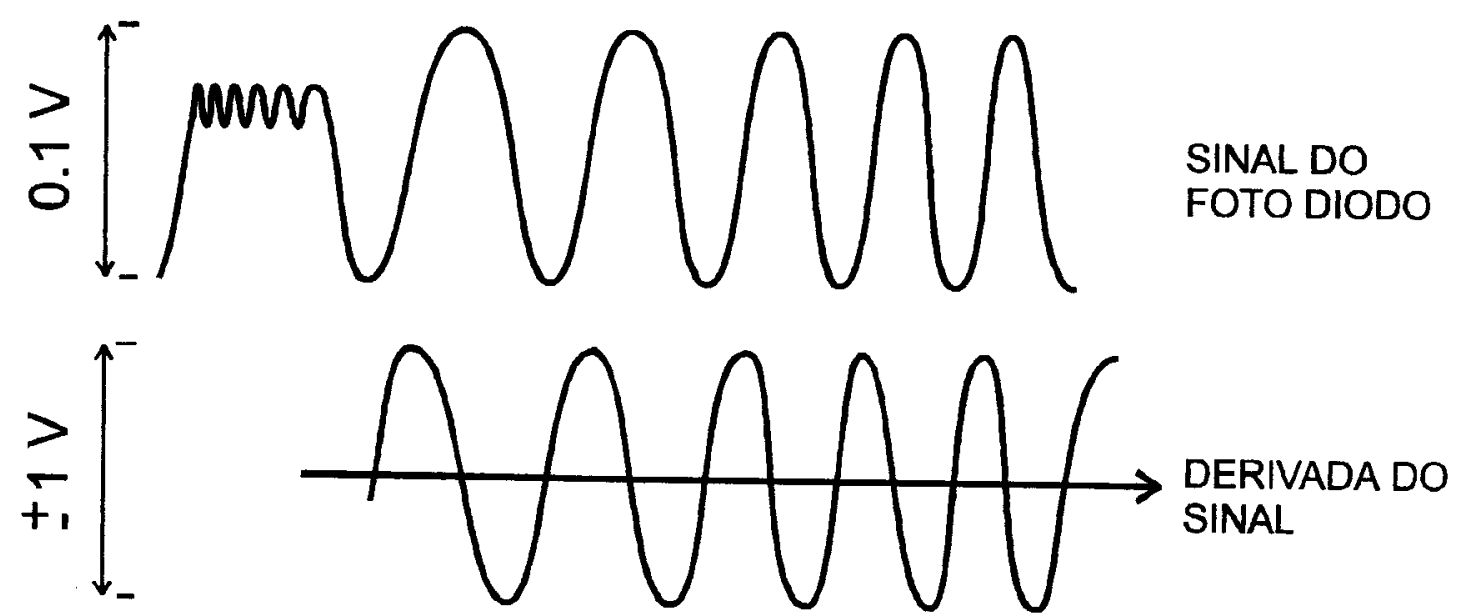

$>\uparrow^{-}$

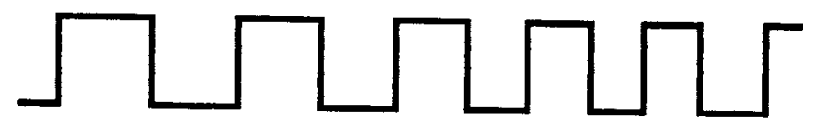

DERIVADA

DIGITALIZADA

$\vec{L} \uparrow^{-}$

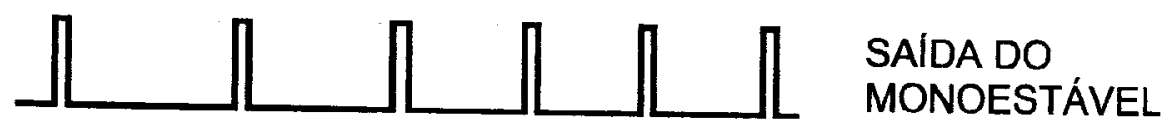

$\overrightarrow{i n} \uparrow$

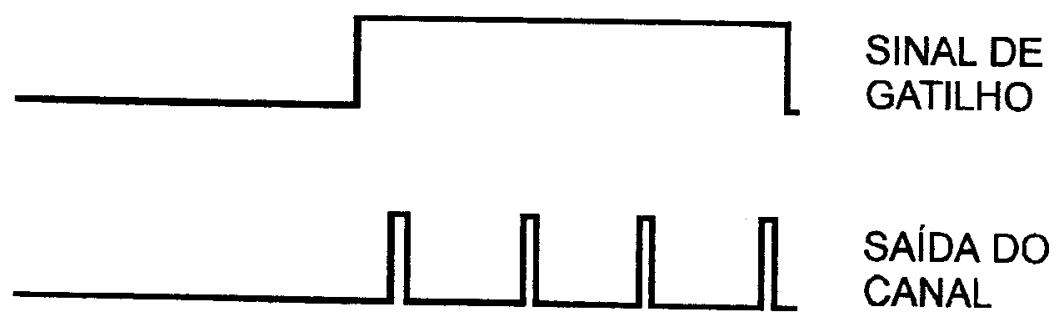

Figura 34 - Carta de tempos de um canal da placa analógica.

Através deste sinal de gatilho é possivel escolher quais franjas devem ser enviadas para o computador. $O$ processo de aquisição está então sincronizado com a rampa que vai ao galvo-motor. A figura 35 ilustra os sinais elétricos que são enviados ao microcomputador e a figura 36 mostra o esquema elétrico do circuito que gera os pulsos do gatilho a partir do sinal rampa do galvo-motor. Este circuito utiliza a rampa que é injetada no galvo-motor. 


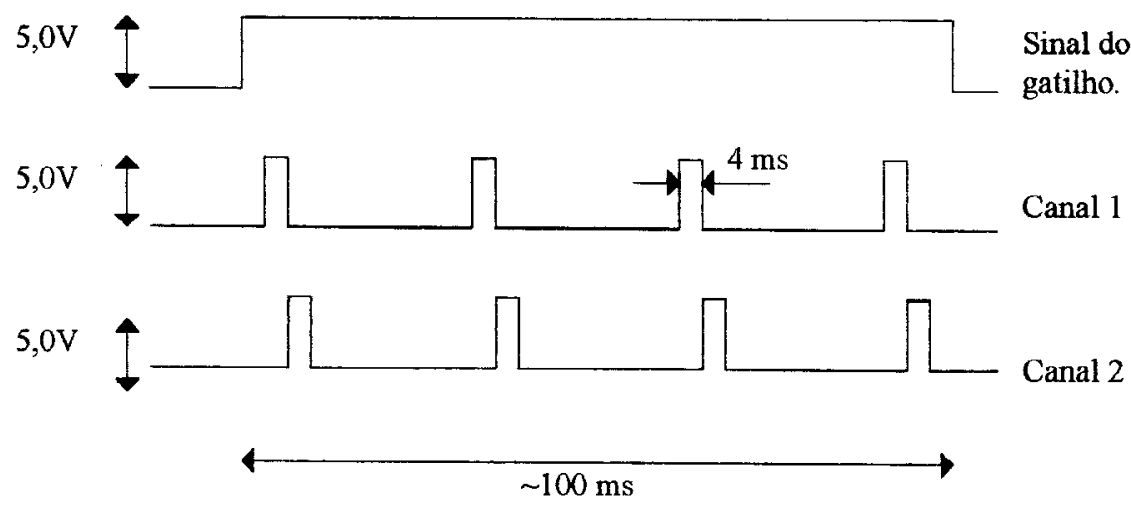

Figura 35 - Sinais do medidor Fabry-Pérot que vão ao microcomputador.

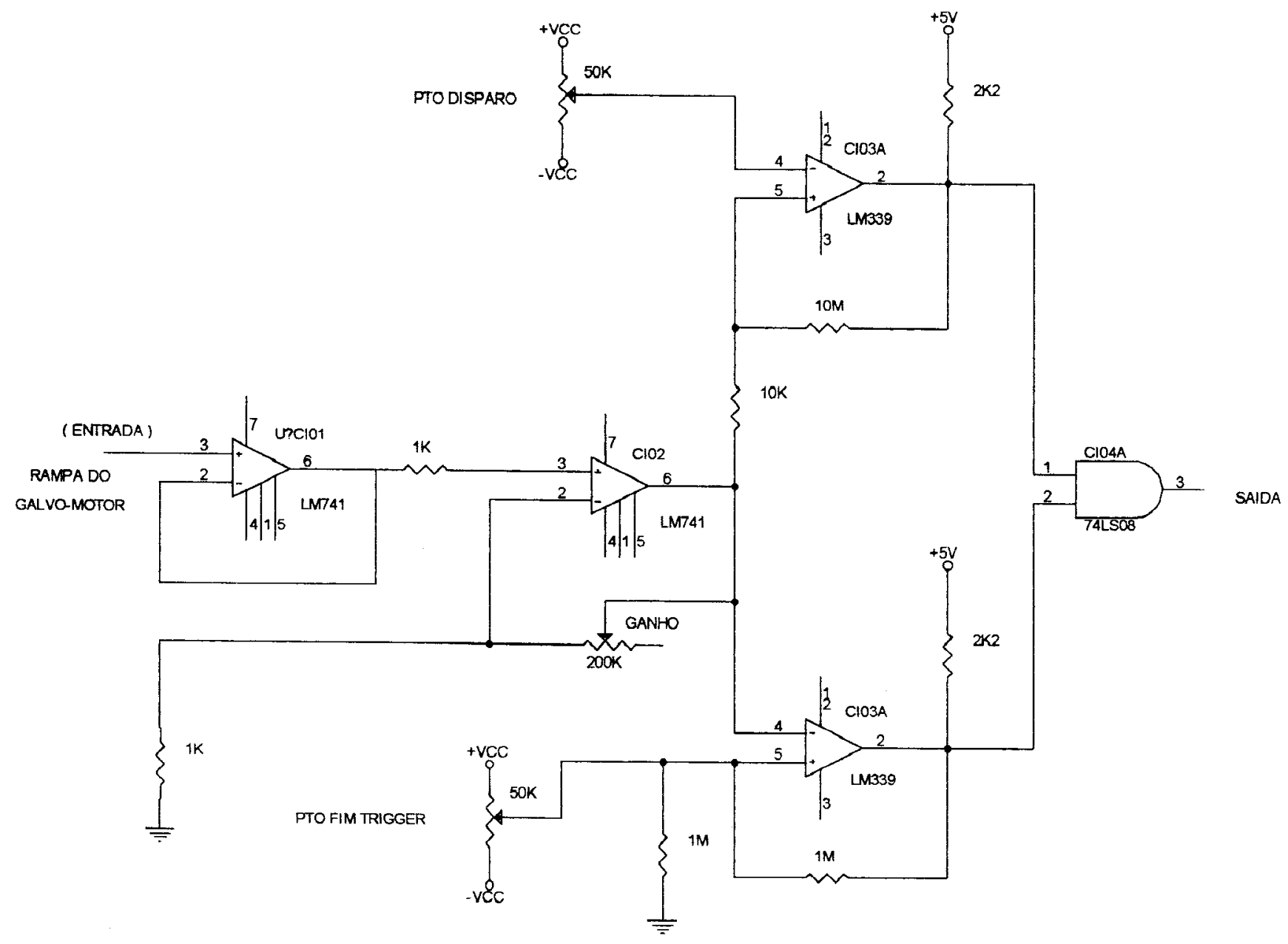

Figura 36 - Diagrama esquemático do gerador de gatilho. 
Primeiramente a rampa deve ser amplificada e em seguida injetada em dois comparadores. O primeiro deles é um comparador de tensão ajustável não inversor, servindo para especificar em que ponto da rampa o gatilho dispara, pois este está sempre em nível lógico baixo, subindo apenas quando a rampa supera uma tensão pré-determinada. O segundo deles é um comparador de tensão ajustável inversor, servindo para especificar em que ponto da rampa o gatilho desliga, pois este está sempre em nivel lógico alto, descendo apenas quando a rampa supera uma determinada tensão.

Fazendo-se um "E" lógico entre as saídas destes dois comparadores teremos um pulso digital de duração ajustável (dependendo das programações dos comparadores) que pode variar de zero até o tamanho da rampa. A figura 37 mostra a carta de tempos dos sinais elétricos principais do gerador de gatilho.

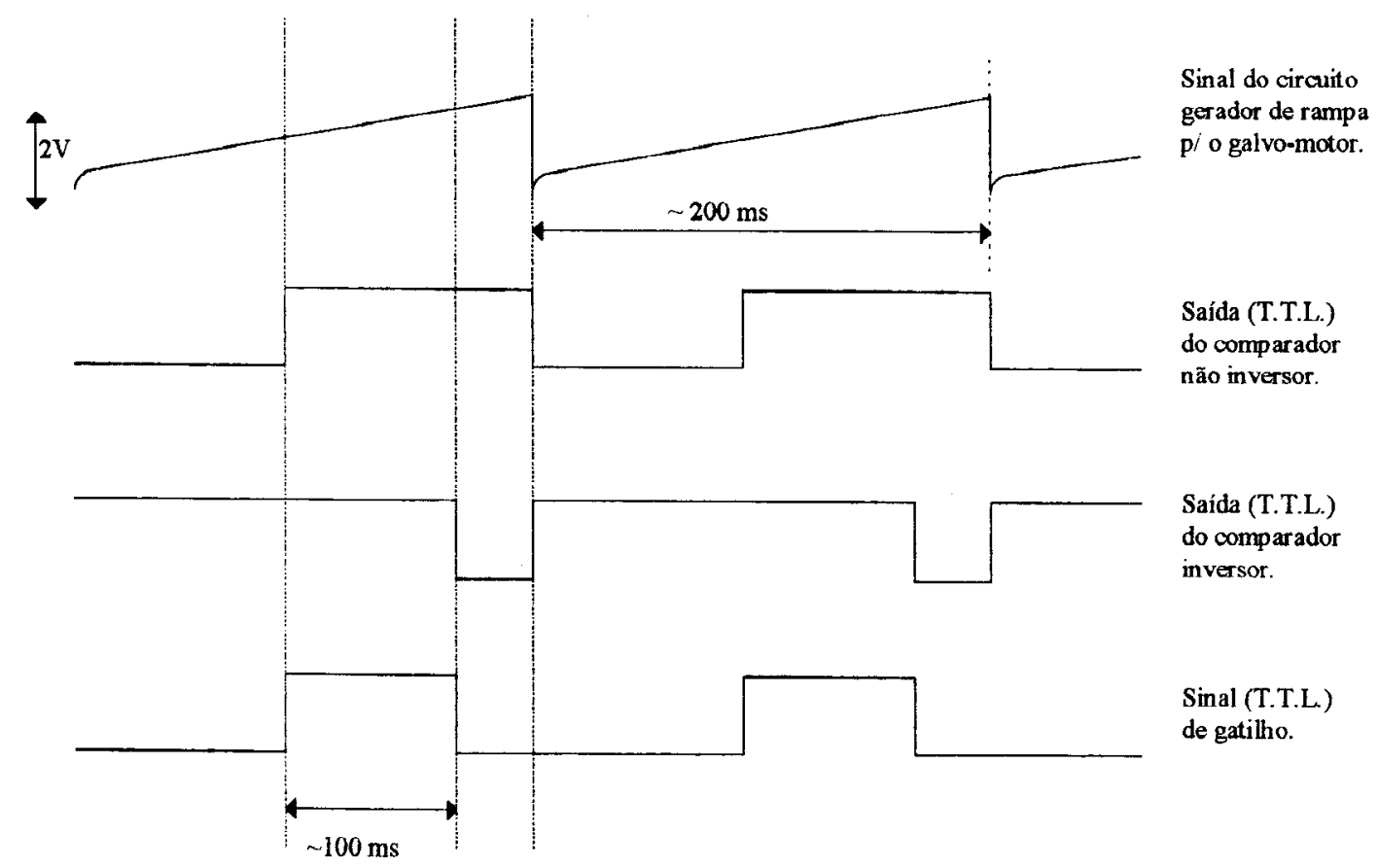

Figura 37 - Carta de tempos do gerador de gatilhos. 
O pulso de gatilho é utilizado pela placa analógica como se fosse uma janela, permitindo apenas o envio de determinado fração do conjunto de franjas. $O$ circuito permite, através de um simples ajuste, que se escolha qual região da varredura das franjas será considerada para se realizar uma medida do comprimento de onda da luz.

\subsection{2- Tratamento dos sinais digitais}

A placa que efetua a medida do espaçamento entre os picos adjacentes dos dois sinais captados pelos fotosensores nas saídas dos étalons é a mesma que foi utilizada no estágio anterior. Foi adicionado em sua entrada um circuito de chaveamento, que controlado pelo programa, faz a placa funcionar alternadamente, hora processando os sinais do medidor por atividade óptica e noutra os sinais vindos do Vernier Fabry-Pérot. Similarmente ao primeiro estágio, a placa digital recebe também três sinais vindos da placa analógica que compõe este estágio.

O primeiro sinal vem do canal 1 , que é utilizado para medir a largura temporal entre dois picos de um mesmo conjunto de franjas, servindo como referência para os cálculos. O segundo sinal vem do canal 2 , servindo então para a medida da largura temporal entre dois picos, um em cada conjunto de franjas, fornecendo a defasagem entre os dois conjuntos de franjas. Quanto ao terceiro, trata-se do sinal de gatilho discutido na secção anterior. Este sinal serve para sincronizar o programa com os ciclos da varredura. O circuito de monitoração da placa digital pode fornecer informações ao programa sobre o nível lógico do sinal de gatilho vindo da placa analógica a qualquer momento que for necessário. A 
figura 38 mostra todos os sinais que ambas as etapas do medidor de onda enviam à placa digital que está conectada no barramento do microcomputador.

Sinais vindos do medidor por atividade óptica

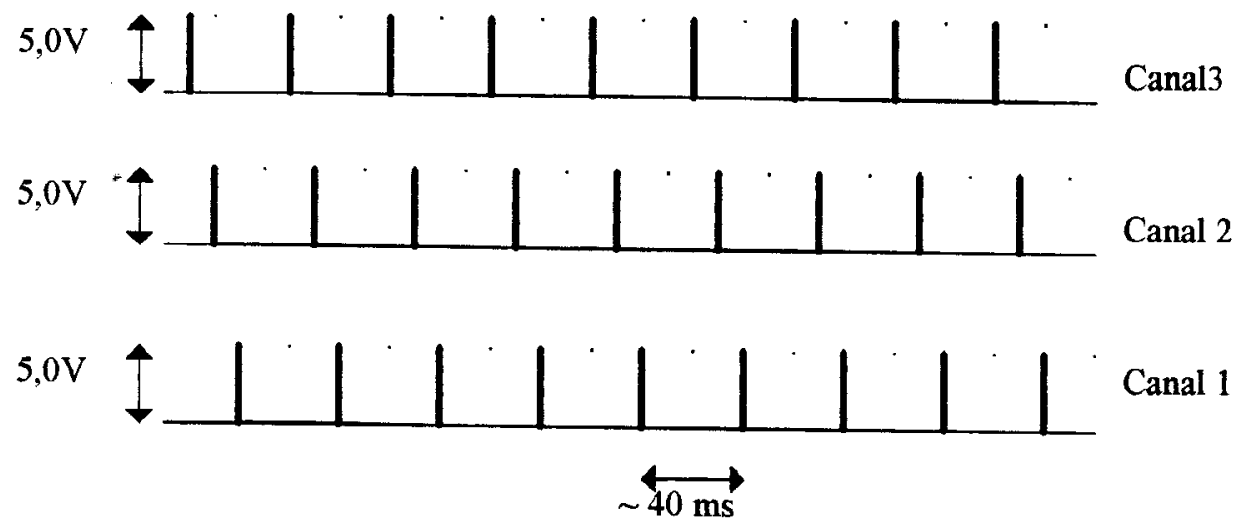

Sinais vindos do medidor Fabry-Perot

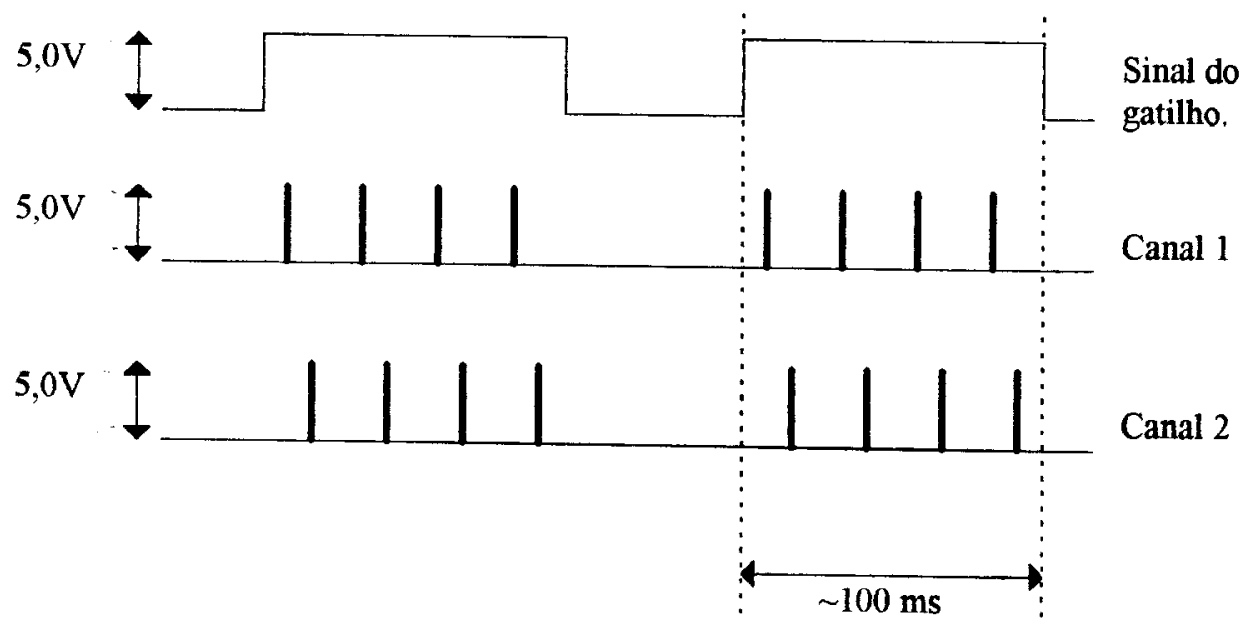

Figura 38 - Sinais recebidos pela placa digital do medidor.

Para que a placa digital possa trabalhar com o medidor Fabry-Pérot, foram feitas três pequenas alterações em seu circuito: 1) adição de um circuito de 
chaveamento duplo nas entradas da placa, 2) alteração no circuito de controle, 3) alteração no circuito de monitoração

\subsubsection{Circuito de chaveamento}

O circuito de chaveamento duplo (multiplexador) foi adicionado à placa digital para que o programa tenha meios de selecionar qual conjunto de sinais está sendo medido em um determinado instante. O programa pode escolher livremente entre trabalhar com os sinais vindos do medidor por atividade óptica ou com os sinais oriundos do medidor Fabry-Pérot. A mesma placa digital realiza separadamente a medida dos dois estágios do medidor. Mostramos na figura 390 diagrama esquemático do circuito multiplexador responsável pelo chaveamento entre um ou outro modo de operação.

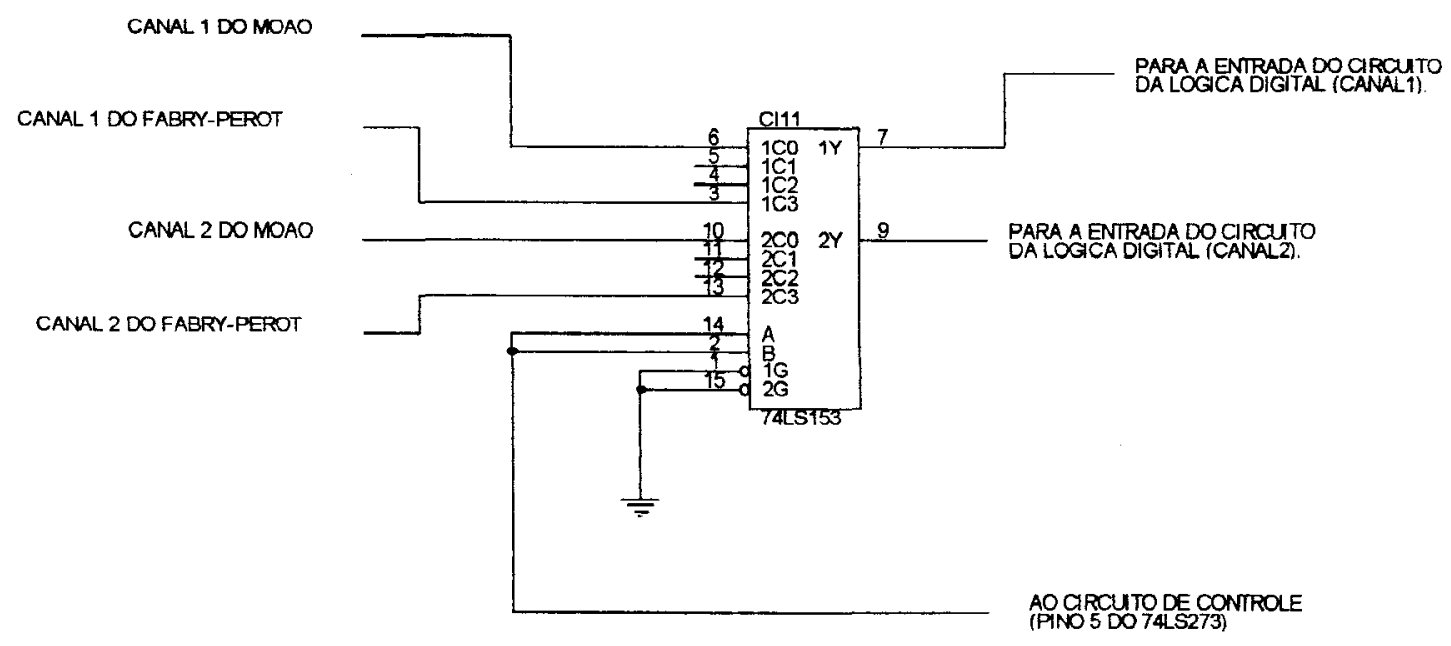

Figura 39 - Esquema elétrico do multiplexador de entrada. 
Enquanto o circuito de controle mantiver um nível lógico alto $(+5 \mathrm{~V})$ nos pinos 14 e 2 do circuito integrado 74LS153, a placa digital "enxerga" apenas os sinais vindos do Fabry-Pérot. Se o nivel lógico nestes pinos for baixo (OV) os sinais do medidor por atividade óptica são aqueles que estão sendo medidos.

\subsubsection{2- Alteração no circuito de controle}

O circuito de controle, que já foi apresentado na figura 18 , sofreu uma pequena alteração. Para poder controlar também o circuito de chaveamento o circuito teve mais uma via ligada. A figura 40 mostra o esquema final do circuito de controle.

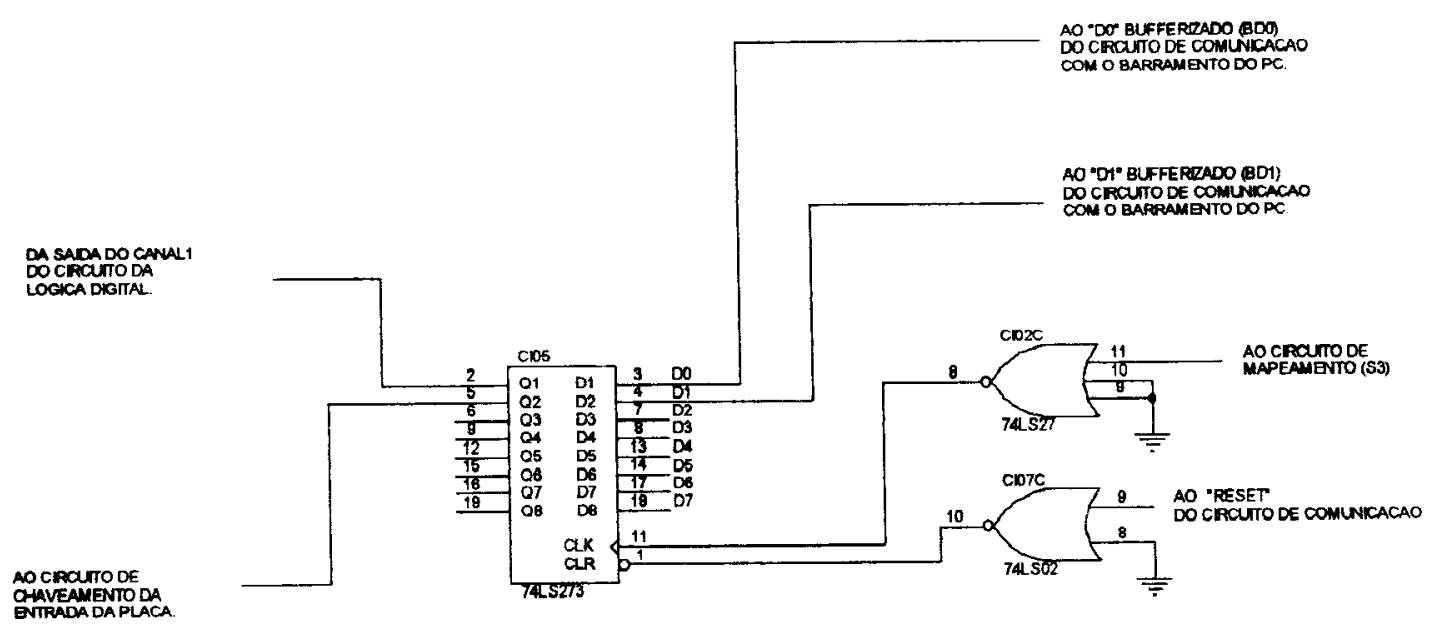

Figura 40 - Esquema elétrico do circuito de controle modificado. 
Para chavear a placa e trabalhar com o medidor com Vernier basta que se escrever no endereço $030 \mathrm{C}$ Hexadecimal, qualquer valor em base binária que possua o segundo dígito menos significativo igual a um, ou seja, um número binário do tipo " $X X X X X X 1 X "$, onde o "X" significa "0" ou "1", indiferentemente. $A$ única maneira de alterar o chaveamento da placa digital para que ela volte a trabalhar como anteriormente (com os dados vindos do medidor por atividade óptica), é escrever no endereço $030 \mathrm{C}$ hexadecimal um número binário do tipo "XXXXXXOX".

\subsubsection{3- Alteração no circuito de monitoração}

A alteração no circuito de monitoração foi feita para que o programa pudesse acompanhar também o estado lógico do sinal de gatilho utilizado no medidor Fabry-Pérot. A ligação de mais uma via foi a pequena modificação realizada no circuito da figura 20 . As antigas funções deste circuito não foram alteradas e através dele o programa ainda monitora o sinal de porto do contador 1. Agora, para que o programa saiba qual o nivel lógico do gatilho em determinado instante, basta que ele monitore o segundo dígito menos significativo do valor em base binária que estiver no endereço 0308 hexadecimal. A figura 41 mostra o esquema elétrico do circuito já alterado. 


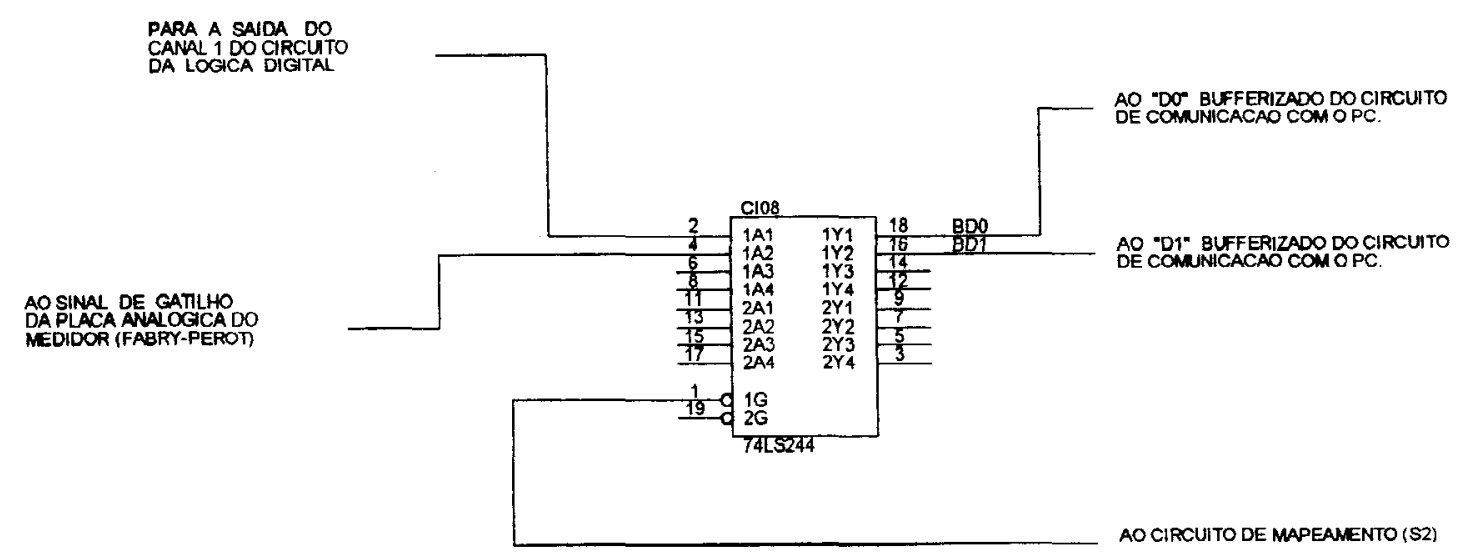

Figura 41 - Esquema elétrico do circuito de monitoração modificado.

\subsection{3- Placa geradora de rampa}

Para que as franjas de interferências "corram" há a necessidade de alterar o caminho óptico dentro dos étalons. Isto foi conseguido através de uma pequena lâmina de vidro móvel acoplada a um galvo-motor, colocada dentro do Vernier. Foi projetado e construído um circuito gerador de rampa, para que a lâmina se movesse e que as franjas fossem varridas. Um circuito RC foi utilizado para conseguir a rampa. O capacitor vai se carregando através do resistor e quando a sua tensão atinge um certo valor, um transistor numa configuração não muito usual (figura 43) se encarrega de descarregá-lo rapidamente. Este sinal periódico é tratado, reforçado e injetado no galvo-motor, que possui a lâmina de vidro fixada em seu eixo rotativo. O ângulo que esta lâmina de vidro forma com os feixes que atravessam o Vernier acompanha este sinal. Consequentemente, os caminhos ópticos percorridos pela luz dentro dos étalons variam periodicamente, fazendo com que as franjas se movam também periodicamente. 0 sinal gerado pelo 
gerador de rampa está mostrado na figura 42 enquanto que a figura 43 apresenta o esquema elétrico deste circuito.

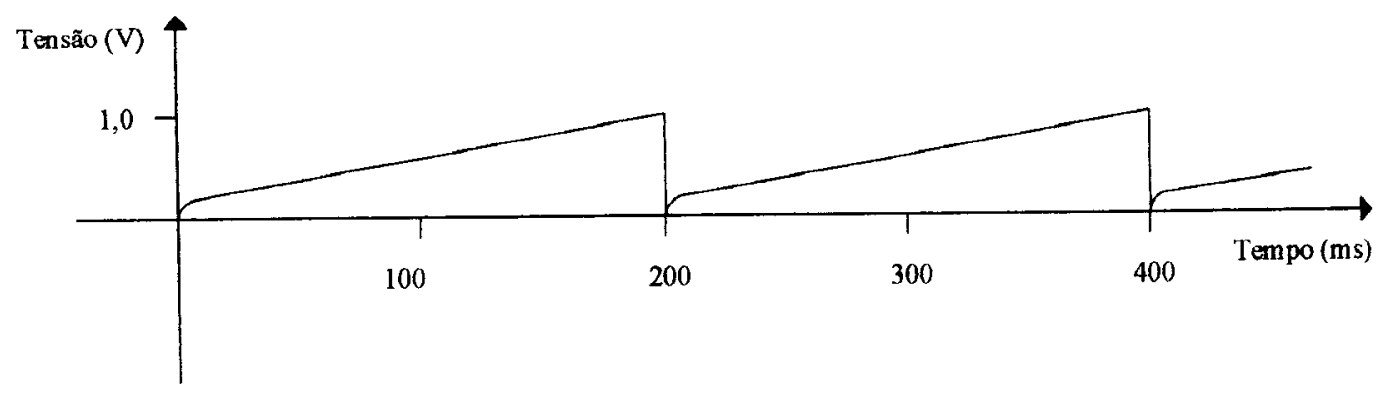

Figura 42 - Sinal obtido pelo gerador de rampa.

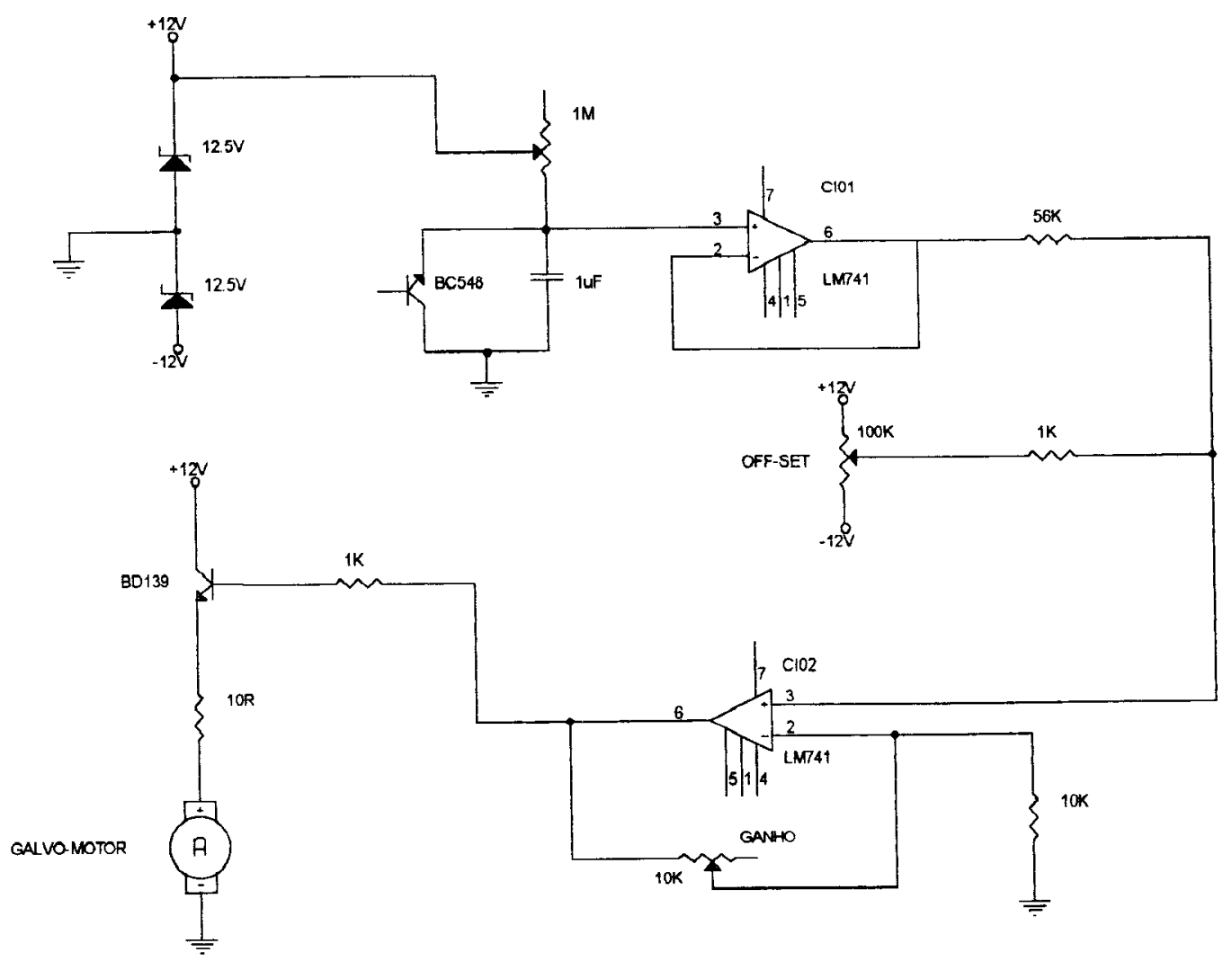

Figura 43 - Esquema elétrico do gerador de rampa para o galvo-motor. 


\subsection{4- Fonte de alimentação}

A fonte de alimentação é exatamente igual a fonte de baixa potência utilizada no estágio anterior. Optou-se pela construção de uma segunda fonte para que a primeira trabalhasse com folga, pois o galvo-motor é uma carga relativamente pesada e havia espaço físico disponível.

\section{4- Programas}

Os programas praticamente não se alteraram, somente foi introduzida uma subrotina a mais no corpo da DLL, chamada LER2, que é encarregada de fazer as leituras das defasagens entre as franjas. O programa de alto nível que faz todos os cálculos apenas precisa receber os dados da subrotina LER2, resolver numericamente um polinômio e mostrar o comprimento de onda. Tudo isto já havia sido feito na etapa anterior, bastando algumas poucas adaptações.

6.4.1- Função Ler2

Esta subrotina, foi desenvolvida para trabalhar com a etapa do Fabry-Pérot e é muito semelhante à subrotina "LER" vista anteriormente, diferenciando-se apenas por chavear a entrada da placa digital para operar com os sinais vindos do 
medidor Fabry_Pérot, e pelo fato de medir a defasagem de apenas dois canais. Segue abaixo a listagem do código desta subrotina.

\section{LER2 PROC FAR}

WINPROLOG

MOV DX,POR244

ESPEO:

IN AL,DX

;Espera $244=0$

TEST AL,2

JNZ ESPEO

ESPE1:

IN Al, dx

;Espera $244=1$

TEST AL,2

JZ ESPE1

MOV DX,POR273

;Destrava os Flips

MOV AL,3

;e chaveia para

OUT DX,AL

;Fabry-Perot

MOV DX,POR244

;Seleciona O 244

ESP1: IN AL,DX

;Espera $244=1$

TEST AL, 1

$J Z \quad E S P 1$

ESPO: IN AL,DX

;Espera $244=0$ 
TEST AL, 1

JNZ ESPO

MOV DX,POR273 ;trava os Flips

MOV AL,2 ;e chaveia para

OUT DX,AL ;Fabry-Perot

MOV DX,TIMEO ;Seta Contadores

MOV AL,OFFH

OUT DX,AL

OUT DX,AL

MOV DX,TIME1

OUT DX,AL

OUT DX,AL

MOV DX,TIME2

OUT DX,AL

OUT DX,AL

MOV DX,POR273 ;Destrava os Flips

MOV AL,3 ;e chaveia para

OUT DX,AL ;Fabry-Pérot

MOV DX,POR244

ESP_1:

IN AL,DX

;Espera $244=1$ 
TEST AL, 1

JZ ESP_1

ESP_O:

IN $\mathrm{Al}, \mathrm{dx}$

TEST AL, 1

JNZ ESP_O

MOV DX,POR273

;Trava os flips

MOV AL,O

OUT DX,AL

MOV DX,TIMEO

;Lê os contadores

IN AL,DX

MOV CL,AL

IN AL,DX

MOV AH,AL

MOV AL,CL

LES BX,DWORD PTR [BP+6]

MOV ES:[BX],AX

MOV DX,TIME1

IN AL,DX

MOV CL,AL

IN AL,DX

MOV AH,AL

MOV AL,CL

;Espera $244=0$ 
LES BX,DWORD PTR [BP+10]

MOV ES:[BX],AX

WINEPILOG

RET 8

LER2 ENDP 


\section{7- CONCLUSÕES E SUGESTÕES PARA TRABALHOS FUTUROS}

Neste trabalho descrevemos os principios de funcionamento e a construção de um medidor de onda de alta precisão baseado em dois estágios. O primeiro estágio, que é baseado na atividade óptica do cristal de quartzo, foi concluído com sucesso, resultando num dispositivo com uma precisão de uma parte em dez mil e está sendo útil para monitorar a frequência de operação de lasers de corante sintonizáveis utilizados em medidas de aprisionamentos magneto-ópticos.

O segundo estágio do medidor (Vernier Fabry-Pérot) foi concluído mas não foi calibrado. Não havia nenhum instrumento com precisão suficiente para podermos comparar com o medidor construido. Por ser baseado em étalons, este estágio mostrou-se muito sensível ao alinhamento do feixe de laser e às vibrações mecânicas externas. O problema do alinhamento do feixe somente poderá ser resolvido com a utilização de uma fibra óptica para se captar a luz a ser medida. A forte sensibilidade às vibrações mecânicas externas tornou critico o manuseio e a utilização do medidor, o que afasta o protótipo de duas característica básicas impostas na idealização do projeto: a simplicidade de uso e a robustez. Somente para exemplificar, o primeiro estágio opera sem problemas sobre quase qualquer superfície, não havendo a necessidade de se utilizar uma mesa óptica, o que não acontece com a utilização deste segundo estágio mais preciso.

Como a precisão obtida pelo primeiro estágio mostrou-se suficiente para a realização dos experimentos em andamento nos laboratórios de óptica, resolvemos interromper o andamento do projeto neste ponto. Entretanto, para se atingir a precisão de 1 parte em $10^{7}$ serão necessários a execução dos seguintes passos: a) instalação da fibra óptica para se captar a luz a ser medida para que a defasagem entre as franjas que "correm" não dependa da forma que a luz entra no 
medidor e b) calibração do medidor com vernier, utilizando-se absorções saturadas ou mesmo um medidor de melhor precisão como padrão. 


\section{8- REFERÊNCIAS}

1. W. Demtröder, Laser Spectroscopy, Springer Series in Chemical Physics 5 , Springer-Verlag, Berlin (1982).

2. J. C. Lehmann, Contemp. Phys. 19, 449 (1978).

3. S. Gerstenkorn and P. Luc, Absolute iodine standards measured by means of Fourier transform spectroscopy, Editions du CNRS (1977).

4. G. R. Fowles, Introduction to Modern Optics, Holt, Rinehart and Winston, NY (1968).

5. R. C. Jones, J. Opt. Soc. Am. 31, 488 (1941)

6. D. F. Horne, Optical Production Technology, Crane Russak (1972).

7. M. Born and M. Wolf, Principles of Optics, $3^{\text {rd }}$ edition, Pergamon, Oxford (1970).

8. TEXAS INSTRUMENTS. TTL Logic Standard TTL, SchottKy, Low-Power Schottky Data Book, 1988.

9. NATIONAL. Linear Data Book, 1976.

10. INTEL. Peripheral Components, 1995.

11. S. A. TONISSI JÚNIOR, Dissertação de mestrado (Instrumentação eletrônica para pesquisa na área de óptica), IFQSC-USP, São Carlos, SP, (1992).

12. MICROSOFT. MS-DOS 5.0 Guia do Usuário.

13. MONIDATA. Manual Técnico do PC-XT Monidata.

14. S.C.Zilio, Apostila do curso de Óptica - SFI 156, 1992. 


\title{
Apêndice A - Listagem do programa principal
}

\author{
LISTAGEM DO "WAVMETER.BAS"
}

\author{
Global Contl As Long \\ Global Cont2 As Long \\ Global Cont3 As Long \\ Global contadArq As Integer \\ Global contad2 As Integer \\ Global A As Single \\ Global B As Single \\ Global C As Single \\ Global D As Single \\ Global Ell As Single \\ Global E12 As Single \\ Global Numptos As Integer \\ Global Maisdef As Single \\ Global Menosdef As Single \\ Global Referen As Single \\ Global Angmaior As Single \\ Global Angmenor As Single \\ Global somaior As Single \\ Global somenor As Single \\ Global soma2 As Single \\ Global JaPodeMostrarMedia \\ Global Cont Vetor 10Inst As Integer \\ Global Lambdas(100, 100) As Single \\ Global MedUlt(10) As Single \\ Global Ordenado(100) As Single \\ Global Desvio1 As Single \\ Global A0 As Single \\ Global Al As Single \\ Global A2 As Single \\ Global A3 As Single \\ Global Meio As String \\ Global Dimensao As String \\ Global Arquivo As String \\ Global AltaPresc
}

Sub Checkl_Click ()

End Sub

Sub Check3_Click ()

$$
\text { ComprOnda }=\text { True }
$$

End Sub 


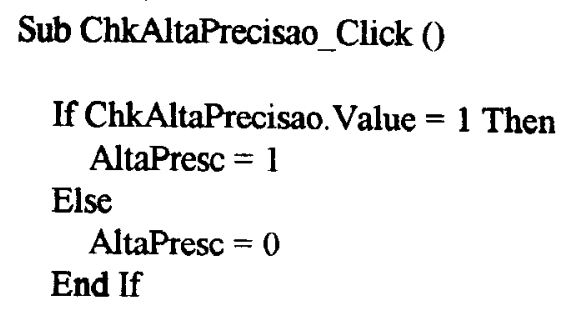

End Sub

Sub CmdMeio_Click ()

If Meio $=$ "Ar" Then

CmdMeio. Caption = "\&Vácuo"

Meio = "Vacuo"

Else

WaveMeter.LblMeio. Caption = "Vácuo"

CmdMeio Caption = "\&Ar"

Meio = "Ar"

End If

WaveMeter.LblMeio. Caption = "Ar"

JapodeMostrarMedia $=$ False

Cont Vetor 10Inst $=0$

WaveMeter LblSaida10 $="$

End Sub

Sub Command1_Click ()

Configuracao. Visible $=$ False

End Sub

Sub Form_Deactivate ()

If OptNm(0). Value $=$ True Then Dimensao $=$ "nm"

If OptAngstrons $(0)$. Value $=$ True Then Dimensao $=$ "Angstrons"

If OptNumOnda( $(0)$. Value $=$ True Then Dimensao $=" 1 / \mathrm{cm}^{\prime \prime}$

Numptos $=$ HscNumMedias. Value

End Sub

Sub Form_Load ()

If Meio = "Ar" Then CmdMeio. Caption = "\&Ar"

If Meio = "Vacuo" Then CmdMeio.Caption = "\&Vácuo"

HscNumMedias. Value $=$ Numptos

TxtNumMedias $=$ HscNumMedias. Value

If Dimensao = "nm" Then

OptNm(0). Value $=$ True

OptAngstrons $(0)$. Value $=$ False

OptNumOnda $(0)$. Value $=$ False

End If

If Dimensao = "Angstrons" Then 


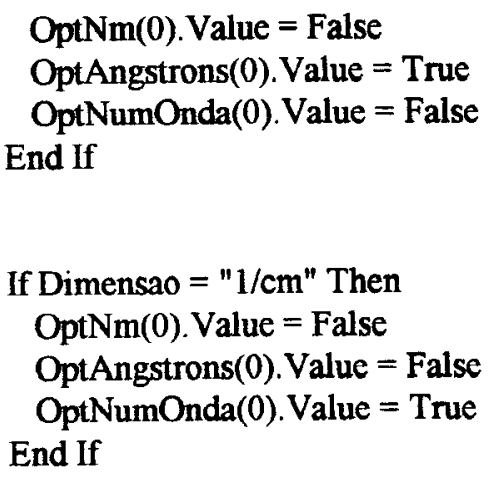

If AltaPresc $=1$ Then ChkAltaPrecisao. Value $=1$

If AltaPresc $=0$ Then ChkAltaPrecisao. Value $=0$

\section{End Sub}

Sub HscNumMedias_Change ()

TxtNumMedias = HscNumMedias . Value Numptos $=$ HscNumMedias. Value JapodeMostrarMedia $=$ False ContVetor 10Inst $=0$

WaveMeter.LblSaida10 = "

End Sub

Sub OptAngstrons_Click (Index As Integer)

Dimensao $=$ "Angstrons"

End Sub

Sub OptDimensao_Click (Index As Integer)

Dimensao = "Angstrons"

End Sub

Sub OptMedidaNum_Click (Index As Integer)

Dimensao $=" 1 / \mathrm{cm}^{\prime \prime}$

End Sub

Sub OptNm_Click (Index As Integer)

Dimensao $=" \mathrm{Nm} "$

End Sub

Sub OptNumOnda_Click (Index As Integer)

Dimensao $=" 1 / \mathrm{cm} "$

End Sub 


\section{LISTAGEM DO "WAVMETER.FRM"}

Declare Sub Inic55 Lib "c:iwavmeterlinpout.d1l" ()

Declare Sub Ler Lib "c:lwavmeterlinpout.dll" (Valor1\&, valor2\&, valor3\&)

Declare Sub Carrega Lib "c:lwavmeterinpout.dll" 0

Declare Sub Ler2 Lib "c:lwavmeterinpout.dll" (Medida1\&, Medida2\&)

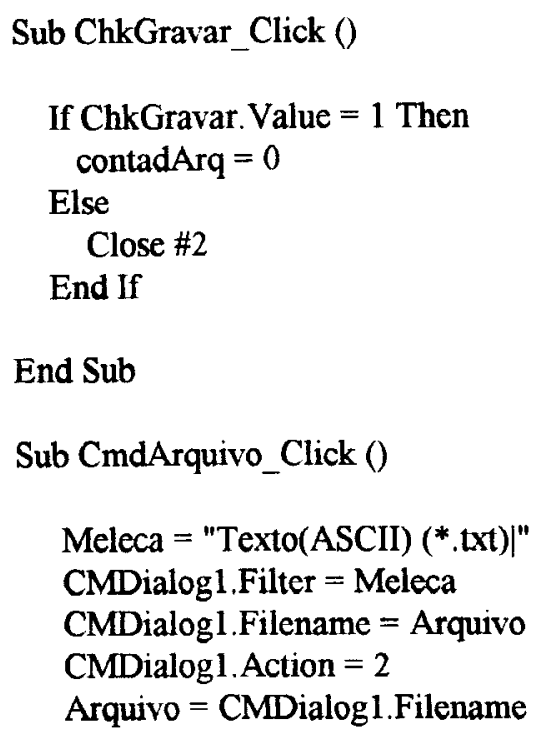

End Sub

Sub CmdConfigura_Click ()

Configuracao . Visible $=$ True

End Sub

Sub cmdend_Click ()

End

End Sub

Sub cmaSair_Click ()

'****** Grava configuração atual

Open "c:iwavmeterlWavmeter.cfg" For Output As \#1

Print \#1, Meio

Print \#1, NumPtos

Print \#1, Dimensao

Print \#1, Arquivo

Print \#1. ALTApRESC

Close \#1

End 'Sai do programa

End Sub

Sub Command1_Click () 
End Sub

Sub Form_Activate ()

LblDimensao . Caption $=$ Dimensao

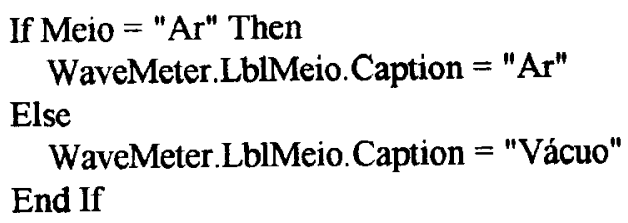

End Sub

Sub Form_Load ()

NumPtos $=10 \quad$ 'Número de elemento do vetor Ordenado()

Desviol $=.45$ 'Define o intervalo de tolerância ao $\mathrm{M}$

JapodeMostrarMedia = False 'Se já tem 10 ptos p/ calc. a média do vet.

ContVetor10Inst $=0$

ContVetor $=0$

contad $=0$

$\operatorname{contad} 2=0$

RazaoCristal $=1.0392$

$\mathrm{EL} 1=9.99655$

$\mathrm{EL} 2=$ RazaoCristal $*$ EL1

Rem Parâmetros do polinômio que descreve o cristal

$\mathrm{A}=4.06354656602 \mathrm{E}-10$

$\mathrm{B}=-1.98990930216 \mathrm{E}-05$

$\mathrm{C}=.325180901437$

$\mathrm{D}=-\mathbf{1 7 6 6 . 4 3 3 5 8 3 5 2}$

Rem Parâmetros do polinômio de correção fina.

$\mathrm{A} 0=\mathbf{7 4 0 8 3 . 8 2 2}$

$\mathrm{A} 1=-362.79848$

$\mathrm{A} 2=.59204349$

$\mathrm{A} 3=-.00032195$

'****** Carrega a configuração gravada

Open "c: lwavmeterlWavmeter.cfg" For Input As \#1

Input \#1, Meio

Input \#1, NumPtos

Input \#1, Dimensao

Input \#1, Arquivo

Input \#1, ALTApRESC

Close \#1

Open Arquivo For Output As \#2

Inic55 'Inicializa a placa 
End Sub

Sub HScroll2_Change ()

End Sub

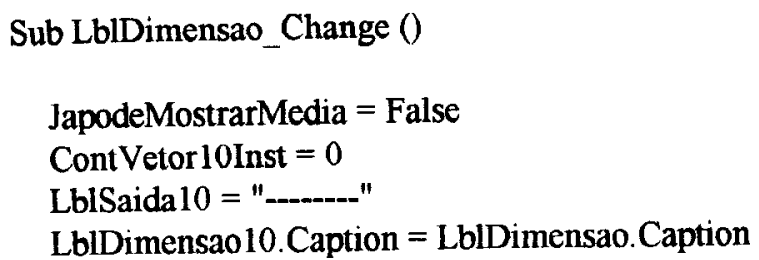

End Sub

Sub Timer1_Timer 0

For aux $\%=1$ To NumPtos 'Tamanho do vetor ORDENADO() $\mathrm{p} /$ tirar ruidos

'DoEvents

'Ler2 cont2, cont $1 \quad$ 'Pergunta $\mathrm{p} /$ placa uma leitura

'Beep

'DoEvents

'Transforma a contagem descendente da placa em ascendente

'contl $=65535$ - cont 1

'cont $2=65535$ - cont 2

'LblSaida.Caption $=$ cont 1

'LbiSaida10. Caption $=$ cont2

'contadArq = contadArq $+1 \quad$ 'Contador do Arquivo

'razao $=$ cont $1 /$ cont 2

'Print \#2, cont1, cont2, razao

'Beep

'GoTo 333

5 DoEvents

はキ*****

- GoTo 7

1******

DoEvents

Ler cont 1 , cont 2 , cont 3 'Pergunta $\mathrm{p} /$ placa uma leitura

DoEvents

'Transforma a contagem descendente da placa em ascendente

maisdef $=65535$ - cont $1 \quad$ 'Canal 2 (mais cristal)

mnosdef $=65535$ - cont $2 \quad$ 'Canal 1

referen $=65535-$ cont $3 \quad$ 'Canal 3

If referen $<=0$ Then GoTo 5 'Impede erros de overflow

$1 * * * * * * * * * * * * * * * * * * *$ Converte em ângulos $* * * * * * * * * * * * * * * * * * * * * * *$

Rem angulo do MAIOR cristal 


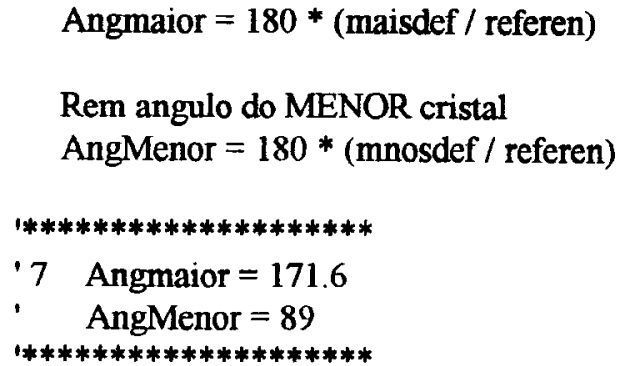

'Cuida p/ que o AngMaior seja realmente maior

If Angmaior $<$ AngMenor Then Angmaior $=180+$ Angmaior

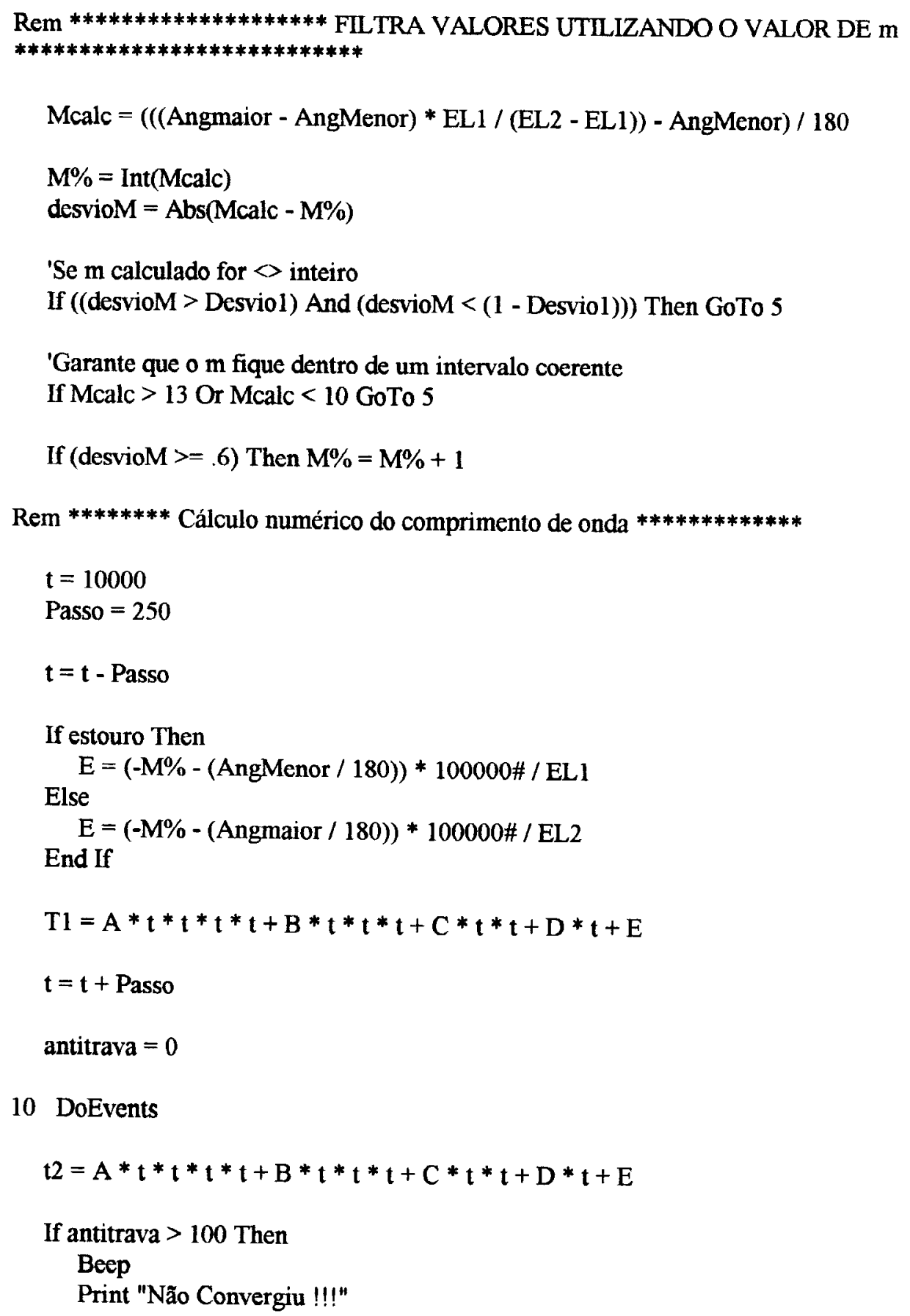

10 DoEvents 
End If

GoTo 100

If $\operatorname{Abs}(t 2-T 1)<.005$ Then GoTo 100

$\mathrm{T} \mathbf{l}=\mathbf{t} 2$

If $\mathrm{t} 2>0$ Then

$\mathrm{t}=\mathrm{t}-$ Passo

Passo $=$ Passo $/ 4$

End If

$\mathbf{t}=\mathbf{t}+$ Passo

GoTo 10

100 Rem ******** Valor do comprimento de onda

Lambda $=1 / \mathrm{t} * 100000000 \#$ 'Resposta em Angstrons (ar)

If Meio = "Vacuo" Then Lambda $=$ Lambda * 1.00031605563

Lambda = Lambda / $10 \quad$ 'converte Angstrons em Nm

If NumPtos = 1 Then GoTo 500 'Se não tem médias pula

lambdas(aux\%, 1) = Lambda 'Carrega o vetor lambdas

lambdas $(a u x \%, 2)=0$

Next aux\%

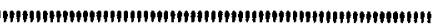

'**************** Filtra os ruídos espúrios

'Ordena "NumPtos" de medidas em um vetor ORDENADO0, mostrando ' 'p/ o usuário apenas o valor que está no centro do vetor.

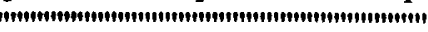

'Varre o vet Lambdas procurando o maior valor para 'armazenar no último elemento do vet Ordenado.

DoEvents

ordenado(NumPtos) $=0$

For aux $1 \%=1$ To NumPtos 'Varre o vet Lambdas

If lambdas(aux $1 \%, 1)>$ ordenado(NumPtos) Then

DoEvents

ordenado(NumPtos) $=$ lambdas $(\operatorname{aux} 1 \%, 1)$

UltTermo $=$ aux $1 \%$

End If

Next aux $1 \%$

lambdas(UltTermo, 2) $=1$

DoEvents 
'Carrega o resto do vetor ordenado()

For aux $1 \%=($ NumPtos - 1$)$ To 1 Step -1 'SemiVarre o vet Ordenado

ordenado $(\operatorname{aux} 1 \%)=0$

primeiraVez $=$ True

For aux $2 \%=1$ To NumPtos 'Varre o vet Lambdas

If lambdas $(\operatorname{aux} 2 \%, 1)<=$ ordenado $(\operatorname{aux} 1 \%+1)$ And lambdas $(\operatorname{aux} 2 \%, 1)>=$ ordenado(aux $1 \%)$

And lambdas $(\operatorname{aux} 2 \%, 2)=0$ Then

\section{DoEvents}

If Not primeiraVez Then lambdas(UltTermo, 2) $=0$

primeiraVez $=$ False

ordenado $(\operatorname{aux} 1 \%)=\operatorname{lambdas}(\operatorname{aux} 2 \%, 1)$

UltTermo $=$ aux $2 \%$

\section{End If}

Next aux $2 \%$

lambdas(UltTermo, 2) $=1$

Next aux 1\%

'Fim da ordenação do vetor

Rem Escolhe o ponto no meio do vetor

Lambda $=\operatorname{ordenado}(\operatorname{Int}($ NumPtos / 2) $)$

$500 \operatorname{Rem}^{* * * * * * * * * * * * * *}$ Ajuste fino do valor *********************

ErroFino $=\mathrm{A} 0+\mathrm{A} 1 *$ Lambda $+\mathrm{A} 2 * \operatorname{Lambda}^{\wedge} 2+\mathrm{A} 3 * \operatorname{Lambda}^{\wedge} 3$

Lambda $=$ Lambda - ErroFino

If $\mathrm{ALTApRESC}=0$ Then $\quad$ ***** Se a alta precisão está ativada

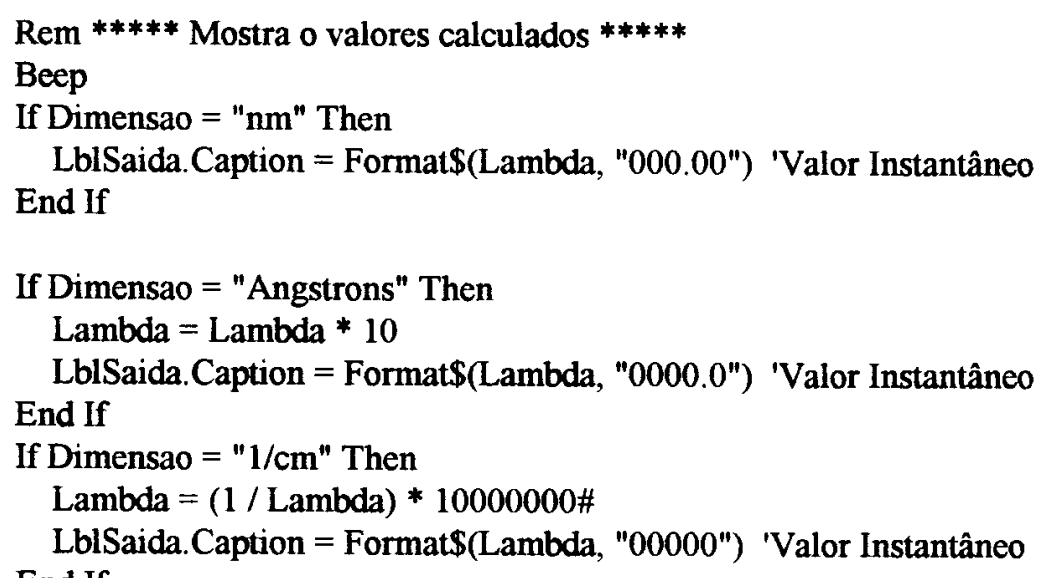
End If

LblSaida.Refresh

Rem ***** Cuida da média instantânea continua dos 10 últimos

ContVetor 10Inst $=$ ContVetor10Inst +1 'Cuida da atualização contínua sequêncial 
'dos registros do vetor

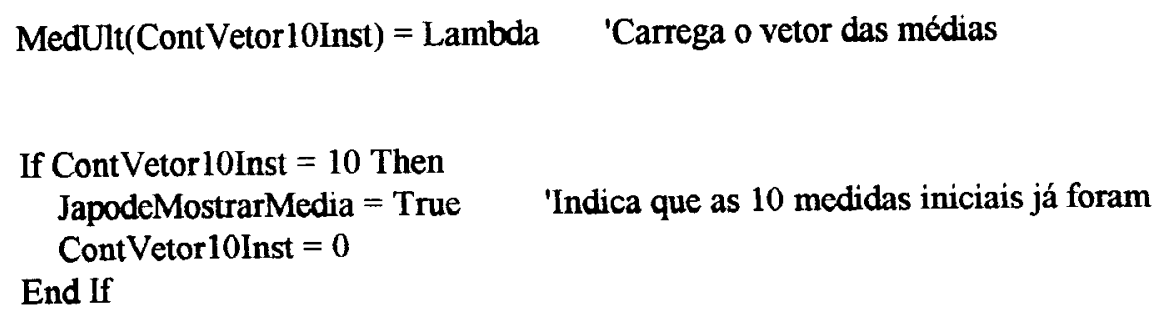

End If

If ChkGravar = 1 Then 'Se a gravação está autorizada

1***** Grava as médias no Arquivo contadArq $=$ contadArq +1 'Contador do Arquivo Print \#2, contadArq, LblSaida.Caption, Meio, Lb1Saida10.Caption, LblDimensao 10.Caption Beep

End If

Else 'Se a alta precisão está ativada

End If 'Fim da chave da alta precisão

1000 End Sub 


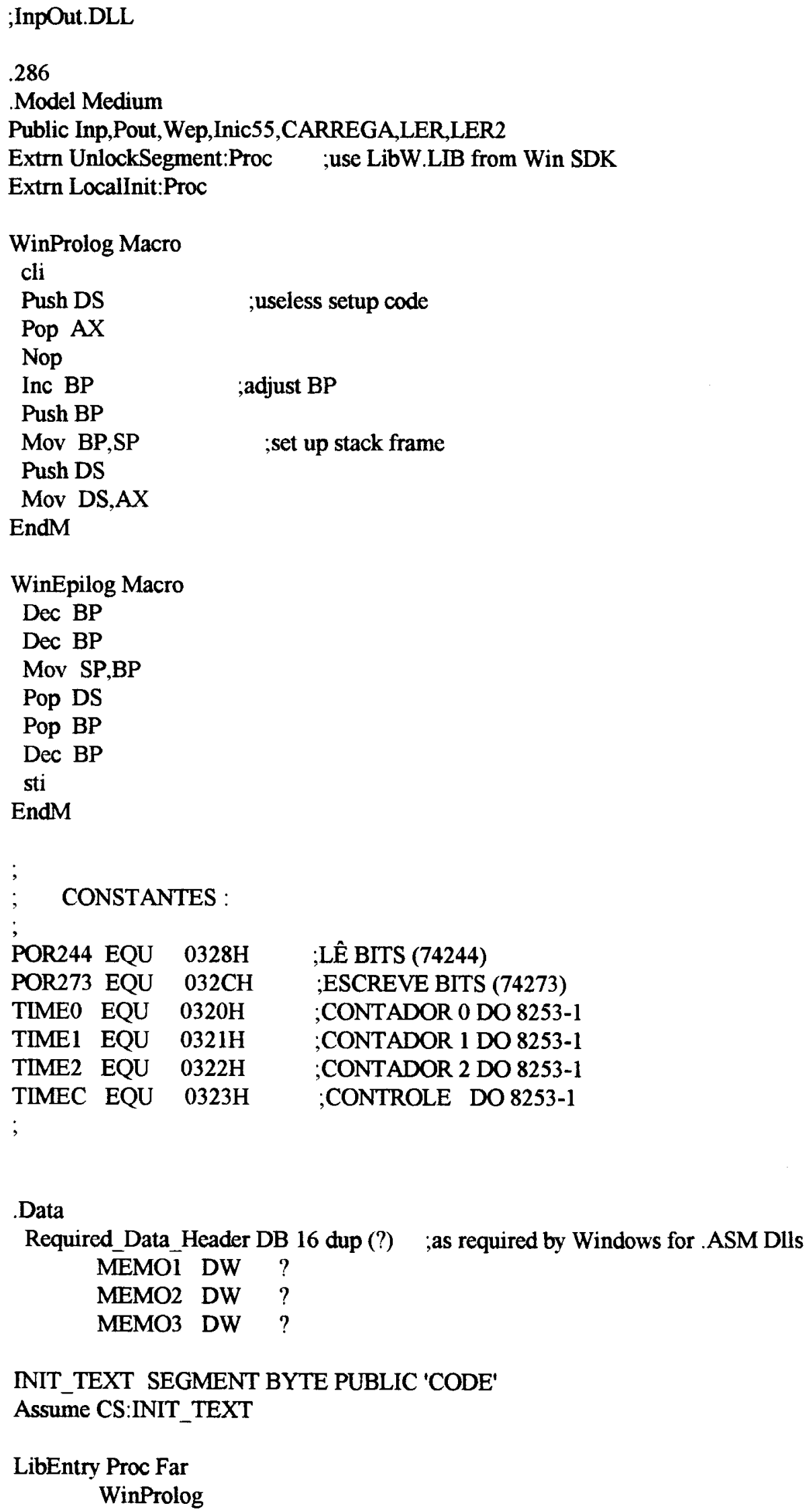

NNIT_TEXT SEGMENT BYTE PUBLIC 'CODE'

Assume CS:INIT_TEXT

LibEntry Proc Far

WinProlog 
$\begin{array}{lll}\text { push } & \text { di } & \text {; handle of the module instance } \\ \text { push } & \text { ds } & \text {; library data segment } \\ \text { push } & \text { cx } & \text {; heap size }\end{array}$

; if we have some heap then initialize it

jcxz CallMain ; jump if no heap specified

; call the Windows function LocalInit() to set up the heap

; Locallnit((LPSTR)start, WORD cbHeap);

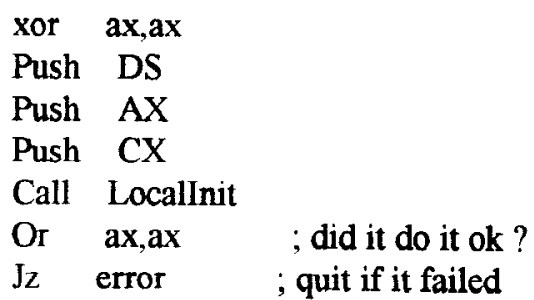

; invoke the asm routine to do any special initialization

CallMain:

Call Far Ptr LibMain ; invoke the startup routine (result in AX)

Jmp short exit $\quad$; LibMain is responsible for stack clean up

error:

$\begin{array}{ll}\text { pop } & c x \\ \text { pop } & \text { ds } \\ \text { pop } & \text { di }\end{array}$

exit:

WinEpilog

Ret

LibEntry EndP

INIT_TEXT EndS

.Code

; Libmain gets these parameters

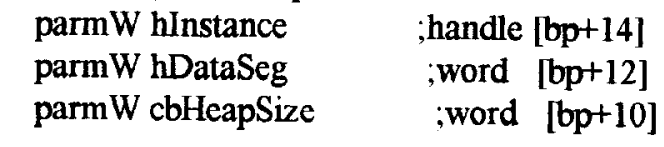

LibMain Proc Far WinProlog

;windows prolog code

Push -1 ;unlock data segment (just in case)

Call UnlockSegment

Mov AX.1

WinEpilog

;return a 1 to caller

;windows epilog code

Ret 6

$; 3$ variables (6 bytes)

LibMain EndP

Wep Proc Far

WinProlog

Mov AX.1

WinEpilog 
Ret

Wep EndP

;Declare Function Inp Lib "InpOut.DLL" (Port\%) as Integer

PortNumb\% $=$ \&h378

;PortValue\% = Inp(PortNumb\%)

Inp Proc Far

WinProlog

Mov DX,[BP+6]

In AL,DX

Xor AH,AH

WinEpilog

Ret 2

Inp EndP

;standard prolog macro

;load DX with port to check out

;input a byte

:clear high byte for return in AX

;standard epilog macro

;Declare Sub Out Lib "InpOut.DLL" (Port\%,Value\%)

;PortNumb\% $=$ \&h378

;for example only, don't try this

:Value $\%=65$

;Out PortNumb\%,Value\%

Pout Proc Far ;Warning errors can be ignored!

WinProlog ;standard prolog macro

Mov $\mathrm{AL},[\mathrm{BP}+6] \quad$;get data value into $\mathrm{AL}$ (bytes only)

Mov DX,[BP+8] ;get port value into DX

Out DX,AL

WinEpilog

;output the byte

Ret 4

;standard epilog macro

Pout EndP

;return clearing 4 bytes off stack

***** CORPO DAS SUBROTINAS *****

INIC55 PROC FAR

WINPROLOG

$\begin{array}{lcc}\text { MOV } & \text { DX,TIMEC } & \text {;Programa Contadores } \\ \text { MOV } & \text { AX,38H } & \text {;AL=00111000 } \\ \text { OUT } & \text { DX,AL } & \text {;Prog. cont0 do 8254 } \\ \text { MOV } & \text { AX,78H } & \text {;AL=01111000 } \\ \text { OUT } & \text { DX,AL } & \text {;Prog. cont1 do 8254 } \\ \text { MOV } & \text { AX,0B8H } & \text {;AL=10111000 } \\ \text { OUT DX,AL } & \text {;Prog. cont2 do 8254 } \\ & \\ \text { WINEPILOG } & \\ \text { RET } & \\ \text { INIC55 ENDP } & \end{array}$




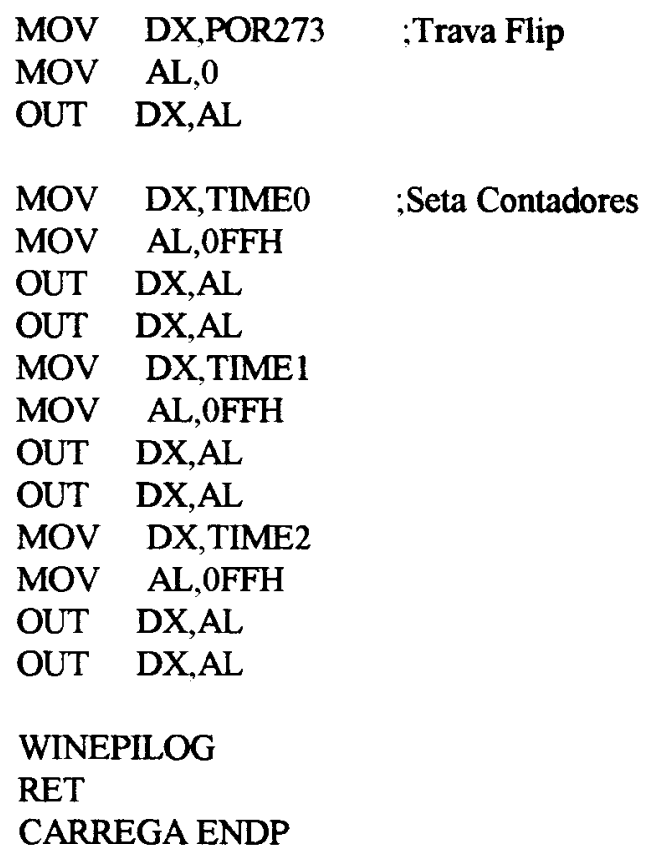


KONG:

IN AL,DX ;Espera 244 =0

TEST AL, 1

JNZ KONG

MOV DX,POR273 ; Trava os flips

MOV AL, 0

OUT DX,AL

MOV DX,TIME0 ;Lê os contadores

IN AL,DX

MOV CL,AL

IN AL,DX

MOV AH,AL

MOV AL,CL

LES BX,DWORD PTR [BP+6]

MOV ES:[BX],AX

MOV DX,TIME1

IN AL,DX

MOV CL,AL

IN AL,DX

MOV AH,AL

MOV AL,CL

LES BX,DWORD PTR [BP+10]

MOV ES:[BX],AX

MOV DX,TIME2

IN AL,DX

MOV CL,AL

IN AL,DX

MOV AH,AL

MOV AL,CL

LES BX,DWORD PTR [BP+14]

MOV ES:[BX],AX

WINEPILOG

RET 12

LER ENDP

;

LER2 PROC FAR

WINPROLOG

MOV DX,POR244

ESPE0:

IN AL,DX ;Espera 244 $=0$

TEST AL,2

JNZ ESPE0

ESPE1:

IN $\mathrm{Al}, \mathrm{dx} \quad$;Espera 244 $=1$

TEST AL,2

JZ ESPE1

MOV DX,POR273 ;Destrava os Flips 


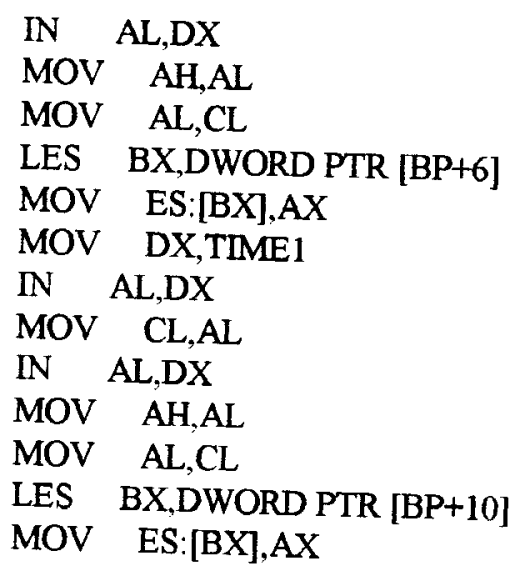

WINEPILOG

RET 8

LER2 ENDP

End 


\section{Apêndice C - Esquema elétrico da interface digital do PC.}

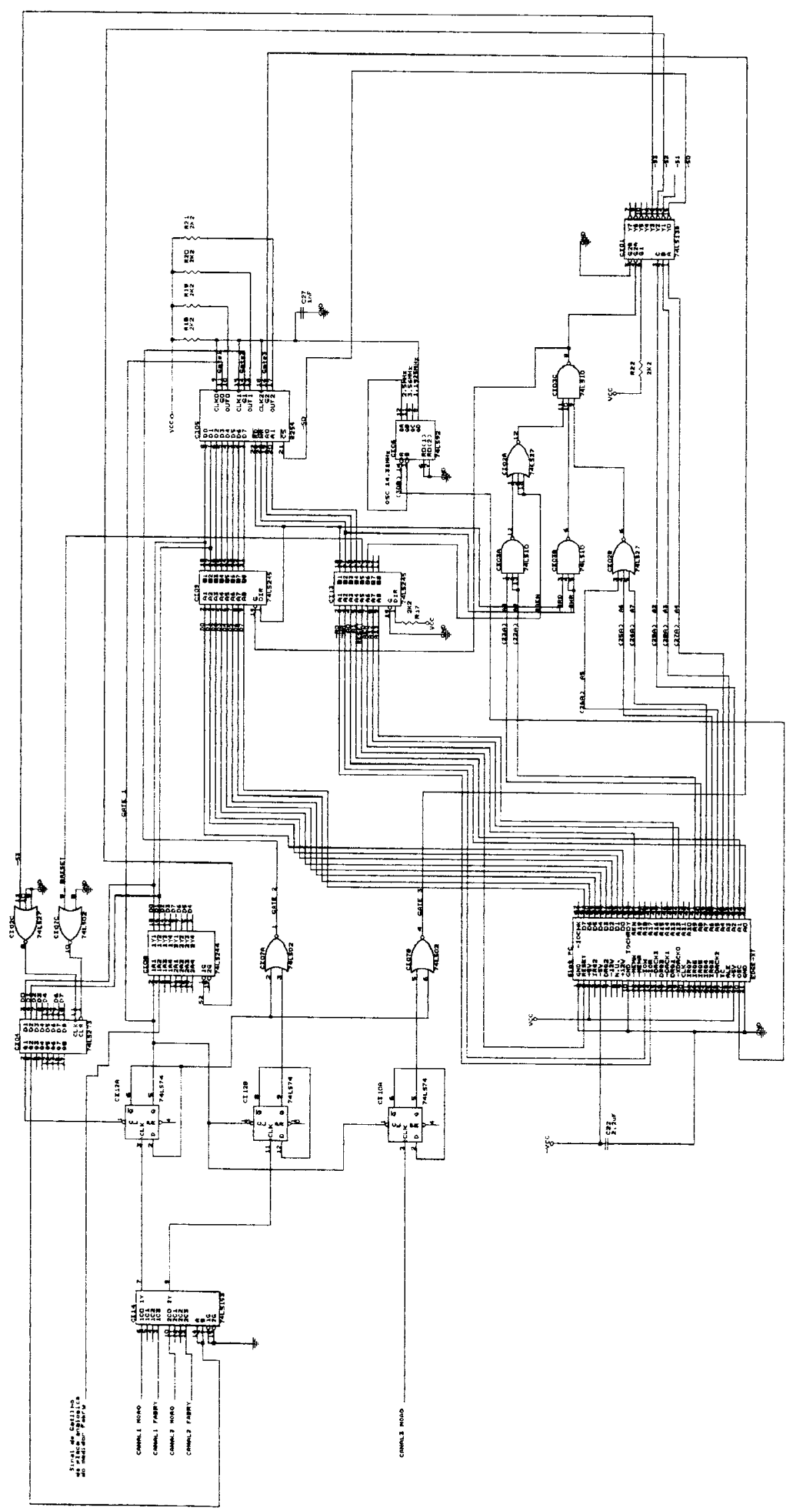


Apêndice D - Fotografias da parte opto-mecânica do sistema
construído.
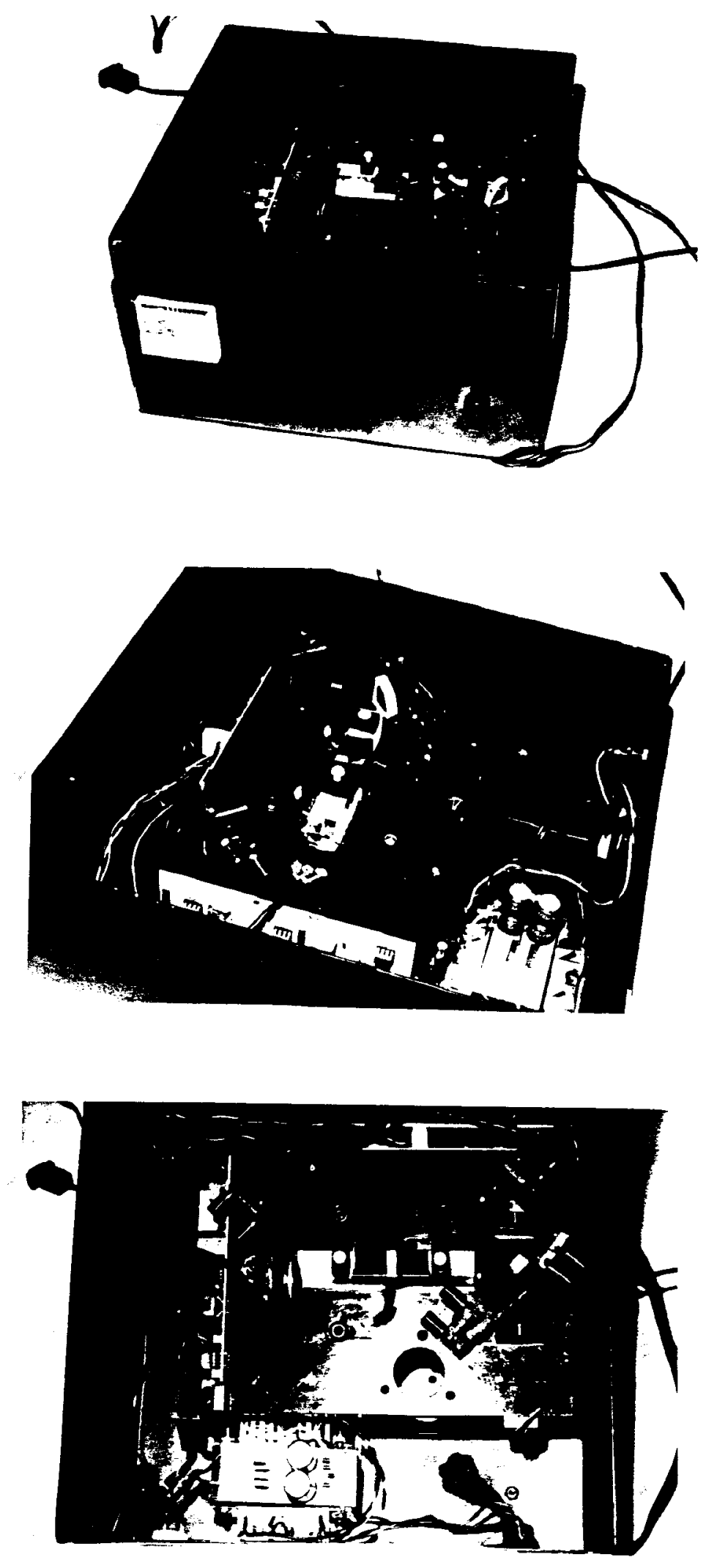